Cochrane Database of Systematic Reviews

\title{
Ivermectin and permethrin for treating scabies (Review)
}

Rosumeck S, Nast A, Dressler C

Rosumeck S, Nast A, Dressler C.

Ivermectin and permethrin for treating scabies.

Cochrane Database of Systematic Reviews 2018, Issue 4. Art. No.: CD012994.

DOI: 10.1002/14651858.CD012994.

www.cochranelibrary.com

Ivermectin and permethrin for treating scabies (Review) 
TABLE OF CONTENTS

PLAIN LANGUAGE SUMMARY

SUMMARY OF FINDINGS

BACKGROUND

OBJECTIVES

METHODS

RESULTS

Figure 1.

Figure 2.

Figure 3.

Figure 4.

Figure 5.

Figure 6.

DISCUSSION

AUTHORS' CONCLUSIONS

ACKNOWLEDGEMENTS

REFERENCES

CHARACTERISTICS OF STUDIES

DATA AND ANALYSES

Analysis 1.1. Comparison 1 Ivermectin $200 \mu \mathrm{g} / \mathrm{kg}$ (1 to 3 doses) versus permethrin $5 \%$ cream (1 to 3 applications), Outcome 1 Complete clearance - week 1.

Analysis 1.2. Comparison 1 Ivermectin $200 \mu \mathrm{g} / \mathrm{kg}$ (1 to 3 doses) versus permethrin 5\% cream (1 to 3 applications), Outcome 2 Complete clearance - week 2.

Analysis 1.3. Comparison 1 Ivermectin $200 \mu \mathrm{g} / \mathrm{kg}$ (1 to 3 doses) versus permethrin $5 \%$ cream (1 to 3 applications), Outcome 3 Complete clearance - week 4.

Analysis 1.4. Comparison 1 Ivermectin $200 \mu \mathrm{g} / \mathrm{kg}$ (1 to 3 doses) versus permethrin 5\% cream (1 to 3 applications), Outcome 4 Subgroup analysis for 1.3.2 - complete clearance - week 4.

Analysis 1.5. Comparison 1 Ivermectin $200 \mu \mathrm{g} / \mathrm{kg}$ ( 1 to 3 doses) versus permethrin $5 \%$ cream ( 1 to 3 applications), Outcome 5 Number of participants with $\geq 1$ adverse event - week 2 .

Analysis 1.6. Comparison 1 Ivermectin $200 \mu \mathrm{g} / \mathrm{kg}$ ( 1 to 3 doses) versus permethrin 5\% cream (1 to 3 applications), Outcome 6 Number of participants with $\geq 1$ adverse event - week 4 .

Analysis 1.7. Comparison 1 Ivermectin $200 \mu \mathrm{g} / \mathrm{kg}$ ( 1 to 3 doses) versus permethrin 5\% cream (1 to 3 applications), Outcome 7 Withdrawal due to adverse event - week 4.

Analysis 2.1. Comparison 2 Ivermectin $200 \mu \mathrm{g} / \mathrm{kg}$ ( 1 to 2 doses) versus permethrin $5 \%$ lotion ( 1 to 5 applications), Outcome 1 Complete clearance - week 1.

Analysis 2.2. Comparison 2 Ivermectin $200 \mu \mathrm{g} / \mathrm{kg}$ (1 to 2 doses) versus permethrin 5\% lotion ( 1 to 5 applications), Outcome 2 Complete clearance - week 2.

Analysis 2.3. Comparison 2 Ivermectin $200 \mu \mathrm{g} / \mathrm{kg}$ ( 1 to 2 doses) versus permethrin $5 \%$ lotion ( 1 to 5 applications), Outcome 3 Number of participants with $\geq 1$ adverse event - week 2 .

Analysis 2.4. Comparison 2 Ivermectin $200 \mu \mathrm{g} / \mathrm{kg}$ (1 to 2 doses) versus permethrin 5\% lotion ( 1 to 5 applications), Outcome 4 Withdrawal due to adverse event - week 2.

Analysis 3.1. Comparison 3 Ivermectin $200 \mu \mathrm{g} / \mathrm{kg}$ ( 1 to 3 doses) versus ivermectin $1 \%$ lotion/solution ( 1 to 3 applications), Outcome 1 Complete clearance - week 1.

Analysis 3.2. Comparison 3 Ivermectin $200 \mu \mathrm{g} / \mathrm{kg}$ ( 1 to 3 doses) versus ivermectin $1 \%$ lotion/solution ( 1 to 3 applications), Outcome 2 Complete clearance - week 2.

Analysis 3.3. Comparison 3 Ivermectin $200 \mu \mathrm{g} / \mathrm{kg}$ (1 to 3 doses) versus ivermectin 1\% lotion/solution (1 to 3 applications), Outcome 3 Complete clearance - week 4.

Analysis 3.4. Comparison 3 Ivermectin $200 \mu \mathrm{g} / \mathrm{kg}$ ( 1 to 3 doses) versus ivermectin $1 \%$ lotion/solution ( 1 to 3 applications), Outcome 4 Number of participants with $\geq 1$ adverse event - week 4 .

Analysis 3.5. Comparison 3 Ivermectin $200 \mu \mathrm{g} / \mathrm{kg}$ ( 1 to 3 doses) versus ivermectin 1\% lotion/solution ( 1 to 3 applications), Outcome 5 Withdrawal due to adverse event - week 4.

Analysis 4.1. Comparison 4 Ivermectin 1\% lotion ( 1 to 3 applications) versus permethrin $5 \%$ cream ( 1 to 3 applications), Outcome 1 Complete clearance - week 4. 
Analysis 4.2. Comparison 4 Ivermectin $1 \%$ lotion ( 1 to 3 applications) versus permethrin $5 \%$ cream (1 to 3 applications), Outcome 2 Number of participants with $\geq 1$ adverse event - week 4 .

Analysis 5.1. Comparison 5 Ivermectin $200 \mu \mathrm{g} / \mathrm{kg}$ (1 dose) versus ivermectin $200 \mu \mathrm{g} / \mathrm{kg}$ (2 doses), Outcome 1 Complete clearance - week 4.

APPENDICES

CONTRIBUTIONS OF AUTHORS

DECLARATIONS OF INTEREST 
[Intervention Review]

\section{Ivermectin and permethrin for treating scabies}

Stefanie Rosumeck ${ }^{1}$, Alexander Nast ${ }^{1}$, Corinna Dressler ${ }^{1}$

1Division of Evidence Based Medicine, Department of Dermatology, Venerology and Allergology, Charité - Universitätsmedizin Berlin, corporate member of Freie Universität Berlin, Humboldt-Universität zu Berlin, and Berlin Institute of Health, Berlin, Germany

Contact: Stefanie Rosumeck, Division of Evidence Based Medicine, Department of Dermatology, Venerology and Allergology, Charité Universitätsmedizin Berlin, corporate member of Freie Universität Berlin, Humboldt-Universität zu Berlin, and Berlin Institute of Health, Charitéplatz 1, Berlin, Berlin, 10117, Germany.Stefanie.Rosumeck@charite.de.

Editorial group: Cochrane Infectious Diseases Group.

Publication status and date: Unchanged, published in Issue 4, 2018.

Citation: Rosumeck S, Nast A, Dressler C. Ivermectin and permethrin for treating scabies. Cochrane Database of Systematic Reviews 2018, Issue 4. Art. No.: CD012994. DOI: 10.1002/14651858.CD012994.

Copyright ( $\subseteq 2018$ The Authors. Cochrane Database of Systematic Reviews published by John Wiley \& Sons, Ltd. on behalf of The Cochrane Collaboration. This is an open access article under the terms of the Creative Commons Attribution-Non-Commercial Licence, which permits use, distribution and reproduction in any medium, provided the original work is properly cited and is not used for commercial purposes.

\section{A B S T R A C T}

\section{Background}

Scabies is an intensely itchy parasitic infection of the skin. It occurs worldwide, but is particularly problematic in areas of poor sanitation, overcrowding, and social disruption. In recent years, permethrin and ivermectin have become the most relevant treatment options for scabies.

\section{Objectives}

To assess the efficacy and safety of topical permethrin and topical or systemic ivermectin for scabies in people of all ages.

\section{Search methods}

We searched the following databases up to 25 April 2017: the Cochrane Infectious Diseases Group Specialized Register, CENTRAL, MEDLINE, Embase, LILACS, and IndMED. We searched the World Health Organization International Clinical Trials Registry Platform, the ISRCTN registry, CenterWatch Clinical Trials Listing, ClinicalTrials.gov, TrialsCentral, and the UK Department of Health National Research Register for ongoing trials. We also searched multiple sources for grey literature and checked reference lists of included studies for additional trials.

\section{Selection criteria}

We included randomized controlled trials that compared permethrin or ivermectin against each other for people with scabies of all ages and either sex.

\section{Data collection and analysis}

Two review authors independently screened the identified records, extracted data, and assessed the risk of bias for the included trials.

The primary outcome was complete clearance of scabies. Secondary outcomes were number of participants re-treated, number of participants with at least one adverse event, and number of participants withdrawn from study due to an adverse event.

We summarized dichotomous outcomes using risk ratios (RR) with $95 \%$ confidence intervals (CI). If it was not possible to calculate the point estimate, we described the data qualitatively. Where appropriate, we calculated combined effect estimates using a random-effects model and assessed heterogeneity. We calculated numbers needed to treat for an additional beneficial outcome when we found a difference. 
We assessed the certainty of the evidence using the GRADE approach. We used the control rate average to provide illustrative clearance rates in the comparison groups.

\section{Main results}

Fifteen studies (1896 participants) comparing topical permethrin, systemic ivermectin, or topical ivermectin met the inclusion criteria. Overall, the risk of bias in the included trials was moderate: reporting in many studies was poor. Nearly all studies were conducted in South Asia or North Africa, where the disease is more common, and is associated with poverty.

\section{Efficacy}

Oral ivermectin (at a standard dose of $200 \mu \mathrm{g} / \mathrm{kg}$ ) may lead to slightly lower rates of complete clearance after one week compared to permethrin 5\% cream. Using the average clearance rate of $65 \%$ in the trials with permethrin, the illustrative clearance with ivermectin is $43 \%$ (RR $0.65,95 \% \mathrm{Cl} 0.54$ to $0.78 ; 613$ participants, 6 studies; low-certainty evidence). However, by week two there may be little or no difference (illustrative clearance of permethrin $74 \%$ compared to ivermectin $68 \%$; RR $0.91,95 \% \mathrm{Cl} 0.76$ to 1.08 ; 459 participants, 5 studies; low-certainty evidence). Treatments with one to three doses of ivermectin or one to three applications of permethrin may lead to little or no difference in rates of complete clearance after four weeks' follow-up (illustrative cures with 1 to 3 applications of permethrin 93\% and with 1 to 3 doses of ivermectin 86\%; RR 0.92, 95\% Cl 0.82 to 1.03; 581 participants, 5 studies; low-certainty evidence).

After one week of treatment with oral ivermectin at a standard dose of $200 \mu \mathrm{g} / \mathrm{kg}$ or one application of permethrin $5 \%$ lotion, there is probably little or no difference in complete clearance rates (illustrative cure rates: permethrin $73 \%$, ivermectin $68 \% ; \mathrm{RR} 0.93,95 \% \mathrm{Cl} 0.74$ to $1.17 ; 120$ participants, 1 study; moderate-certainty evidence). After two weeks of treatment, one dose of systemic ivermectin compared to one application of permethrin lotion may lead to similar complete clearance rates (extrapolated cure rates: 67\% in both groups; RR 1.00, $95 \% \mathrm{Cl} 0.78$ to $1.29 ; 120$ participants, 1 study; low-certainty evidence).

There is probably little or no difference in rates of complete clearance between systemic ivermectin at standard dose and topical ivermectin $1 \%$ lotion four weeks after initiation of treatment (illustrative cure rates: oral ivermectin 97\%, ivermectin lotion $96 \%$; RR 0.99, 95\% Cl 0.95 to 1.03; 272 participants, 2 studies; moderate-certainty evidence). Likewise, after four weeks, ivermectin lotion probably leads to little or no difference in rates of complete clearance when compared to permethrin cream (extrapolated cure rates: permethrin cream $94 \%$, ivermectin lotion 96\%; RR 1.02, 95\% Cl 0.96 to 1.08; 210 participants, 1 study; moderate-certainty evidence), and there is little or no difference among systemic ivermectin in different doses (extrapolated cure rates: 2 doses $90 \%, 1$ dose $87 \%$; RR 0.97, 95\% $\mathrm{Cl} 0.83$ to $1.14 ; 80$ participants, 1 study; high-certainty evidence).

\section{Safety}

Reporting of adverse events in the included studies was suboptimal. No withdrawals due to adverse events occurred in either the systemic ivermectin or the permethrin group (moderate-certainty evidence). Two weeks after treatment initiation, there is probably little or no difference in the proportion of participants treated with systemic ivermectin or permethrin cream who experienced at least one adverse event (55 participants, 1 study; moderate-certainty evidence). After four weeks, ivermectin may lead to a slightly larger proportion of participants with at least one adverse event (extrapolated rates: permethrin 4\%, ivermectin 5\%; RR 1.30, $95 \% \mathrm{Cl} 0.35$ to $4.83 ; 502$ participants, 4 studies; low-certainty evidence).

Adverse events in participants treated with topical ivermectin were rare and of mild intensity and comparable to those with systemic ivermectin. For this comparison, it is uncertain whether there is any difference in the number of participants with at least one adverse event (very low-certainty evidence). No withdrawals due to adverse events occurred (62 participants, 1 study; moderate-certainty evidence).

It is uncertain whether topical ivermectin or permethrin differ in the number of participants with at least one adverse event (very lowcertainty evidence). We found no studies comparing systemic ivermectin in different doses that assessed safety outcomes.

\section{Authors' conclusions}

We found that for the most part, there was no difference detected in the efficacy of permethrin compared to systemic or topical ivermectin. Overall, few and mild adverse events were reported. Our confidence in the effect estimates was mostly low to moderate. Poor reporting is a major limitation.

\section{April 2019}

Up to date

All studies incorporated from most recent search

All eligible published studies found in the last search (25 Apr, 2017) were included and one ongoing study was identified (see 'Characteristics of ongoing studies' section) 


\section{PLAIN LANGUAGE SUMMARY}

\section{Ivermectin and permethrin for treating scabies}

\section{What is the aim of this review?}

The aim of this Cochrane Review was to assess the efficacy and safety of topical permethrin and topical or systemic ivermectin for scabies in people of all ages. We searched for all relevant studies to answer this question and found 15 studies, which we collected and analysed.

\section{Key messages}

We found that for the most part, there was no difference detected in the efficacy of permethrin compared to systemic or topical ivermectin. Overall, few and mild adverse events were reported. Our confidence in the effect estimates was mostly low to moderate. Poor reporting of studies was a major limitation.

Additional high-certainty studies are needed to strengthen the confidence in the results and improve the evidence base.

\section{What was studied in the review?}

Scabies is an intensely itchy parasitic infection of the skin. It occurs throughout the world, but is particularly problematic in areas of poor sanitation, overcrowding, and social disruption. In recent years, permethrin and ivermectin have become the most relevant treatment options for scabies.

We examined topical permethrin, topical ivermectin, and systemic ivermectin as a treatment for scabies in women and men of all ages. We assessed efficacy as complete clearance of skin lesions at different time points after the start of the treatment. Other outcomes were the number of participants re-treated, the number of participants with at least one adverse event, and the number of participants who stopped participating in the study because they experienced an adverse event.

\section{What are the main results of the review?}

We found 15 relevant studies. Nearly all studies were set in South Asia or North Africa. These studies compared systemic ivermectin with topical permethrin, topical ivermectin with topical permethrin, or systemic ivermectin with topical ivermectin to treat people with scabies. All studies were conducted at a single centre with mostly small numbers of participants per study group.

Oral ivermectin may lead to slightly lower rates of complete clearance after one week compared to permethrin cream (low-certainty evidence), but little or no difference in rates of complete clearance by week two (low-certainty evidence). Treatments with one to three doses of ivermectin or one to three applications of permethrin may lead to little or no difference in rates of complete clearance after four weeks (low-certainty evidence).

There is probably little or no difference in complete clearance rates after one week of treatment with oral ivermectin or one application of permethrin lotion (moderate-certainty evidence).

There is probably little or no difference in rates of complete clearance between systemic ivermectin at standard dose and topical ivermectin lotion four weeks after initiation of treatment (moderate-certainty evidence). Likewise, after four weeks, ivermectin lotion probably leads to little or no difference in rates of complete clearance when compared to permethrin cream (moderate-certainty evidence), and there is little or no difference among treatments with systemic ivermectin in different doses (high-certainty evidence).

No participants in the systemic ivermectin or the permethrin group stopped participating in the study because they experienced an adverse event (moderate-certainty evidence). Two weeks after treatment initiation, there is probably little or no difference in the proportion of participants treated with systemic ivermectin or permethrin cream who experienced at least one adverse event (moderate-certainty evidence). After four weeks, ivermectin may lead to a slightly larger proportion of participants with at least one adverse event (low-certainty evidence).

Adverse events in participants treated with topical ivermectin were rare and of mild intensity and comparable to those with systemic ivermectin. For this comparison, it is uncertain whether there is any difference in the number of participants with at least one adverse event (very low-certainty evidence). No participants in the topical or systemic ivermectin group stopped participating in the study because they experienced an adverse event (moderate-certainty evidence).

It is uncertain whether topical ivermectin and permethrin differ in the number of participants with at least one adverse event (very lowcertainty evidence). We found no studies comparing one dose versus two doses of systemic ivermectin that assessed safety outcomes.

\section{How up-to-date is this review?}

We searched for studies published up to 25 April 2017. 


\section{SUMMARY OF FINDINGS}

Summary of findings for the main comparison. Oral ivermectin $200 \mu \mathrm{g} / \mathrm{kg}$ (1 to 3 doses) compared to topical permethrin $5 \%$ cream (1 to 3 applications)

Oral ivermectin $200 \mu \mathrm{g} / \mathrm{kg}$ (1 to 3 doses) compared to topical permethrin $5 \%$ cream (1 to 3 applications) for treating scabies

Patient or population: people with scabies, 2 to 80 years of age

Location: India, Pakistan

Intervention: oral ivermectin $200 \mu \mathrm{g} / \mathrm{kg}$

Comparison: topical permethrin $5 \%$ cream

\begin{tabular}{|c|c|c|c|c|c|c|}
\hline \multirow[t]{2}{*}{ Outcomes } & \multicolumn{2}{|c|}{$\begin{array}{l}\text { Anticipated absolute effects }{ }^{*} \\
(95 \% \mathrm{Cl})\end{array}$} & \multirow[t]{2}{*}{$\begin{array}{l}\text { Relative effect } \\
(95 \% \mathrm{CI})\end{array}$} & \multirow{2}{*}{$\begin{array}{l}\text { Number of par- } \\
\text { ticipants } \\
\text { (trials) }\end{array}$} & \multirow{2}{*}{$\begin{array}{l}\text { Certainty of } \\
\text { the evidence } \\
\text { (GRADE) }\end{array}$} & \multirow[t]{2}{*}{ Comments } \\
\hline & $\begin{array}{l}\text { Risk with per- } \\
\text { methrin } 5 \% \\
\text { cream }\end{array}$ & $\begin{array}{l}\text { Risk with iver- } \\
\text { mectin } 200 \mu \mathrm{g} / \\
\text { kg }\end{array}$ & & & & \\
\hline $\begin{array}{l}\text { Complete clearance } \\
\text { - week } 1\end{array}$ & 654 per 1000 & $\begin{array}{l}425 \text { per } 1000 \\
\text { ( } 353 \text { to } 510)\end{array}$ & $\begin{array}{l}\text { RR } 0.65 \\
\text { (0.54 to } 0.78)\end{array}$ & $\begin{array}{l}613 \\
(6 \mathrm{RCTs})^{1}\end{array}$ & $\begin{array}{l}\oplus \oplus \ominus \ominus \\
\text { LOW2,3 }\end{array}$ & - \\
\hline $\begin{array}{l}\text { Complete clearance } \\
\text { - week } 2\end{array}$ & 744 per 1000 & $\begin{array}{l}677 \text { per } 1000 \\
\text { (565 to } 804)\end{array}$ & $\begin{array}{l}\text { RR } 0.91 \\
\text { (0.76 to } 1.08)\end{array}$ & $\begin{array}{l}459 \\
(5 \mathrm{RCTs})^{4}\end{array}$ & $\begin{array}{l}\oplus \oplus \ominus \ominus \\
\text { LOW } 2,5\end{array}$ & $\begin{array}{l}\text { In } 1 \text { study non-responders were re-treated after } 1 \\
\text { week; in } 1 \text { study } 44.44 \% \text { of participants (IVER) and } \\
17.86 \% \text { of participants (PER) were re-treated after } \\
1 \text { week (absolute numbers are unclear). }\end{array}$ \\
\hline $\begin{array}{l}\text { Complete clearance - } \\
\text { week } 4 \text { - IVER } 1 \text { dose } \\
\text { versus PER } 1 \text { applica- } \\
\text { tion }\end{array}$ & 900 per 1000 & $\begin{array}{l}900 \text { per } 1000 \\
\text { (774 to } 1000)\end{array}$ & $\begin{array}{l}\text { RR } 1.00 \\
\text { (0.86 to } 1.16)\end{array}$ & $\begin{array}{l}80 \\
(1 \mathrm{RCT})^{6}\end{array}$ & $\begin{array}{l}\oplus \oplus \oplus \oplus \\
\mathrm{HIGH}\end{array}$ & - \\
\hline $\begin{array}{l}\text { Complete clearance } \\
\text { - week } 4 \text { - IVER } 1 \text { to } 3 \\
\text { doses versus PER } 1 \\
\text { to } 3 \text { applications }\end{array}$ & 932 per 1000 & $\begin{array}{l}857 \text { per } 1000 \\
\text { (764 to 959) }\end{array}$ & $\begin{array}{l}\text { RR } 0.92 \\
\text { (0.82 to } 1.03 \text { ) }\end{array}$ & $\begin{array}{l}581 \\
(5 \mathrm{RCTs})^{7}\end{array}$ & $\begin{array}{l}\oplus \oplus \ominus \ominus \\
\operatorname{LOW}^{2,8}\end{array}$ & $\begin{array}{l}\text { In } 3 \text { studies non-responders were re-treated once; } \\
\text { in } 1 \text { study non-responders were re-treated after } 2 \\
\text { and/or } 3 \text { weeks (absolute numbers are unclear); } \\
\text { in } 1 \text { study } 12 \text { participants (IVER) and } 1 \text { participant } \\
\text { (PER) were re-treated after } 2 \text { weeks. }\end{array}$ \\
\hline $\begin{array}{l}\text { Complete clearance - } \\
\text { week } 4 \text { - IVER } 2 \text { doses } \\
\text { versus PER } 1 \text { applica- } \\
\text { tion }\end{array}$ & 900 per 1000 & $\begin{array}{l}873 \text { per } 1000 \\
\text { (747 to } 1000)\end{array}$ & $\begin{array}{l}\text { RR } 0.97 \\
\text { (0.83 to } 1.14 \text { ) }\end{array}$ & $\begin{array}{l}80 \\
(1 \mathrm{RCT})^{6}\end{array}$ & $\begin{array}{l}\oplus \oplus \oplus \oplus \\
\mathrm{HIGH}\end{array}$ & - \\
\hline
\end{tabular}




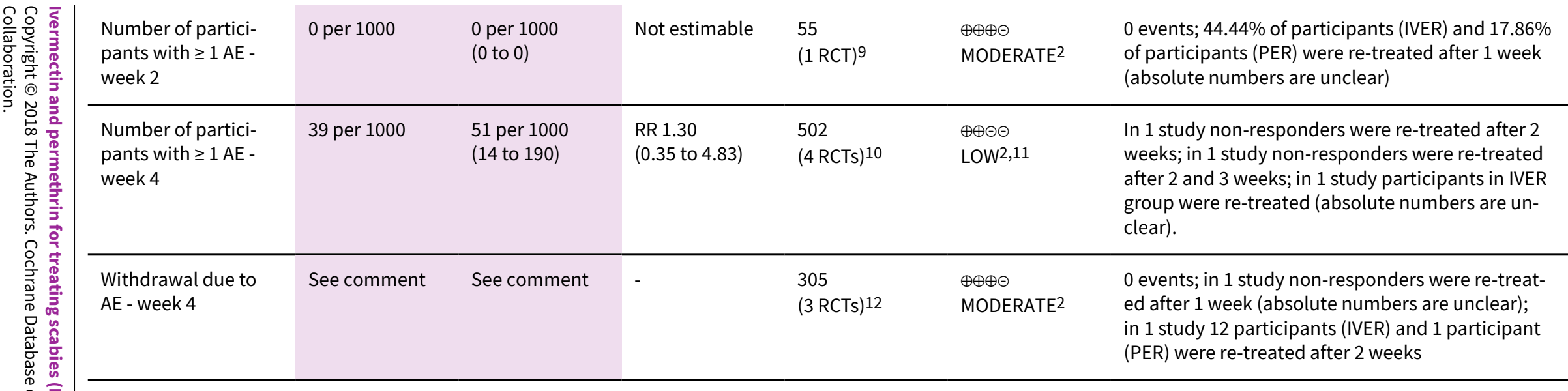

*The risk in the intervention group (and its $95 \% \mathrm{Cl}$ ) is based on the assumed risk in the comparison group and the relative effect of the intervention (and its $95 \% \mathrm{Cl}$ ). Abbreviations: AE: adverse event; CI: confidence interval; IVER: ivermectin; PER: permethrin; RCT: randomized controlled trial; RR: risk ratio.

\section{GRADE Working Group grades of evidence}

High certainty: we are very confident that the true effect lies close to that of the estimate of the effect.

Moderate certainty: we are moderately confident in the effect estimate: the true effect is likely to be close to the estimate of the effect, but there is a possibility that it is substantially different.

Low certainty: our confidence in the effect estimate is limited: the true effect may be substantially different from the estimate of the effect.

Very low certainty: we have very little confidence in the effect estimate: the true effect is likely to be substantially different from the estimate of effect.

1Usha 2000; Bachewar 2009; Sharma 2011; Rohatgi 2013; Meenakshi 2014; Wankhade 2016.

2Downgraded by 1 for serious risk of bias: assessed as moderate.

3Downgraded by 1 for serious imprecision: $\mathrm{Cl}$ crosses minimal clinically important difference threshold: statistically significant difference of uncertain clinical importance.

4Usha 2000; Bachewar 2009; Mushtaq 2010; Sharma 2011; Rohatgi 2013.

5Downgraded by 1 for serious inconsistency: $I^{2}=61 \%(P=0.04)$.

6Sharma 2011.

7Usha 2000; Mushtaq 2010; Chhaiya 2012; Rohatgi 2013; Wankhade 2016.

8 Downgraded by 1 for serious inconsistency: $I^{2}=74 \%(P=0.004)$

9Bachewar 2009.

10 Mushtaq 2010; Sharma 2011; Chhaiya 2012; Wankhade 2016.

11Downgraded by 1 for serious imprecision: $\mathrm{Cl}$ crosses line of no effect and minimal clinically important difference thresholds: uncertain whether there is any difference.

12Usha 2000; Manjhi 2014; Wankhade 2016.

Summary of findings 2. Oral ivermectin $200 \mu \mathrm{g} / \mathrm{kg}$ (1 to 2 doses) compared to topical permethrin $5 \%$ lotion ( 1 to 5 applications)

Oral ivermectin $200 \mu \mathrm{g} / \mathrm{kg}$ (1 to 2 doses) compared to topical permethrin $5 \%$ lotion ( 1 to 5 applications) for treating scabies 
Patient or population: people with scabies, 5 to 60 years of age

Location: Egypt, Pakistan

Intervention: oral ivermectin $200 \mu \mathrm{g} / \mathrm{kg}$

Comparison: topical permethrin $5 \%$ lotion

\begin{tabular}{|c|c|c|c|c|c|c|}
\hline \multirow[t]{2}{*}{ Outcomes } & \multicolumn{2}{|c|}{ Anticipated absolute effects ${ }^{\star}(95 \% \mathrm{Cl})$} & \multirow{2}{*}{$\begin{array}{l}\text { Relative effect } \\
(95 \% \mathrm{Cl})\end{array}$} & \multirow{2}{*}{$\begin{array}{l}\text { Number of par- } \\
\text { ticipants } \\
\text { (trials) }\end{array}$} & \multirow{2}{*}{$\begin{array}{l}\text { Certainty of } \\
\text { the evidence } \\
\text { (GRADE) }\end{array}$} & \multirow[t]{2}{*}{ Comments } \\
\hline & $\begin{array}{l}\text { Risk with per- } \\
\text { methrin } 5 \% \text { lo- } \\
\text { tion }\end{array}$ & $\begin{array}{l}\text { Risk with iver- } \\
\text { mectin } 200 \mu \mathrm{g} / \mathrm{kg}\end{array}$ & & & & \\
\hline $\begin{array}{l}\text { Complete clearance - week } 1 \text { - IVER } 1 \text { dose versus } \\
\text { PER } 1 \text { application }\end{array}$ & 733 per 1000 & $\begin{array}{l}682 \text { per } 1000 \\
(543 \text { to } 858)\end{array}$ & $\begin{array}{l}\text { RR } 0.93 \\
\text { (0.74 to } 1.17)\end{array}$ & $\begin{array}{l}120 \\
(1 \mathrm{RCT})^{1}\end{array}$ & $\begin{array}{l}\oplus \oplus \oplus \ominus \\
\text { MODERATE } 2\end{array}$ & - \\
\hline $\begin{array}{l}\text { Complete clearance - week } 2 \text { - IVER } 1 \text { dose versus } \\
\text { PER } 1 \text { application }\end{array}$ & 667 per 1000 & $\begin{array}{l}667 \text { per } 1000 \\
(520 \text { to } 860)\end{array}$ & $\begin{array}{l}\text { RR } 1.00 \\
\text { (0.78 to } 1.29)\end{array}$ & $\begin{array}{l}120 \\
(1 \mathrm{RCT})^{1}\end{array}$ & $\begin{array}{l}\oplus \oplus \ominus \ominus \\
\text { LOW } 2,4\end{array}$ & - \\
\hline $\begin{array}{l}\text { Complete clearance - week } 2 \text { - IVER } 2 \text { doses ver- } \\
\text { sus PER on } 5 \text { consecutive nights }\end{array}$ & 815 per 1000 & $\begin{array}{l}790 \text { per } 1000 \\
\text { (660 to } 953)\end{array}$ & $\begin{array}{l}\text { RR } 0.97 \\
\text { (0.81 to } 1.17)\end{array}$ & $\begin{array}{l}107 \\
(1 \mathrm{RCT})^{3}\end{array}$ & $\begin{array}{l}\oplus \oplus \oplus \ominus \\
\text { MODERATE } 2\end{array}$ & - \\
\hline $\begin{array}{l}\text { Number of participants with } \geq 1 \mathrm{AE} \text { - week } 2 \text { - } \\
\text { IVER } 2 \text { doses versus PER on } 5 \text { consecutive nights }\end{array}$ & 0 per 1000 & $\begin{array}{l}0 \text { per } 1000 \\
(0 \text { to } 0)\end{array}$ & $\begin{array}{l}\text { RR } 5.00 \\
\text { (0.25 to } 101.58)\end{array}$ & $\begin{array}{l}100 \\
(1 \mathrm{RCT})^{1}\end{array}$ & $\begin{array}{l}\oplus \ominus \ominus \ominus \\
\text { VERY LOW } 2,5\end{array}$ & - \\
\hline $\begin{array}{l}\text { Withdrawal due to AE - week } 2 \text { - IVER } 1 \text { dose ver- } \\
\text { sus PER } 1 \text { application }\end{array}$ & 0 per 1000 & $\begin{array}{l}0 \text { per } 1000 \\
(0 \text { to } 0)\end{array}$ & Not estimable & $\begin{array}{l}120 \\
(1 \mathrm{RCT})^{1}\end{array}$ & $\begin{array}{l}\oplus \oplus \oplus \ominus \\
\text { MODERATE2 }\end{array}$ & 0 events \\
\hline
\end{tabular}

${ }^{*}$ The risk in the intervention group (and its $95 \% \mathrm{Cl}$ ) is based on the assumed risk in the comparison group and the relative effect of the intervention (and its $95 \% \mathrm{Cl}$ ).

Abbreviations: AE: adverse event; CI: confidence interval; IVER: ivermectin; PER: permethrin; RCT: randomized controlled trial; RR: risk ratio

\section{GRADE Working Group grades of evidence}

High certainty: we are very confident that the true effect lies close to that of the estimate of the effect.

Moderate certainty: we are moderately confident in the effect estimate: the true effect is likely to be close to the estimate of the effect, but there is a possibility that it is

substantially different.

Low certainty: our confidence in the effect estimate is limited: the true effect may be substantially different from the estimate of the effect.

Very low certainty: we have very little confidence in the effect estimate: the true effect is likely to be substantially different from the estimate of effect.

1Saqib 2012.

2Downgraded by 1 for serious risk of bias: assessed as moderate.

3Abdel-Raheem 2016. 
${ }^{4}$ Downgraded by 1 for serious imprecision: $\mathrm{Cl}$ crosses line of no effect and minimal clinically important difference thresholds: uncertain whether there is any difference. ${ }^{5}$ Downgraded by 2 for very serious imprecision: $\mathrm{Cl}$ crosses line of no effect and minimal clinically important difference thresholds: uncertain whether there is any difference and wide $\mathrm{Cl}$.

\section{Summary of findings 3. Oral ivermectin $200 \mu \mathrm{g} / \mathrm{kg}$ (1 to 3 doses) compared to topical ivermectin $1 \%$ lotion/solution (1 to 3 applications)}

\section{Oral ivermectin $200 \mu \mathrm{g} / \mathrm{kg}$ (1 to 3 doses) compared to topical ivermectin $1 \%$ lotion/solution (1 to 3 applications) for treating scabies}

Patient or population: people with scabies, 5 to 80 years of age

Location: Egypt, India

Intervention: oral ivermectin $200 \mu \mathrm{g} / \mathrm{kg}$

Comparison: topical ivermectin $1 \%$ lotion/solution

\begin{tabular}{|c|c|c|c|c|c|c|}
\hline \multirow[t]{2}{*}{ Outcomes } & \multicolumn{2}{|c|}{$\begin{array}{l}\text { Anticipated absolute effects }{ }^{*}(95 \% \\
\text { CI) }\end{array}$} & \multirow[t]{2}{*}{$\begin{array}{l}\text { Relative effect } \\
(95 \% \mathrm{CI})\end{array}$} & \multirow{2}{*}{$\begin{array}{l}\text { Number of par- } \\
\text { ticipants } \\
\text { (trials) }\end{array}$} & \multirow{2}{*}{$\begin{array}{l}\text { Certainty of } \\
\text { the evidence } \\
\text { (GRADE) }\end{array}$} & \multirow[t]{2}{*}{ Comments } \\
\hline & $\begin{array}{l}\text { Risk with iver- } \\
\text { mectin } 1 \% \text { lo- } \\
\text { tion/solution }\end{array}$ & $\begin{array}{l}\text { Risk with iver- } \\
\text { mectin } 200 \mu \mathrm{g} / \\
\text { kg }\end{array}$ & & & & \\
\hline $\begin{array}{l}\text { Complete clear- } \\
\text { ance - week } 1\end{array}$ & 875 per 1000 & $\begin{array}{l}735 \text { per } 1000 \\
(569 \text { to } 945)\end{array}$ & $\begin{array}{l}\text { RR } 0.84 \\
(0.65 \text { to } 1.08)\end{array}$ & $\begin{array}{l}62 \\
(1 \mathrm{RCT})^{1}\end{array}$ & $\begin{array}{l}\oplus \oplus \ominus \ominus \\
\text { LOW2,3 }\end{array}$ & - \\
\hline $\begin{array}{l}\text { Complete clear- } \\
\text { ance-week } 2\end{array}$ & 1000 per 1000 & $\begin{array}{l}1000 \text { per } 1000 \\
(940 \text { to } 1000)\end{array}$ & $\begin{array}{l}\text { RR } 1.00 \\
\text { (0.94 to } 1.06)\end{array}$ & $\begin{array}{l}62 \\
(1 \mathrm{RCT})^{1}\end{array}$ & $\begin{array}{l}\oplus \oplus \oplus \ominus \\
\text { MODERATE } 2\end{array}$ & $\begin{array}{l}8 \text { participants (oral IVER) and } 4 \text { participants (topical } \\
\text { IVER) were re-treated after } 1 \text { week. }\end{array}$ \\
\hline $\begin{array}{l}\text { Complete clear- } \\
\text { ance - week } 4\end{array}$ & 971 per 1000 & $\begin{array}{l}961 \text { per } 1000 \\
(922 \text { to } 1000)\end{array}$ & $\begin{array}{l}\text { RR } 0.99 \\
\text { (0.95 to } 1.03)\end{array}$ & $\begin{array}{l}272 \\
(2 \mathrm{RCTs})^{1,4}\end{array}$ & $\begin{array}{l}\oplus \oplus \oplus \ominus \\
\text { MODERATE } 2\end{array}$ & $\begin{array}{l}\text { In } 1 \text { study } 8 \text { participants (oral IVER) and } 4 \text { partici- } \\
\text { pants (topical IVER) were re-treated after } 1 \text { week; in } \\
1 \text { study non-responders were re-treated after } 2 \text { and/ } \\
\text { or } 3 \text { weeks (absolute numbers are unclear). }\end{array}$ \\
\hline $\begin{array}{l}\text { Number of partic- } \\
\text { ipants with } \geq 1 \mathrm{AE} \\
\text { - week } 4\end{array}$ & 0 per 1000 & $\begin{array}{l}0 \text { per } 1000 \\
(0 \text { to } 0)\end{array}$ & $\begin{array}{l}\text { RR } 5.05 \\
(0.25 \text { to } 103.87)\end{array}$ & $\begin{array}{l}201 \\
(1 \mathrm{RCT})^{4}\end{array}$ & $\begin{array}{l}\oplus \odot \Theta \odot \\
\text { VERY LOW } 2,5\end{array}$ & $\begin{array}{l}\text { Non-responders were re-treated after } 2 \text { and/or } 3 \\
\text { weeks (absolute numbers are unclear). }\end{array}$ \\
\hline $\begin{array}{l}\text { Withdrawal due } \\
\text { to } A E \text { - week } 4\end{array}$ & 0 per 1000 & $\begin{array}{l}0 \text { per } 1000 \\
(0 \text { to } 0)\end{array}$ & Not estimable & $\begin{array}{l}62 \\
(1 \mathrm{RCT})^{4}\end{array}$ & $\begin{array}{l}\oplus \oplus \oplus \ominus \\
\text { MODERATE } 2\end{array}$ & $\begin{array}{l}0 \text { events; } 8 \text { participants (oral IVER) and } 4 \text { participants } \\
\text { (topical IVER) were re-treated after } 1 \text { week. }\end{array}$ \\
\hline
\end{tabular}

*The risk in the intervention group (and its $95 \% \mathrm{Cl}$ ) is based on the assumed risk in the comparison group and the relative effect of the intervention (and its $95 \% \mathrm{Cl}$ ). Abbreviations: AE: adverse event; Cl: confidence interval; IVER: ivermectin; RCT: randomized controlled trial; RR: risk ratio.

\section{GRADE Working Group grades of evidence}

High certainty: we are very confident that the true effect lies close to that of the estimate of the effect. 
Moderate certainty: we are moderately confident in the effect estimate: the true effect is likely to be close to the estimate of the effect, but there is a possibility that it is substantially different.

Low certainty: our confidence in the effect estimate is limited: the true effect may be substantially different from the estimate of the effect.

Very low certainty: we have very little confidence in the effect estimate: the true effect is likely to be substantially different from the estimate of effect.

1 Ahmad 2016

2Downgraded by 1 for serious risk of bias: assessed as moderate.

${ }^{3}$ Downgraded by 1 for serious imprecision: $\mathrm{Cl}$ crosses line of no effect and minimal clinically important difference thresholds: uncertain whether there is any difference.

${ }^{4}$ Chhaiya 2012.

5Downgraded by 2 for very serious imprecision: $\mathrm{Cl}$ crosses line of no effect and minimal clinically important difference thresholds: uncertain whether there is any difference and wide $\mathrm{Cl}$.

\section{Summary of findings 4. Topical ivermectin 1\% lotion (1 to 3 applications) compared to topical permethrin $5 \%$ cream (1 to 3 applications)}

Topical ivermectin $1 \%$ lotion (1 to 3 applications) compared to topical permethrin $5 \%$ cream (1 to 3 applications) for treating scabies

Patient or population: people with scabies, 5 to 80 years of age

Location: India

Intervention: topical ivermectin $1 \%$ lotion

Comparison: topical permethrin $5 \%$ cream

\begin{tabular}{|c|c|c|c|c|c|c|}
\hline \multirow[t]{2}{*}{ Outcomes } & \multicolumn{2}{|c|}{ Anticipated absolute effects ${ }^{\star}(95 \% \mathrm{Cl})$} & \multirow{2}{*}{$\begin{array}{l}\text { Relative effect } \\
(95 \% \mathrm{Cl})\end{array}$} & \multirow{2}{*}{$\begin{array}{l}\text { Number of par- } \\
\text { ticipants } \\
\text { (trials) }\end{array}$} & \multirow{2}{*}{$\begin{array}{l}\text { Certainty of } \\
\text { the evidence } \\
\text { (GRADE) }\end{array}$} & \multirow[t]{2}{*}{ Comments } \\
\hline & $\begin{array}{l}\text { Risk with per- } \\
\text { methrin 5\% } \\
\text { cream }\end{array}$ & $\begin{array}{l}\text { Risk with ivermectin } \\
1 \% \text { lotion }\end{array}$ & & & & \\
\hline $\begin{array}{l}\text { Complete clear- } \\
\text { ance - week } 4\end{array}$ & 943 per 1000 & $\begin{array}{l}962 \text { per } 1000 \\
(905 \text { to } 1000)\end{array}$ & $\begin{array}{l}\text { RR } 1.02 \\
\text { (0.96 to } 1.08)\end{array}$ & $\begin{array}{l}210 \\
(1 \mathrm{RCT})^{1}\end{array}$ & $\begin{array}{l}\oplus \oplus \oplus \ominus \\
\text { MODERATE } 2\end{array}$ & $\begin{array}{l}\text { Non-responders were re-treated after } 2 \text { and/or } \\
3 \text { weeks (absolute numbers are unclear). }\end{array}$ \\
\hline
\end{tabular}

${ }^{*}$ The risk in the intervention group (and its $95 \% \mathrm{Cl}$ ) is based on the assumed risk in the comparison group and the relative effect of the intervention (and its $95 \% \mathrm{Cl}$ ). Abbreviations: AE: adverse event; $\mathrm{Cl}$ : confidence interval; RCT: randomized controlled trial; RR: risk ratio.

\section{GRADE Working Group grades of evidence}

High certainty: we are very confident that the true effect lies close to that of the estimate of the effect.

Moderate certainty: we are moderately confident in the effect estimate: the true effect is likely to be close to the estimate of the effect, but there is a possibility that it is substantially different.

Low certainty: our confidence in the effect estimate is limited: the true effect may be substantially different from the estimate of the effect. 
1Chhaiya 2012.

2Downgraded by 1 for serious risk of bias: assessed as moderate.

3Downgraded by 2 for very serious imprecision: $\mathrm{Cl}$ crosses line of no effect and minimal clinically important difference thresholds: uncertain whether there is any difference and wide $\mathrm{Cl}$.

\section{Summary of findings 5 . Oral ivermectin $200 \mu \mathrm{g} / \mathrm{kg}$ (1 dose) compared to oral ivermectin $200 \mu \mathrm{g} / \mathrm{kg}$ ( $2 \mathrm{doses}$ )}

Oral ivermectin $200 \mu \mathrm{g} / \mathrm{kg}$ (1 dose) compared to oral ivermectin $200 \mu \mathrm{g} / \mathrm{kg}$ ( 2 doses) for treating scabies

Patient or population: people with scabies, over 5 years of age

Location: India

Intervention: oral ivermectin $200 \mu \mathrm{g} / \mathrm{kg} 1$ dose

Comparison: oral ivermectin $200 \mu \mathrm{g} / \mathrm{kg} 2$ doses

\begin{tabular}{|c|c|c|c|c|c|c|}
\hline \multirow[t]{2}{*}{ Outcomes } & \multicolumn{2}{|c|}{ Anticipated absolute effects ${ }^{\star}(95 \% \mathrm{Cl})$} & \multirow{2}{*}{$\begin{array}{l}\text { Relative effect } \\
(95 \% \mathrm{Cl})\end{array}$} & \multirow{2}{*}{$\begin{array}{l}\text { Number of par- } \\
\text { ticipants } \\
\text { (trials) }\end{array}$} & \multirow{2}{*}{$\begin{array}{l}\text { Certainty of the } \\
\text { evidence } \\
\text { (GRADE) }\end{array}$} & \multirow[t]{2}{*}{ Comments } \\
\hline & $\begin{array}{l}\text { Risk with ivermectin } 200 \\
\mu \mathrm{g} / \mathrm{kg} 2 \text { doses }\end{array}$ & $\begin{array}{l}\text { Risk with ivermectin } 200 \mu \mathrm{g} / \mathrm{kg} 1 \\
\text { dose }\end{array}$ & & & & \\
\hline $\begin{array}{l}\text { Complete clear- } \\
\text { ance - week } 4\end{array}$ & 900 per 1000 & $\begin{array}{l}873 \text { per } 1000 \\
\text { (747 to } 1000)\end{array}$ & $\begin{array}{l}\text { RR } 0.97 \\
\text { (0.83 to } 1.14 \text { ) }\end{array}$ & $\begin{array}{l}80 \\
(1 \mathrm{RCT})^{1}\end{array}$ & $\begin{array}{l}\oplus \oplus \oplus \oplus \\
\mathrm{HIGH}\end{array}$ & - \\
\hline
\end{tabular}

${ }^{*}$ The risk in the intervention group (and its $95 \% \mathrm{Cl}$ ) is based on the assumed risk in the comparison group and the relative effect of the intervention (and its $95 \% \mathrm{Cl}$ ). Abbreviations: $\mathrm{Cl}$ : confidence interval; RR: risk ratio.

\section{GRADE Working Group grades of evidence}

High certainty: we are very confident that the true effect lies close to that of the estimate of the effect.

Moderate certainty: we are moderately confident in the effect estimate. The true effect is likely to be close to the estimate of the effect, but there is a possibility that it is substantially different.

Low certainty: our confidence in the effect estimate is limited. The true effect may be substantially different from the estimate of the effect.

Very low certainty: we have very little confidence in the effect estimate. The true effect is likely to be substantially different from the estimate of effect. 


\section{B A C K G R O U N D}

This section is based on Strong 2007.

\section{Description of the condition}

Scabies is an intensely itchy parasitic infection of the skin that is caused by the Sarcoptes scabiei mite. It occurs worldwide, but is particularly problematic in areas of poor sanitation, overcrowding, and social disruption. The global prevalence of scabies ranges from $0.2 \%$ to $71.4 \%$, with large variations in geographical region (Roman 2015a). Highest scabies prevalence is noted in Pacific and Central/ South American regions. Children are particularly affected (Romani 2015a); for example, in Germany, infectious disease surveillance data on centralized homes for asylum seekers from 2004 to 2014 revealed 119 outbreaks. Of 615 people diagnosed with an infectious disease, $19 \%$ had scabies (Kühne 2016). The Global Burden of Disease Study 2015 concluded that $0.21 \%$ of all disability-adjusted life-years were caused by scabies worldwide (Karimkhani 2017).

In resource-rich communities, scabies tends to occur in cyclical epidemics, particularly within institutional living situations such as nursing homes (Scheinfeld 2004), or the army (Mimouni 1998; Mimouni 2003). There is some seasonal variation, with incidence being greater in the winter than in the summer, perhaps related to a tendency of indoor overcrowding, as well as increased mite survival in colder weather (Downs 1999; Hay 2012). In resourcepoor communities, the occurrence pattern is quite different, with the disease being endemic in many areas (Chosidow 2000). The prevalence of infections in a community is potentially influenced by changes in social attitudes, population movements, wars, misdiagnosis, inadequate treatment, and changes in the immune status of the population. Scabies infestation represents a considerable burden of ill health in many communities, and although the disease is rarely life-threatening, it causes widespread debilitation and misery (Green 1989).

The $S$ scabiei life cycle begins with the pregnant female laying two to three eggs a day in burrows several millimetres to several centimetres in length in the stratum corneum (outermost layer) of the skin. After about 50 to 72 hours, larvae emerge and make new burrows. They mature, mate, and repeat this 10- to 17-day cycle. Mites usually live for 30 to 60 days (Green 1989). Mites survive for up to three days outside of the human body (CDC 2017a).

Humans are the main reservoir for $S$ scabiei var. hominis (variety of the mite named to reflect the main host species). Scabies is usually spread person to person via direct skin contact, including sexual contact, though transfer via inanimate objects such as clothing or furnishings is also possible (Hay 2004). The mite can burrow beneath the skin within 2.5 minutes, though around 20 minutes is more usual (Alexander 1984). The level of infectiousness of an individual depends in part on the number of mites harboured, which can vary from just a single mite to millions (Chosidow 2000). Humans can also be transiently infected by the genetically distinct animal varieties of $S$ scabiei (for example, var. canis), though crossinfectivity is low (Fain 1978; Walton 2004a).

Clinical infection with the scabies mite causes discomfort and often intense itching of the skin, particularly at night, with irritating papular or vesicular eruptions. While infestation with the scabies mite is not life-threatening, the severe, persistent itch debilitates and depresses people (Green 1989). The classical sites of infestation are between the fingers, the wrists, axillary areas, female breasts (particularly the skin of the nipples), peri-umbilical area, penis, scrotum, and buttocks. Infants are usually affected on the face, scalp, palms, and soles of the feet. Much of the itching associated with scabies is a result of the host immune reaction, and symptoms can take several weeks to appear after initial infection in a person exposed to scabies for the first time. Symptoms appear after a much shorter interval (one to two days) after re-infestation (Arlian 1989).

A more severe or 'crusted' presentation of infestation is associated with extreme incapacity and with disorders of the immune system, such as HIV infection. Clinically this atypical form of scabies presents with a hyperkeratotic dermatosis resembling psoriasis. Lymphadenopathy and eosinophilia can be present, but itching may be unexpectedly mild. People with crusted scabies may harbour millions of mites and are highly infectious (Meinking 1995). The dermatological distribution of mites in such people is often atypical (for example, including the head), and treatment in hospital is advised (Chosidow 2000; Sunderkötter 2016).

Complications are few, although secondary bacterial infection of the skin lesions by group A Streptococcus pyogenes or Staphylococcus aureus, or both, can occur following repeated scratching, particularly in warmer climates (Meinking 1995). Secondary infection with group A Streptococcus can lead to acute glomerulonephritis, outbreaks of which have been associated with scabies (Green 1989; Hoy 2012; Hay 2013).

\section{Diagnosis}

Diagnosis on clinical grounds is usually made based on a history of itching (particularly if contacts are also affected) and the finding of lesions at the classical sites. The diagnosis can in most cases be confirmed by microscopically identifying a mite, egg, or mite faeces in a skin scraping, or by extracting a mite from a burrow (Chosidow 2000).

\section{Description of the intervention}

Various treatments are available for scabies. These include sulfur compounds, benzyl benzoate, crotamiton, hexachlorocyclohexane, malathion, permethrin, and ivermectin. A number of herbal remedies have also been proposed, including tea tree oil, lippia oil, T ointment, and kakawati poultice (Banez 1999; Oladimeji 2000; Alebiosu 2003; Walton 2004b; Oladimeji 2005).

In recent years, topical permethrin and oral ivermectin have become the most relevant treatment options for scabies (Banerji 2015; RKI 2016).

Topical permethrin $5 \%$ was first licensed in 1989 by the US Food and Drug Administration (Currie 2010). It was approved in Germany in October 2004 (Hamm 2006; InfectoScab 2016). In low- and middleincome countries such as India, where permethrin was approved for treating scabies in 1995 (CDSCO), the treatment is considered expensive, while oral ivermectin seems to be cheaper (Sharma 2011).

In contrast, oral ivermectin was first approved for the treatment of scabies in France in 2001 (Currie 2010); in the past few years it has been approved in Australia and the Netherlands (AusPAR 2013; Merck 2015). Oral ivermectin was approved for the treatment of scabies in Germany in February 2016 (Scabioral 2016), whereas in the USA it is still used off-label (CDC 2017b). 
Topical ivermectin has also been investigated for the treatment of scabies in recent years due to the expected therapeutic efficacy. It is not approved for the treatment of scabies, but for treating head lice (0.5\% lotion, FDA 2012) and inflammatory lesions of rosacea ( $1 \%$ cream, FDA 2014).

Systemic ivermectin is associated with adverse reactions such as nausea, rash, dizziness, itching, abdominal pain, and fever. Many of these symptoms may be an allergic reaction to the dead parasites rather than to ivermectin itself (Fawcett 2003). An increased risk of death amongst elderly patients in a long-term care facility has been reported with the use of ivermectin (Barkwell 1997). However, the validity of this report has been discussed considerably (Bredal 1997; Coyne 1997; Diazgranados 1997; Reintjes 1997), and its findings could not be confirmed by multiple subsequent studies.

Rare adverse reactions have been reported with the use of permethrin, including neck dystonia (Coleman 2005), pruritus, burning, and stinging (Fawcett 2003).

\section{Prevention}

Prevention is based on principles common to most infectious diseases, that is limitation of contact with the mite. An infested person can spread scabies even if no symptoms are present. The probability of transmission is highest with direct and close skin-to-skin contact and happens most frequently between family members. Linen used and worn three days before the start of treatment should be washed thoroughly to avoid spreading scabies (CDC 2017a). Contacts of cases are usually advised to treat themselves at the same time as the case in order to reduce the risk of re-exposure and re-infestation (Sunderkötter 2016).

\section{How the intervention might work}

Ivermectin is a broad-spectrum anthelmintic agent, which affects the nervous system of the scabies mite and causes its death (AusPAR 2013). Unlike permethrin, it is not ovicidal. Ivermectin is available as systemic antiscabies drug $(200 \mu \mathrm{g} / \mathrm{kg} / \mathrm{dose}$; CDC $2017 \mathrm{~b})$. Permethrin is usually available as a $5 \%$ cream or $5 \%$ lotion. It is a synthetic pyrethroid, which kills the scabies mite and the eggs (CDC 2017b).

In general, permethrin is applied as 5\% cream to all areas of the body from head/neck to toe. It is left on overnight or up to 24 hours and then rinsed off. Application is sometimes repeated once, about one to two weeks later. Children aged two months or older can also be treated (Currie 2010; Banerji 2015; CDC 2015; Sunderkötter 2016; CDC 2017b; Salavastru 2017).

Ivermectin is taken orally as a tablet with a dosage of $200 \mu \mathrm{g} / \mathrm{kg}$ body weight, usually once but sometimes a second time after one to two weeks. It has not been tested in pregnant or lactating woman and children weighing less than $15 \mathrm{~kg}$. Furthermore, opinions diverge on whether the tablet should be taken with food or on an empty stomach (Currie 2010; Banerji 2015; CDC 2015; Sunderkötter 2016; CDC 2017b; Salavastru 2017).

A follow-up visit to determine whether the patient is cured should ideally occur one month after the initiation of treatment. This time allows for lesions to heal and for any eggs and mites to reach maturity in case the treatment did not work (that is, beyond the longest incubation interval). Patients should be advised that itching may persist for one to two weeks after treatment, even if the mite is successfully eradicated (Buffet 2003). Because of this delay in symptom relief, it may sometimes be difficult to distinguish reinfestation from primary treatment failure.

\section{Why it is important to do this review}

Apart from a non-Cochrane systematic review that considered several scabies treatments (Dressler 2016a), there is currently no systematic review focusing on the available evidence comparing ivermectin with permethrin. Using data from randomized controlled trials, this review summarizes and evaluates the existing evidence on the efficacy and safety of permethrin and ivermectin for scabies. We aimed to answer the following questions in relation to safety and efficacy.

- Is oral ivermectin superior to topical permethrin?

- Is oral ivermectin superior to topical ivermectin?

- Is topical ivermectin superior to topical permethrin?

- Is a single dose of oral ivermectin superior to multiple doses of oral ivermectin?

Global epidemics and an increasing number of asylum seekers due to the Middle Eastern population migration highlights the importance of this review to investigate and understand scabies interventions (Kühne 2016; Bloch-Infanger 2017).

A Cochrane Review on 'Interventions for treating scabies' was published in 2007 (Strong 2007). This includes an evaluation of crotamiton, lindane, sulfur, and benzyl benzoate; Strong 2007 and earlier published versions are listed in the 'Other published versions of this review' section.

\section{O B JECTIVES}

To assess the efficacy and safety of topical permethrin and topical or systemic ivermectin for scabies in people of all ages.

\section{METHODS}

\section{Criteria for considering studies for this review \\ Types of studies}

We only included randomized controlled trials (RCTs). We considered all study reports irrespective of their publication status and language of publication.

The review protocol was registered with PROSPERO International prospective register of systematic reviews in October 2016 (Rosumeck 2016). Very few changes have been made to the proposed methods; see the 'Differences between protocol and review' section.

\section{Types of participants}

Children or adults of both sexes with a diagnosis of classical scabies, as defined by the study authors.

\section{Types of interventions}

\section{Intervention}

- Topical permethrin.

- Topical ivermectin.

- Systemic ivermectin. 


\section{Control}

- One of the above mentioned interventions.

\section{Types of outcome measures}

\section{Primary outcomes}

- Complete clearance (outcome assessment at 7, 14, and 30 days' post-initiation of treatment).

\section{Secondary outcomes}

- Number of people re-treated.

- Number of people with at least one adverse event (outcome assessment at the end of active study period).

- Number of people withdrawn from study due to adverse event (outcome assessment at the end of active study period).

\section{Search methods for identification of studies}

We attempted to identify all RCTs regardless of language or publication status (published, unpublished, in press, or in progress).

\section{Electronic searches}

\section{Databases}

We searched the following databases up to 25 April 2017 using the search terms and strategy described in Appendix 1: the Cochrane Infectious Disease Group Specialized Register; the Cochrane Central Register of Controlled Trials (CENTRAL, published in the Cochrane Library; Issue 4, 2017); MEDLINE (PubMed, from 1946); Embase Ovid (from 1974); LILACS (Latin American and Caribbean Center on Health Sciences Information) (lilacs.bvsalud.org/, from 1982), and IndMED (indmed.nic.in/, from 1985). We also searched EconLit (Economic Literature database, EBSCOHost, from 1993 to 26 July 2016) and ERIC (Education Resources Information Center, EBSCOHost, from 1966 to 26 July 2016).

\section{Grey literature}

We searched the following sources for published and unpublished trials up to 26 July 2016:

- British Library Index of Conference Proceedings (explorecatalogue.bl.uk/), search term: "scabies" AND ("trial" OR "study" OR "treatment");

- British Library for Development Studies (blds.ids.ac.uk/), search term: "scabies";

- BRIDGE (www.bridge.ids.ac.uk/), search term: "scabies";

- Social Care Online (www.scie-socialcareonline.org.uk/), search term: "scabies";

- Institute for Development Studies (www.ids.ac.uk/search), search term: "scabies";

- IIED (www.iied.org/), search term: "scabies"; and

- Science.gov (www.science.gov/), search term: "scabies" AND ("trial" OR "study" OR "treatment").

\section{Trials registers}

We searched the following sources for registered trials using the term "scabies" up to 25 April 2017:
- World Health Organization International Clinical Trials Registry Platform (WHO ICTRP, apps.who.int/trialsearch);

- ISRCTN registry (www.isrctn.com);

- CenterWatch Clinical Trials Listing (www.centerwatch.com);

- US National Institutes of Health Ongoing Trials Register ClinicalTrials.gov (www.clinicaltrials.gov);

- TrialsCentral (www.trialscentral.org); and

- UK Department of Health National Research Register (www.nihr.ac.uk).

\section{Searching other resources}

\section{Reference lists}

We scanned the reference lists of all included RCTs for further studies.

\section{Correspondence}

We attempted to obtain unpublished data via e-mail correspondence with first authors if contact details were available or could be identified.

\section{Data collection and analysis}

Several of the following sections may be identical to parts of the Cochrane Handbook for Systematic Reviews of Interventions (Higgins 2011).

\section{Selection of studies}

Two review authors independently screened the titles and abstracts of all studies identified by the search to determine those that were potentially relevant. The full texts of all records assessed as eligible by at least one of the review authors were obtained. We read all available full texts to assess study eligibility according to the inclusion criteria.

We scrutinized the trial reports to ensure that multiple publications from the same trial were identified so that data were only included once (see the Characteristics of included studies table). Reasons for the exclusion of studies during the full-text screening phase are listed in the Characteristics of excluded studies table.

We illustrated the study selection process in a PRISMA flow diagram.

\section{Data extraction and management}

Two review authors (SR and CD) independently extracted data from the included trial reports using a standardized data extraction form (Microsoft Word). Items extracted include study characteristics, inclusion and exclusion criteria, baseline data, definition of outcomes, adverse events, and whether participants were retreated. The form was piloted.

We extracted the number of participants randomized as well as the number of participants analysed for each study arm. For each dichotomous outcomes, we recorded the number of participants experiencing the event in each arm of the trial. If efficacy data were not reported using an intention-to-treat approach, we imputed these data employing a non-responder imputation approach for all intervention and control groups. 
Where primary or secondary outcomes were measured at more than one time point, we aimed to extract all relevant data corresponding to 7,14 , and 30 days post-treatment initiation.

For one study, Usha 2000, we extracted percentages of participants achieving 'complete clearance of lesions' (graded as good improvement) from a graph using the Engauge Digitizer software (Engauge Digitizer). We converted the percentages into absolute numbers, as no withdrawals or dropouts were reported.

After comparing the extracted data and resolving any differences through discussion, one review author (SR) entered the data into Review Manager 5 (RevMan 5) (RevMan 2014), and a second review author (CD) checked the data for accuracy.

\section{Assessment of risk of bias in included studies}

For each included study, two review authors independently assessed the methodological quality using the Cochrane 'Risk of bias' assessment tool (Higgins 2011). We assessed the following seven domains.

- Random sequence generation.

- Allocation concealment.

- Blinding of participants and personnel.

- Blinding of outcome assessment.

- Completeness of outcome data.

- Selective reporting.

- Other sources of bias.

For each trial, to assess 'selection bias' we described the methods used to generate the randomization list and how the allocation was concealed; to assess 'performance and detection bias' we stated who was blinded and, if reported, how this was done. In order to assess 'attrition bias', we reported the number of participants lost to follow-up and the method study authors used to deal with missing data. If more than $10 \%$ of the participants were lost to follow-up in at least one of the study groups, and no imputation method was used to analyse the study outcomes, we evaluated the risk of bias as high. To assess 'reporting bias', we described any discrepancies between the methods section (planned measurements) and the results as reported in the included records. For the domain 'other bias', we have listed and assessed any other potential sources of bias that may have influenced the studies' results.

For each of the domains 'selection bias', 'reporting bias', and 'other bias', we made one assessment ('low risk', 'high risk', or 'unclear risk' of bias). For the domains 'performance bias', 'detection bias', and 'attrition bias', we made two assessments: one for all efficacy outcomes and one for all safety outcomes per study. Discrepancies in assessments were resolved by discussion.

Review authors' judgements about each 'Risk of bias' item for each included study are presented in the 'Risk of bias' summary figure.

\section{Measures of treatment effect}

We presented results as risk ratios (RRs) with corresponding 95\% confidence intervals ( $\mathrm{Cls}$ ). If an outcome was positive (for example, clearance), RRs greater than one demonstrate a favourable outcome of the intervention of interest, and these were presented to the right of the line of no effect. In case of negative outcomes (for example, safety), RRs smaller than one demonstrate a favourable outcome of the intervention of interest (represented to the left of the line of no effect). We expressed all statistically significant results as numbers needed to treat for an additional beneficial outcome (NNTB) with 95\% Cls (Christensen 2006).

To avoid the problem of multiplicity, we chose only one primary outcome and a limited number of secondary outcomes.

\section{Unit of analysis issues}

To avoid unit of analysis errors, we included every study only once in each comparison (for each outcome at each time point). We also used this approach for multi-arm studies given that for each comparison a single effect measure was calculated. This precluded the same group of participants being included more than once in the same meta-analysis.

In one comparison, we combined two arms of a three-arm study for the outcome 'complete clearance' (Sharma 2011). In both arms oral ivermectin $200 \mu \mathrm{g} / \mathrm{kg}$ body weight was administered on day one. After two weeks, participants in one of these arms received an additional dose of oral ivermectin. We considered both arms as treated equally and hence combined the number of events and participants when assessing the outcome after one and two weeks of treatment.

\section{Dealing with missing data}

For dichotomous efficacy data, we performed an intention-to-treat analysis. We imputed outcome data for the missing participants using a non-responder imputation approach for the intervention and the control groups, meaning that we assumed treatment failure for all missing participant data (conservative approach, Higgins 2011). Participants were analysed in the group to which they had been randomized. We specified the amount of imputed participant data as footnotes in the forest plots.

Some study authors reported insufficient information on safety outcomes. In such cases we reported data as presented by the study authors.

If there were inconsistencies within a publication regarding the reported data, we asked the author for clarification. We sent two e-mails if contact details were provided in the publication or if we were able to identify them elsewhere.

\section{Assessment of heterogeneity}

We assessed heterogeneity by visually inspecting forest plots, calculating an $\mathrm{I}^{2}$ statistic, and carrying out a $\mathrm{Chi}^{2}$ test for heterogeneity using RevMan 5 (RevMan 2014). If we detected heterogeneity (that is, $I^{2}$ statistic > 50\%), we undertook subgroup or sensitivity analysis, or both, to explore the causes of the heterogeneity (Higgins 2011).

If heterogeneity was low or not detected, we pooled results from trials using a random-effects meta-analysis model, because we anticipated that the different studies would estimate different intervention effects (DerSimonian 1986; Higgins 2011).

\section{Assessment of reporting biases}

Had we included 10 or more studies comparing the same intervention, we would have evaluated a funnel plot. However, this was not the case, and we were unable to assess publication bias. We aimed at avoiding the introduction of other types of reporting bias 
at the systematic review level by conducting extensive searches and including all languages.

\section{Data synthesis}

We have summarized and presented qualitative information (for example, study design, description of participants, study groups, outcome measurements) in the Characteristics of included studies tables. We calculated RRs and 95\% Cls using Review Manager 5 for each of the preselected outcomes and pooled data using a randomeffects model if appropriate (RevMan 2014).

Where a meta-analysis could not be performed (for example, due to effects being reported as percentages only), we described the results in the text.

\section{'Summary of findings' tables}

For each assessed comparison we created a 'Summary of findings' table, which included an evaluation of the certainty of evidence according to the GRADE approach described in the Cochrane Handbook for Systematic Reviews of Interventions (Higgins 2011; Schünemann 2013). Using the online tool GRADEpro GDT, we assessed the certainty of the evidence as either high, moderate, low, or very low (GRADEpro GDT). Randomized controlled trials start as high-certainty evidence and are rated down depending on the presence of study limitations (risk of bias), inconsistency, indirectness, imprecision, and publication bias.

\section{Risk of bias}

If most of the information was from studies with an overall assessment of moderate or high risk of bias, we downgraded one (serious limitations) or two levels (very serious limitations) (Guyatt 2011a).

\section{Inconsistency}

We judged large and unexplained inconsistency based on similarity of point estimates and the extent of overlap of Cls. Depending on the magnitude of inconsistency in study results, we rated down by one or two levels (Guyatt 2011d).

\section{Imprecision}

We examined $95 \% \mathrm{Cl}$ for imprecision. If the confidence limit crossed the minimal clinically important difference thresholds, we downgraded one level. Minimal important difference represents the smallest difference between treatment groups for an outcome that clinicians or patients identify as meaningful. By default, these thresholds are 0.75 for appreciable harm and 1.25 for appreciable benefit. If both thresholds were crossed and $\mathrm{Cls}$ were wide, we downgraded the certainty by two levels (Guyatt 2011c).

\section{Indirectness}

We assessed differences in patient populations, (co-)interventions, and measurement of the outcomes of the pooled studies.
Depending on the extent of differences, we downgraded one or two levels (Guyatt 2011e).

\section{Publication bias}

Due to the small number of studies pooled, it was inappropriate to evaluate a funnel plot. We rated the likelihood of publication bias based on study size and sponsorship. In case of publication bias, we rated down by one level (Guyatt 2011b).

We justified and documented our assessment in the 'Summary of findings' tables (that is, in case of downgrading) using footnotes.

\section{Subgroup analysis and investigation of heterogeneity}

Due to the different study designs with respect to drug dosing, we analysed subgroups according to the number of treatment doses - one, one to two, or two doses - for ivermectin $200 \mu \mathrm{g} / \mathrm{kg}$ body weight compared to permethrin $5 \%$ cream (for the outcome 'complete clearance' assessed after four weeks of treatment).

We investigated statistical heterogeneity by means of sensitivity analysis.

\section{Sensitivity analysis}

For two comparisons and outcomes, we conducted sensitivity analyses due to statistical heterogeneity. We could not identify meaningful groups of studies based on 'Risk of bias' assessments that would help explain the heterogeneity. We reported effect estimates excluding studies with slightly different treatment schemes or with a contrary result, separately (see Appendix 2).

\section{RES U L T S}

\section{Description of studies}

\section{Results of the search}

The electronic searches (see Electronic searches) retrieved 692 references. We found another article coincidentally through a search of the Internet, which we included.

We screened the titles and abstracts of 441 records retrieved through database searches and assessed 19 full-text records for eligibility.

We screened the reference lists of already included trials and found three more potentially relevant studies, two of which met the inclusion criteria.

A total of 15 trials met the inclusion criteria of the review.

Trial register searches identified 17 further studies (including two duplicates); we could include one ongoing trial.

The study selection process can be seen in Figure 1. 
Figure 1. Study flow diagram.

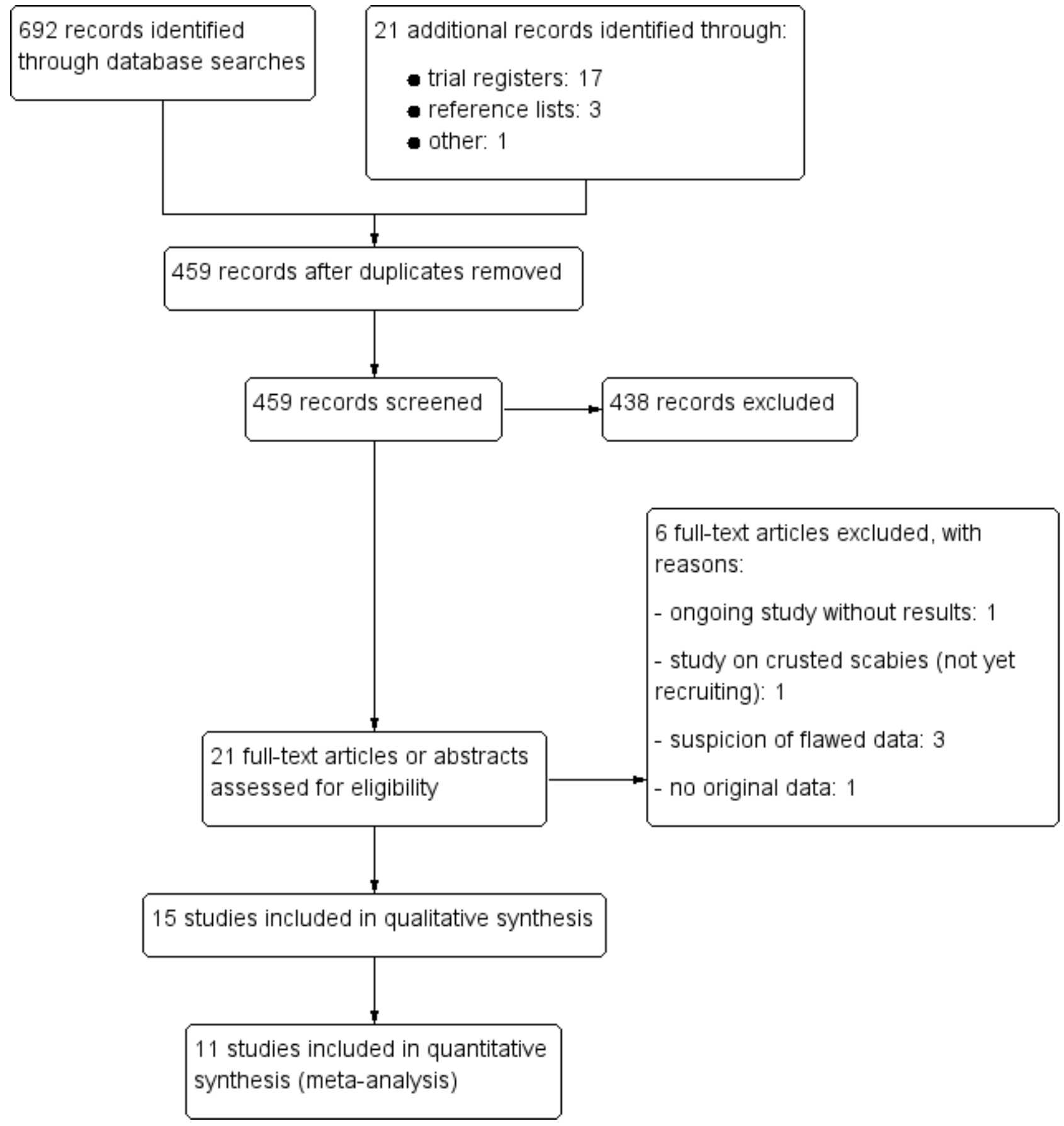

\section{Included studies}

We included 15 RCTs that investigated 1896 participants treated with ivermectin or permethrin. Details of all included studies are provided in the Characteristics of included studies tables.

We contacted the authors of six studies to obtain missing data or to clarify inconsistent information (Das 2006; Mushtaq 2010; Saqib 2012; Rohatgi 2013; Wankhade 2013; Manjhi 2014); the authors of two studies replied (Saqib 2012; Rohatgi 2013). Details are reported in the respective Characteristics of included studies tables.

\section{Design}

All included studies were parallel-group RCTs, and most were conducted as open-label trials. Participants and personnel were blinded to treatment assignment in only one study (Sharma 2011). In a second study, the outcome assessor was blinded (Saqib 2012).

We assumed that all studies recruited participants from one centre, but this was not stated clearly in all study reports.

Seven studies compared two treatment groups. Five of these studies evaluated topical permethrin and systemic ivermectin 
(Usha 2000; Mushtaq 2010; Saqib 2012; Rohatgi 2013; Wankhade 2013); one study compared topical ivermectin with systemic ivermectin (Ahmad 2016); and the remaining study compared one versus three treatments of systemic ivermectin (Macotela-Ruiz 1996).

Five studies compared three treatment groups. One study investigated permethrin, systemic ivermectin, and topical ivermectin (Chhaiya 2012); one study compared permethrin with two different regimens of systemic ivermectin (Sharma 2011); and the remaining three studies investigated systemic ivermectin and permethrin as well as another treatment not addressed in this review (benzyl benzoate 25\% lotion (Bachewar 2009); gamma benzene hexachloride 1\% lotion (Meenakshi 2014); combination of topical permethrin and systemic ivermectin (Wankhade 2016)).

Three studies compared four treatment groups. Abdel-Raheem 2016 investigated topical permethrin and systemic ivermectin (plus two groups treated with sulfur ointment or benzyl benzoate cream not included in this review). Das 2006 also examined the effect of gamma benzene hexachloride $1 \%$ and included a placebo group. Manjhi 2014 investigated topical permethrin and systemic ivermectin (plus two groups treated with gamma benzene hexachloride $1 \%$ lotion or benzyl benzoate $20 \%$ lotion not included in this review).

In two studies, uncured participants were switched to another treatment (Usha 2000; Chhaiya 2012).

The oldest included study was conducted from 1993 to 1995 and was published in 1996 (Macotela-Ruiz 1996), while the three most recent ones were published in 2016 (Abdel-Raheem 2016; Ahmad 2016; Wankhade 2016).

\section{Sample sizes}

The sample size varied from 62, in Ahmad 2016, to 315, in Chhaiya 2012. In two studies the numbers of randomized participants per study group were not reported (Mushtaq 2010; Wankhade 2013).

\section{Study settings}

All studies took place in dermatological outpatient clinics/ dermatological departments of medical colleges or hospitals.

\section{Age}

Eleven studies included children and adults, with an age range of two to 80 years (Usha 2000; Das 2006; Bachewar 2009; Mushtaq 2010; Sharma 2011; Chhaiya 2012; Manjhi 2014; Meenakshi 2014; Abdel-Raheem 2016; Ahmad 2016; Wankhade 2016).

Saqib 2012 included only adults aged 18 to 60 . One trial enrolled only children from five to 15 years of age (Rohatgi 2013).

Only three studies reported the mean age at baseline of all included participants. In the study by Abdel-Raheem 2016, the mean age of the 200 participants who completed the study was 25.33 years (standard deviation (SD) 12.84). The mean age at baseline of the 62 randomized participants in the study by Ahmad 2016 was 21.8 years (SD 15). Macotela-Ruiz 1996 did not report the age of participants, but stated a mean age of 12 and 16 years for male and female participants, respectively, in the group treated with one dose of ivermectin $250 \mu \mathrm{g} / \mathrm{kg}$ body weight, and a mean age of 18 and 20 for male and female participants, respectively, in the three-dose group.
Another study by Wankhade 2013, which was available only as an abstract, did not report age.

\section{Sex}

All studies recruited both women and men. Eleven studies reported the proportion of female participants, including 639 women (45.22\%) and 774 men (Macotela-Ruiz 1996; Usha 2000; Bachewar 2009; Mushtaq 2010; Sharma 2011; Chhaiya 2012; Rohatgi 2013; Meenakshi 2014; Abdel-Raheem 2016; Ahmad 2016; Wankhade 2016).

\section{Geographical region}

Ten studies were conducted in India (Usha 2000; Das 2006; Bachewar 2009; Sharma 2011; Chhaiya 2012; Rohatgi 2013; Wankhade 2013; Manjhi 2014; Meenakshi 2014; Wankhade 2016), two in Pakistan (Mushtaq 2010; Saqib 2012), two in Egypt (AbdelRaheem 2016; Ahmad 2016), and one in Mexico (Macotela-Ruiz 1996).

\section{Diagnosis of scabies}

A detailed description of how scabies was diagnosed in each study is provided as part of the Characteristics of included studies tables.

Diagnostic procedures differed greatly. In six studies clinical diagnosis was confirmed by microscopic examination (Das 2006; Chhaiya 2012; Saqib 2012; Rohatgi 2013; Abdel-Raheem 2016; Ahmad 2016). In the study by Wankhade 2016, participants were included based on clinical criteria, even when the microscopic examination was negative. In four studies scabies was diagnosed clinically only (Usha 2000; Bachewar 2009; Sharma 2011; Meenakshi 2014). In the study by Mushtaq 2010, only in cases of uncertainty confirmation of the clinical diagnosis was sought by an additional microscopic examination. Three studies did not report diagnostic procedures (Macotela-Ruiz 1996; Wankhade 2013; Manjhi 2014).

\section{Interventions}

\section{Treatment duration, frequency, and formulation}

The treatment frequency of permethrin ranged from a single application in most included studies (Usha 2000; Das 2006; Bachewar 2009; Mushtaq 2010; Sharma 2011; Chhaiya 2012; Saqib 2012; Rohatgi 2013; Wankhade 2013; Manjhi 2014; Wankhade 2016), to a single application daily on five days/nights in a row (AbdelRaheem 2016). In one study, permethrin was applied on day one and again after one week (Meenakshi 2014).

Most of the included studies administered permethrin as a $5 \%$ cream (Usha 2000; Das 2006; Bachewar 2009; Mushtaq 2010; Sharma 2011; Chhaiya 2012; Rohatgi 2013; Manjhi 2014; Meenakshi 2014; Wankhade 2016). Two studies investigated permethrin as a lotion (Abdel-Raheem 2016: 5\% for adults, 2.5\% for children and Saqib 2012: 5\%). One study, available as an abstract only, did not report the galenic formulation (Wankhade 2013).

Systemic ivermectin was administered once in 12 studies (Macotela-Ruiz 1996; Usha 2000; Bachewar 2009; Mushtaq 2010; Sharma 2011; Chhaiya 2012; Saqib 2012; Rohatgi 2013; Wankhade 2013; Manjhi 2014; Ahmad 2016; Wankhade 2016). In two studies, systemic ivermectin was administered on day one and again one week later (Meenakshi 2014; Abdel-Raheem 2016). In another two studies, two doses of ivermectin - on day one and again after two 
weeks - were dispensed (Das 2006; Sharma 2011). In Macotela-Ruiz 1996, ivermectin was given three times: on day one, day seven, and day 10.

Systemic ivermectin was administered orally, in five studies in tablet form (Das 2006; Chhaiya 2012; Rohatgi 2013; Meenakshi 2014; Wankhade 2016). The other 10 studies did not specify whether a tablet or a capsule was used (Macotela-Ruiz 1996; Usha 2000; Das 2006; Mushtaq 2010; Sharma 2011; Saqib 2012; Wankhade 2013; Manjhi 2014; Abdel-Raheem 2016; Ahmad 2016).

Two studies investigated a single application of topical ivermectin (Chhaiya 2012; Ahmad 2016), administered as 1\% lotion, in Chhaiya 2012, or as 1\% solution, in Ahmad 2016.

\section{Re-treatment}

Most studies did not report the absolute numbers of participants needing re-treatment or being re-treated. Only two trials comparing ivermectin with permethrin reported numbers of participants needing a second treatment due to non-response, which was higher in the systemic ivermectin group than in the permethrin group.

We specified any available information on number of participants re-treated as footnotes in the forest plots and in Appendix 3.

\section{Treatment of family members and close contacts}

In nine studies, members of the family or close contacts, or both, were treated alongside the study participants.

In four studies, family members, Usha 2000; Rohatgi 2013; AbdelRaheem 2016, or all contacts of the participants, Saqib 2012, received the same medication as the study participant.

In three studies, contacts were treated irrespective of the participant's treatment as follows: Sharma 2011 provided all family contacts with topical permethrin $5 \%$ cream for single overnight application. Macotela-Ruiz 1996 treated 95 contacts with an oral single dose of $250 \mu \mathrm{g} / \mathrm{kg}$ body weight ivermectin. Bachewar 2009 gave benzyl benzoate $25 \%$ lotion to all participants so family members could be treated simultaneously.

Meenakshi 2014 explicitly explained to all participants the importance of treating their family members. Whether medication was dispensed or not was not reported. Ahmad 2016 reported that contacts were treated; the nature and extent of the treatment were not described.

\section{Definition and diagnosis of complete clearance}

Three studies provided no definition of 'clinical cure of scabietic lesions' (Chhaiya 2012), 'improvement clinically' (Das 2006), or 'cure rate' (Wankhade 2013). The other studies provided details of the definition and diagnosis of complete clearance, which are given in Appendix 4.

\section{Excluded studies}

We excluded five studies after full-text assessment (see Figure 1). Reasons for the exclusion of studies are listed in the Characteristics of excluded studies table.

The objective of Chhaiya 2013 was a cost-effectiveness analysis of topical permethrin versus oral ivermectin. The analysis consists of two study groups of Chhaiya 2012. The study did not report any additional relevant data.

We excluded one study on people with crusted scabies, which was not yet open for participant recruitment (NCT02841215). The aim of this study is to assess the efficacy of ivermectin $400 \mu \mathrm{g} / \mathrm{kg}$ body weight compared to ivermectin $200 \mu \mathrm{g} / \mathrm{kg}$ body weight in severe forms of scabies.

We excluded three studies co-authored by Mohamad Goldust due to suspicion of flawed data (Goldust 2012; Goldust 2013; Ranjkesh 2013). We are aware of several other publications on scabies by Goldust and colleagues. Details are reported elsewhere (Dressler 2016b). The issue was presented and discussed at the annual meeting of the Cochrane Skin Group on 9-10 January 2017 in Berlin: a unanimous decision was made to exclude these studies from the review due to the suspicion of flawed data.

\section{Ongoing studies}

One study is still recruiting (NCT02407782), hence results are not yet available.

\section{Risk of bias in included studies}

See Figure 2 for the 'Risk of bias' evaluations of the included trials. For more details on each assessment, see the 'Risk of bias table' for each individual study in the Characteristics of included studies tables. 
Figure 2. 'Risk of bias' summary: review authors' judgements about each risk of bias item for each included trial.

\begin{tabular}{|c|c|c|c|c|c|c|c|c|c|c|}
\hline & 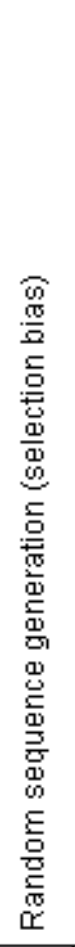 & 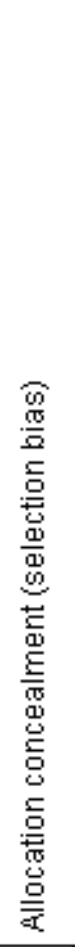 & 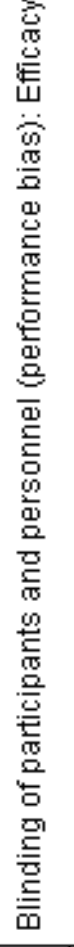 & 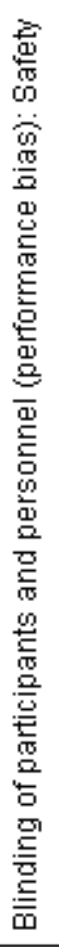 & 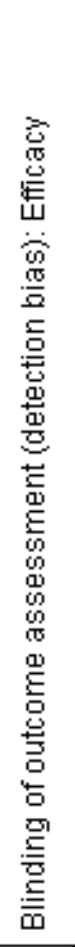 & 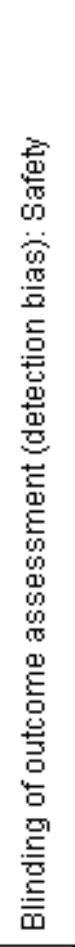 & 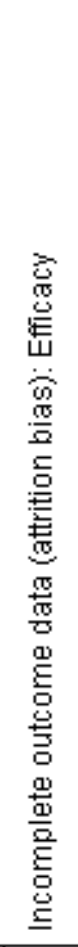 & 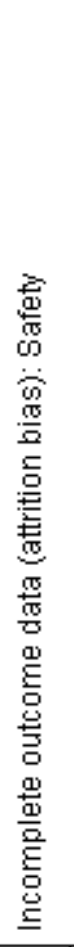 & 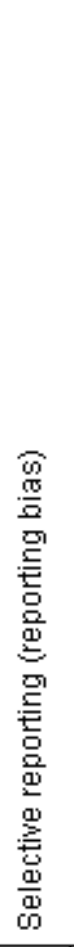 & 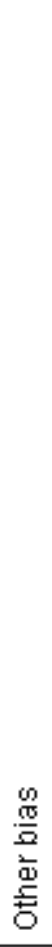 \\
\hline Abdel-Raheem 2016 & + & + & - & $\odot$ & $\odot$ & $\odot$ & 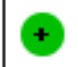 & + & ? & $?$ \\
\hline Ahmad 2016 & + & ? & - & ? & - & - & 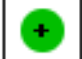 & $?$ & $?$ & $?$ \\
\hline Bachewar 2009 & + & + & & & - & $\odot$ & - & - & $?$ & $?$ \\
\hline Chhaiya 2012 & + & ? & & & ? & - & $?$ & + & $?$ & $?$ \\
\hline Das 2006 & ? & ? & 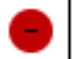 & & $\odot$ & $\odot$ & - & $?$ & $?$ & $?$ \\
\hline Macotela-Ruiz 1996 & ? & ? & & & - & 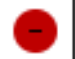 & - & - & - & $?$ \\
\hline Manjhi 2014 & $?$ & $?$ & & & & - & 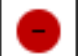 & - & ? & $?$ \\
\hline Meenakshi 2014 & + & $?$ & & & 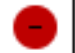 & $\odot$ & - & - & - & $?$ \\
\hline Mushtaq 2010 & + & $?$ & & & ก & $\odot$ & - & - & ? & \\
\hline Rohatgi 2013 & ? & ? & 9 & & - & - & + & $\oplus$ & $?$ & \\
\hline Saqib 2012 & + & + & + & & + & $\odot$ & 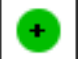 & 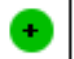 & $?$ & ) \\
\hline Sharma 2011 & + & + & $\oplus$ & 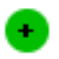 & + & 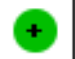 & 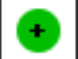 & $?$ & $?$ & $?$ \\
\hline Usha 2000 & ? & ? & & & - & $\odot$ & + & + & $?$ & $?$ \\
\hline Wankhade 2013 & $?$ & $?$ & & & - & $\Rightarrow$ & $O$ & - & $?$ & $?$ \\
\hline Wankhade 2016 & ? & ? & & & - & & 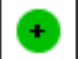 & + & ? & $?$ \\
\hline
\end{tabular}




\section{Allocation}

More than half of the included studies used adequate methods to generate random sequence (Bachewar 2009; Mushtaq 2010; Sharma 2011; Chhaiya 2012; Saqib 2012; Meenakshi 2014; AbdelRaheem 2016; Ahmad 2016). The other seven studies did not report the methods used (Macotela-Ruiz 1996; Usha 2000; Das 2006; Rohatgi 2013; Wankhade 2013; Manjhi 2014; Wankhade 2016).

Four studies reported methods that assured adequate allocation concealment (Bachewar 2009; Sharma 2011; Saqib 2012; AbdelRaheem 2016). We assessed the remaining 11 studies as at unclear risk of bias (Macotela-Ruiz 1996; Usha 2000; Das 2006; Mushtaq 2010; Chhaiya 2012; Rohatgi 2013; Wankhade 2013; Manjhi 2014; Meenakshi 2014; Ahmad 2016; Wankhade 2016).

Consequently, we judged only four out of 15 studies to be at low risk of selection bias (Bachewar 2009; Sharma 2011; Saqib 2012; AbdelRaheem 2016).

\section{Blinding}

We assessed performance and detection bias for efficacy and safety outcomes separately. There were only minor differences. We assessed nearly all included studies as at high risk of performance and detection bias.

Thirteen studies were at high risk of bias with regard to blinding. Of these, seven studies were not blinded (Macotela-Ruiz 1996; Bachewar 2009; Chhaiya 2012; Rohatgi 2013; Meenakshi 2014; Abdel-Raheem 2016; Wankhade 2016), and six study authors did not report anything about steps taken to ensure blinding of participants or personnel, or both (Usha 2000; Das 2006; Mushtaq 2010; Wankhade 2013; Manjhi 2014; Ahmad 2016). We assessed Sharma 2011, which was was double-blind, as at low risk of performance and detection bias. We assessed Saqib 2012 as at low risk of bias regarding efficacy outcomes as at least the physician was blinded to treatment assignment (single-blind study). We rated this study as at high risk of bias regarding adverse events because participants who are aware of their treatment (no blinding) may pay more attention to adverse events related to the specific mode of application (topical versus oral), which introduces bias.

\section{Incomplete outcome data}

We assessed attrition bias for efficacy and safety outcomes separately, which led to different assessments in four studies (Das 2006; Sharma 2011; Chhaiya 2012; Ahmad 2016).

\section{Efficacy outcome}

In seven studies none or less than $10 \%$ of the randomized participants in at least one of the study groups were lost to followup over the duration of the study. We assessed the risk of attrition bias in these studies as low (Usha 2000; Sharma 2011; Saqib 2012; Rohatgi 2013; Abdel-Raheem 2016; Ahmad 2016; Wankhade 2016).

More than $10 \%$ of the randomized participants in at least one of the study groups were lost to follow-up in Bachewar 2009, Mushtaq 2010, and Meenakshi 2014. Das 2006 reported results as percentages only; the number of participants evaluated and thus the number of participants eventually lost to follow-up is unclear. Macotela-Ruiz 1996 and Wankhade 2013 reported no numerical outcome data, therefore we assessed the risk of bias as high. A clear explanation of the scales or items used to assess the outcome was missing in Manjhi 2014, which led to an assessment of high risk of bias regarding the reported efficacy outcomes.

We rated the remaining study by Chhaiya 2012 as at unclear risk of bias because the number of participants lost to follow-up was less than $10 \%$ (15/315), but the number of participants analysed at week two and three was unclear.

\section{Safety outcome}

In six studies, none or less than $10 \%$ of the randomized participants in at least one of the study groups were lost to follow-up. We assessed the risk of attrition bias in these studies as being low (Usha 2000; Chhaiya 2012; Saqib 2012; Rohatgi 2013; Abdel-Raheem 2016; Wankhade 2016).

In contrast, more than $10 \%$ of the randomized participants in at least one of the study groups were lost to follow-up in Bachewar 2009, Mushtaq 2010, and Meenakshi 2014. No numerical outcome data were reported in Macotela-Ruiz 1996, Wankhade 2013, and Manjhi 2014. We rated these six studies as at high risk of attrition bias. We assessed the remaining three studies as at unclear risk of bias. In Das 2006, the number of participants evaluated for safety was unclear. Sharma 2011 did not report adverse events for each study group separately, and Ahmad 2016 did not report numerical data on participants with adverse events per study group.

\section{Selective reporting}

We rated two studies as at high risk of reporting bias. Macotela-Ruiz 1996 and Meenakshi 2014 defined outcomes in the corresponding methods sections but did not report results for these outcomes. We assessed the remaining studies as at unclear risk of reporting bias (Usha 2000; Das 2006; Bachewar 2009; Mushtaq 2010; Sharma 2011; Chhaiya 2012; Saqib 2012; Rohatgi 2013; Wankhade 2013; Manjhi 2014; Abdel-Raheem 2016; Ahmad 2016; Wankhade 2016). None of the included studies provided information about a study protocol.

\section{Other potential sources of bias}

We judged three studies as at high risk of other sources of bias. Mushtaq 2010 and Saqib 2012 reported baseline differences between intervention and control group. In addition, there were minor inconsistencies in the publications. The reports by Rohatgi 2013 revealed discrepancies in response data between the abstract and the doctoral thesis the study author provided. We judged all other included studies to be of unclear risk of other sources of bias.

\section{Effects of interventions}

See: Summary of findings for the main comparison Oral ivermectin $200 \mu \mathrm{g} / \mathrm{kg}$ ( 1 to 3 doses) compared to topical permethrin $5 \%$ cream (1 to 3 applications); Summary of findings 2 Oral ivermectin $200 \mu \mathrm{g} / \mathrm{kg}$ ( 1 to 2 doses) compared to topical permethrin $5 \%$ lotion ( 1 to 5 applications); Summary of findings 3 Oral ivermectin $200 \mu \mathrm{g} / \mathrm{kg}$ (1 to 3 doses) compared to topical ivermectin $1 \%$ lotion/solution (1 to 3 applications); Summary of findings 4 Topical ivermectin $1 \%$ lotion ( 1 to 3 applications) compared to topical permethrin $5 \%$ cream (1 to 3 applications); Summary of findings 5 Oral ivermectin $200 \mu \mathrm{g} / \mathrm{kg}$ (1 dose) compared to oral ivermectin $200 \mu \mathrm{g} / \mathrm{kg}$ (2 doses)

See the 'Summary of findings' tables section.

The included studies investigated the following four comparisons. 
- Oral ivermectin versus topical permethrin.

- Oral ivermectin versus topical ivermectin.

- Topical ivermectin versus topical permethrin.

- Oral ivermectin versus oral ivermectin in different doses.

Data on the following six comparisons are reported here.

- Ivermectin $200 \mu \mathrm{g} / \mathrm{kg}$ body weight (1 to 3 doses) versus permethrin $5 \%$ cream ( 1 to 3 applications).

- Ivermectin $200 \mu \mathrm{g} / \mathrm{kg}$ body weight (1 to 2 doses) versus permethrin $5 \%$ lotion (1 to 5 applications).

- Ivermectin $200 \mu \mathrm{g} / \mathrm{kg}$ body weight (1 dose) versus permethrin $5 \%$ (of unknown ointment base, 1 application).

- Ivermectin $200 \mu \mathrm{g} / \mathrm{kg}$ body weight (1 to 3 doses) versus ivermectin $1 \%$ lotion/solution (1 to 3 applications).

- Ivermectin $1 \%$ lotion ( 1 to 3 applications) versus permethrin $5 \%$ cream (1 to 3 applications).

- Ivermectin systemic (1 dose) versus ivermectin systemic (2 to 3 doses).

We have reported comparisons addressing our predefined outcomes in more detail below. If there is no paragraph describing an outcome or a specific time point, it was not reported in any of the included studies.

\section{Oral ivermectin versus topical permethrin}

\section{Ivermectin $200 \mu \mathrm{g} / \mathrm{kg}$ body weight (1 to 3 doses) versus permethrin 5\% cream (1 to 3 applications) (1129 participants, 10 trials)}

Ten studies compared ivermectin oral with permethrin 5\% cream (Usha 2000; Das 2006; Bachewar 2009; Mushtaq 2010; Sharma 2011; Chhaiya 2012; Rohatgi 2013; Manjhi 2014; Meenakshi 2014; Wankhade 2016).

\section{Complete clearance}

\section{One-week follow-up}

Eight studies reported the outcome 'complete clearance' one week after treatment initiation.

Six studies including a total of 613 participants could be pooled using a random-effects meta-analysis model (Usha 2000; Bachewar 2009; Sharma 2011; Rohatgi 2013; Meenakshi 2014; Wankhade 2016). Heterogenerity was not significant $\left(I^{2}=35 \%, P=0.18\right)$. The pooled estimate shows that permethrin may be slightly more effective than ivermectin (risk ratio (RR) 0.65 , 95\% confidence interval (CI) 0.54 to 0.78 ; Analysis 1.1, Figure 3). This translates to 229 fewer patients per 1000 achieving complete clearance in the ivermectin group (from 144 fewer to 301 fewer; Summary of findings for the main comparison). We rated the certainty of evidence as low; see Summary of findings for the main comparison.

Figure 3. Forest plot of comparison: 1 Ivermectin $200 \mu \mathrm{g} / \mathrm{kg}$ versus permethrin $5 \% \mathrm{cream}$, outcome: 1.1 Complete clearance - week 1.

\begin{tabular}{|c|c|c|c|c|c|c|c|c|c|c|}
\hline \multirow[b]{2}{*}{ Study or Subgroup } & \multicolumn{2}{|c|}{ Ivermectin (single dose) } & \multicolumn{2}{|c|}{ Permethrin (once applied) } & \multirow[b]{2}{*}{ Weight } & \multirow{2}{*}{$\begin{array}{c}\text { Risk Ratio } \\
\text { M-H, Random, } 95 \% \mathrm{Cl}\end{array}$} & \multirow{2}{*}{\multicolumn{4}{|c|}{$\begin{array}{c}\text { Risk Ratio } \\
\text { M-H, Random, 95\% Cl }\end{array}$}} \\
\hline & Events & Total & Events & Total & & & & & & \\
\hline Bachewar 2009 (1) & 15 & 34 & 23 & 34 & $13.1 \%$ & $0.65[0.42,1.02]$ & & $\because-1$ & & \\
\hline Meenakshi 2014 (2) & 32 & 70 & 52 & 70 & $22.7 \%$ & $0.62[0.46,0.82]$ & & $\rightarrow-$ & & \\
\hline Rohatgi 2013 (3) & 28 & 50 & 34 & 50 & $21.0 \%$ & $0.82[0.60,1.12]$ & & $\rightarrow$ & & \\
\hline Sharma 2011 (4) & 26 & 80 & 27 & 40 & $16.2 \%$ & $0.48[0.33,0.71]$ & & $\rightarrow-$ & & \\
\hline Usha $2000(5)$ & 4 & 40 & 14 & 45 & $3.1 \%$ & $0.32[0.12,0.90]$ & & - & & \\
\hline Wankhade 2016 (6) & 29 & 50 & 39 & 50 & $23.8 \%$ & $0.74[0.56,0.98]$ & & $\rightarrow-$ & & \\
\hline Total $(95 \% \mathrm{Cl})$ & & 324 & & 289 & $100.0 \%$ & $0.65[0.54,0.78]$ & & $\bullet$ & & \\
\hline Total events & 134 & & 189 & & & & & & & \\
\hline $\begin{array}{l}\text { Heterogeneity: Tau }{ }^{2}= \\
\text { Test for overall effect: }\end{array}$ & $\begin{array}{l}.02 ; \mathrm{Chi}^{2}=7.6 \\
=4.52(\mathrm{P}<0 .\end{array}$ & $5(P=0$ & $.18) ;\left.\right|^{2}=35 \%$ & & & & 0.01 & Favours permethrin $1 x$ & $\begin{array}{c}10 \\
\text { Favours ivermectin } 1 x\end{array}$ & 100 \\
\hline $\begin{array}{l}\text { Footnotes } \\
\text { (1) IVER: } 7 / 34 \text { impute } \\
\text { (2) IVER: } 12 / 70 \text { imput } \\
\text { (3) IVER: } 2 / 50 \text { ITT-NR } \\
\text { (4) IVER: } 1 / 80 \text { impute } \\
\text { (5) No imputation } \\
\text { (6) No imputation }\end{array}$ & $\begin{array}{l}\text { (NRI); PER: } 6 / \\
\text { d (NRI); PER: } 8 \\
\text { PER: } 2 / 50 \text { ITT- } \\
\text { (NRI); PER: } 2 /\end{array}$ & $\begin{array}{l}\text { outed }(N \\
\text { oputed }(I \\
\text { uted }(N\end{array}$ & $\begin{array}{l}\text { RI) } \\
\text { NRI) } \\
\text { RI) }\end{array}$ & & & & & & & \\
\hline
\end{tabular}

These results are in line with the results reported by Chhaiya 2012, who stated that after one week of treatment $74.8 \%$ of participants treated with permethrin and $30.0 \%$ of participants treated with ivermectin achieved complete clearance; absolute numbers were not reported and could not be deducted.

Manjhi 2014 investigated 'complete improvement' based on pruritus and lesions separately. A difference for complete improvement based on lesions alone was found in favour of permethrin (RR $0.74,95 \% \mathrm{Cl} 0.56$ to $0.99 ; 120$ participants); for complete improvement based on pruritus no difference was found (RR $0.82,95 \% \mathrm{Cl} 0.60$ to $1.11 ; 120$ participants).

\section{Two weeks' follow-up}

Six studies reported the outcome 'complete clearance' after two weeks of treatment (Usha 2000; Bachewar 2009; Mushtaq 2010; Sharma 2011; Chhaiya 2012; Rohatgi 2013). Of these, Chhaiya 2012 reported results as percentages only: $99.0 \%$ of participants treated with permethrin and $63.0 \%$ of participants treated with ivermectin achieved complete clearance after two weeks. Absolute numbers could not be deducted. The combined effect estimate of the remaining five studies showed no difference between the treatment groups (RR $0.91,95 \% \mathrm{Cl} 0.76$ to 1.08 ; 459 participants; Analysis 1.2, Figure 4). A statistically significant heterogeneity test $\left(I^{2}=61 \%, P=0.04\right)$ led us to further investigate the source of heterogeneity. Risk of bias was low to high and very divergent between studies. We could not identify meaningful groups of 
studies based on the 'Risk of bias' assessments that would help explain heterogeneity. In the studies by Bachewar 2009 and Rohatg 2013, uncured participants had been re-treated after one week; absolute numbers were not provided. Visual inspection of the forest plot suggests that the trial by Usha 2000 may be one of the causes of substantial statistical heterogeneity, though we could not identify any clinical or methodological reasons. Omitting either of these studies from the meta-analysis did not substantially change the effect estimate. Sensitivity analyses neither changed the point estimates nor whether the $\mathrm{Cl}$ crossed the line of no effect (Appendix 2). Hence, we pooled data from all five studies. We rated the certainty of the evidence as low (Summary of findings for the main comparison).

Figure 4. Forest plot of comparison: 1 Ivermectin $200 \mu \mathrm{g} / \mathrm{kg}$ versus permethrin $5 \%$ cream, outcome: 1.2 Complete clearance - week 2.

\begin{tabular}{|c|c|c|c|c|c|c|c|}
\hline \multirow[b]{2}{*}{ Study or Subgroup } & \multicolumn{2}{|c|}{ Mermectin } & \multicolumn{2}{|c|}{ Permethrin } & \multirow[b]{2}{*}{ Weight } & \multirow{2}{*}{$\begin{array}{c}\text { Risk Ratio } \\
\text { M-H, Random, } 95 \% \mathrm{Cl} \\
\end{array}$} & \multirow{2}{*}{$\begin{array}{c}\text { Risk Ratio } \\
\text { M-H, Random, } 95 \% \mathrm{Cl} \\
\end{array}$} \\
\hline & Events & Total & Events & Total & & & \\
\hline Bachewar 2009 (1) & 27 & 34 & 27 & 34 & $21.7 \%$ & $1.00[0.79,1.27]$ & $\rightarrow$ \\
\hline Mushtaq $2010(2)$ & 24 & 44 & 20 & 42 & $12.0 \%$ & $1.15[0.76,1.74]$ & \\
\hline Rohatgi 2013 (3) & 45 & 50 & 46 & 50 & $31.1 \%$ & $0.98[0.86,1.11]$ & \\
\hline Sharma 2011 (4) & 57 & 80 & 33 & 40 & $24.9 \%$ & $0.86[0.71,1.05]$ & $\rightarrow$ \\
\hline Usha $2000(5)$ & 14 & 40 & 31 & 45 & $10.3 \%$ & $0.51[0.32,0.81]$ & \\
\hline Total $(95 \% \mathrm{Cl})$ & & 248 & & 211 & $100.0 \%$ & $0.91[0.76,1.08]$ & \\
\hline Total events & 167 & & 157 & & & & \\
\hline $\begin{array}{l}\text { Heterogeneity: Tau² } \\
\text { Test for overall effect }\end{array}$ & $\begin{array}{l}0.02 ; \mathrm{Chi} \\
\mathrm{Z}=1.08\end{array}$ & $\begin{array}{l}P=10.2 \\
P=0.2\end{array}$ & $\begin{array}{l}3, d f=4 \\
8)\end{array}$ & $(P=0.0$ & 4); $\left.\right|^{2}=61$ & 0.01 & $\begin{array}{ccc}0.1 & 1 & 10 \\
\text { Favours permethrin } & \text { Favours ivermectin }\end{array}$ \\
\hline \multicolumn{8}{|c|}{$\begin{array}{l}\text { (1) IVER: } 44.44 \% \text { of participants were re-treated after } 1 \text { week, } 7 / 34 \text { imputed (NRI); PER: } 17.86 \% \text { of participants were re-treated after } 1 \text { wee } \\
\text { (2) IVER: single dose, per-protocol analysis; PER: single application, per-protocol analysis } \\
\text { (3) IVER, PER: participants who showed no signs of cure at } 1 \text { st follow-up were given same treatment again, } 2 / 50 \text { ITT-NRI for each group } \\
\text { (4) IVER: single dose, supervised, } 1 / 80 \text { imputed (NRI); PER: single application, } 2 / 40 \text { imputed (NRI) } \\
\text { (5) IVER: single dose, supervised, no imputation; PER: single application, no imputation }\end{array}$} \\
\hline
\end{tabular}

\section{Four weeks' follow-up}

Seven studies reported 'complete clearance' after four weeks (Usha 2000; Das 2006; Mushtaq 2010; Sharma 2011; Chhaiya 2012; Rohatgi 2013; Wankhade 2016).
A study by Sharma 2011 compared one dose of ivermectin with one application of permethrin 5\% cream. After four weeks of follow-up no difference was found (RR $1.00,95 \% \mathrm{Cl} 0.86$ to 1.16 ; 80 participants). We rated the certainty of the evidence as high (Analysis 1.3: subgroup 1, Figure 5, and Summary of findings for the main comparison). 
Figure 5. Forest plot of comparison: 1 Ivermectin $200 \mu \mathrm{g} / \mathrm{kg}$ ( 1 to 3 doses) versus permethrin $5 \%$ cream ( 1 to 3 applications), outcome: 1.3 Complete clearance - week 4.

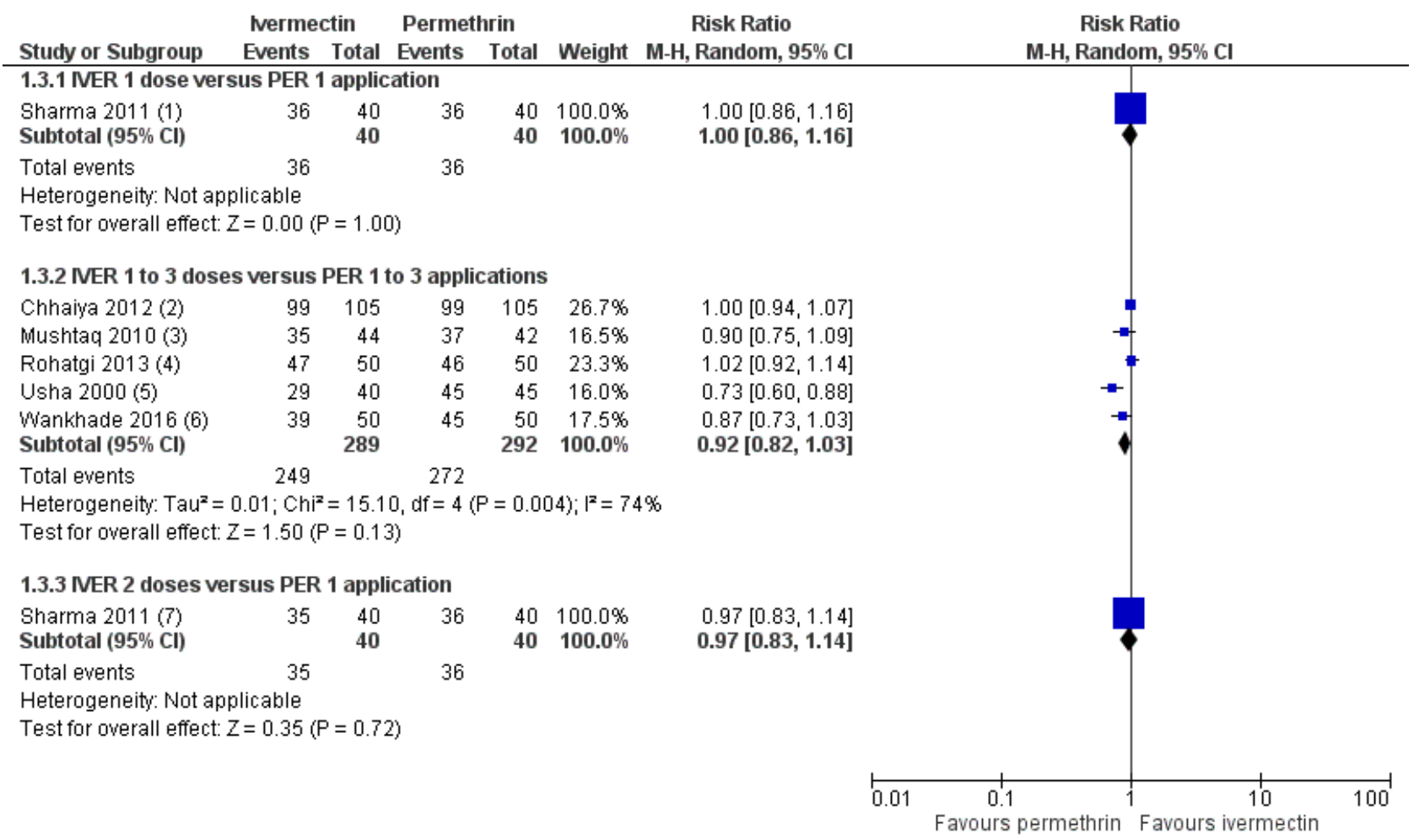

Footnotes

(1) IVER: single dose, no imputation; PER: single application, self-applied, no imputation

(2) IVER, PER: participants who were not cured were prescribed repeat intervention along with anti-histaminic at week 2 and week 3 ; IVER:...

(3) IVER, PER: non-responders to 1 st treatment were given 2 nd dose at week 2 in their respective groups, per-protocol analysis

(4) IVER, PER: participants who showed no signs of cure at 1 st follow-up were given same treatment again, $2 / 50$ ITT-NRI for each group

(5) IVER: 12 participants were re-treated at week 2, no imputation; PER: 1 participant was re-treated at week 2, no imputation

(6) IVER, PER: non-responders to 1 st treatment were given 2 nd dose at week 1 in their respective groups, no imputation

(7) IVER: two doses, 1/40 imputed (NRI); PER: single application, self-applied, 2/40 imputed (NRI)

In five studies uncured participants were re-treated after one week, Chhaiya 2012; Rohatgi 2013; Wankhade 2016, and/or after two weeks (Usha 2000; Mushtaq 2010; Chhaiya 2012; Wankhade 2016). Additionally, Chhaiya 2012 planned to switch non-responders to permethrin $5 \%$ after three weeks. This could have affected only one participant in the ivermectin group (not clearly stated).

We observed statistically significant heterogeneity between the five trials $\left(I^{2}=74 \%, P=0.004\right)$, but could not identify potential reasons based on either the direction of the effect or due to a different treatment regimen. We also performed subgroup analyses, creating a subgroup excluding the two studies from sensitivity analysis. The test for subgroup differences was nonsignificant $\left(I^{2}=6 \%, P=0.30\right.$, see Analysis 1.4). Irrespective of the number of pooled studies, the combined estimates showed no differences between the groups (RR $0.92,95 \% \mathrm{Cl} 0.82$ to 1.03; 581 participants, 5 trials; Analysis 1.3: subgroup 2, Figure 5, Appendix 2 for sensitivity analysis). We rated the certainty of the evidence as low (Summary of findings for the main comparison).

Das 2006 and Sharma 2011 treated participants with two doses of ivermectin (initial treatment and at two weeks' follow-up) compared to one application of permethrin 5\% cream. After four weeks, no difference could be found based on the results reported by Sharma 2011 (RR $0.97,95 \% \mathrm{Cl} 0.83$ to 1.14; 80 participants; Analysis 1.3: subgroup 3, Figure 5). We rated the certainty of the evidence as high (Summary of findings for the main comparison).

In the trial by Das 2006, $90.0 \%$ of participants treated with permethrin and $96.0 \%$ of participants treated with ivermectin achieved 'improvement clinically' after four weeks (no further information provided).

\section{Number of participants re-treated}

None of the included studies had a predefined outcome measure assessing the 'number of participants re-treated'. Hence, reporting differed greatly. Most studies did not report absolute numbers or proportions of participants having been re-treated. In Appendix 3 , we have provided an overview of when treatment was repeated. Only two studies did not repeat their intervention - neither as part of the treatment schedule nor in response to uncured participants.

\section{Number of participants with at least one adverse event}

The reporting of adverse events was poor. 


\section{Two weeks' follow-up}

In the study by Bachewar 2009, none of the 55 participants experienced any adverse events. An effect estimate is not calculable; we rated the certainty of the evidence as moderate (Analysis 1.5 and Summary of findings for the main comparison).

\section{Four weeks' follow-up}

Four studies including 502 participants reported data for participants experiencing at least one adverse event after four weeks (Mushtaq 2010; Sharma 2011; Chhaiya 2012; Wankhade 2016). We found low-certainty evidence that ivermectin may lead to a slightly larger proportion of participants with at least one adverse event (RR 1.30, $95 \% \mathrm{Cl} 0.35$ to 4.83; moderate heterogeneity: $I^{2}=$ $48 \%, P=0.12$; Analysis 1.6 , Figure 6 , Summary of findings for the main comparison).

\section{Figure 6. Forest plot of comparison: 1 Ivermectin $200 \mu \mathrm{g} / \mathrm{kg}$ versus permethrin $5 \% \mathrm{cream}$, outcome: $1.5 \mathrm{Number}$ of} participants with $\geq 1$ adverse event - week 4 .

\begin{tabular}{|c|c|c|c|c|c|c|c|c|c|c|c|}
\hline Study or Subgroup & \multicolumn{2}{|c|}{ Ivermectin } & \multicolumn{2}{|c|}{ Permethrin } & Weight & \multicolumn{2}{|l|}{ Risk Ratio } & \multicolumn{2}{|c|}{$\begin{array}{c}\text { Risk Ratio } \\
\text { M-H, Random, 95\% CI }\end{array}$} & & \\
\hline Chhaiva 2012 (1) & 2 & 100 & 1 & 99 & $193 \%$ & $198[0.18 .21 .49]$ & & & $\Rightarrow$ & & \\
\hline Mushtaq 2010 (2) & 8 & 44 & 1 & 42 & $23.3 \%$ & $7.64[1.00,58.46]$ & & & & & \\
\hline Sharma 2011 (3) & 6 & 79 & 5 & 38 & $38.0 \%$ & $0.58[0.19,1.77]$ & & & - & & \\
\hline Wankhade 2016 (4) & 1 & 50 & 2 & 50 & $19.4 \%$ & $0.50[0.05,5.34]$ & & & & & \\
\hline Total $(95 \% \mathrm{Cl})$ & & 273 & & 229 & $100.0 \%$ & $1.30[0.35,4.83]$ & & & & & \\
\hline Total events & 17 & & 9 & & & & & & & & \\
\hline $\begin{array}{l}\text { Heterogeneity: Tau }{ }^{2}= \\
\text { Test for overall effect: }\end{array}$ & $\begin{array}{l}0.86 ; \mathrm{Chi}^{-} \\
=0.39(\end{array}$ & $\begin{array}{l}=5.79 \\
=0.70\end{array}$ & $d f=3(P$ & $=0.12)$ & $i^{2}=48 \%$ & & 0.01 & $\begin{array}{c}0.1 \\
\text { Favours ivermectin }\end{array}$ & 1 Favours pe & $\begin{array}{l}10 \\
\text { ermethrin }\end{array}$ & 100 \\
\hline
\end{tabular}

\section{Footnotes}

(1) IVER, PER: participants who were not cured were prescribed repeat intervention along with anti-histaminic at week 2 and week 3

(2) Inconsistent data (p. 229 and 300): 8 versus 7 patients with adverse events; IVER, PER: non-responders to 1 st treatment were given 2nd.

(3) IVER: participants from 2 groups combined, participants were treated $1 x$ or $2 x$, almost in same proportion; PER: single application

(4) IVER: single dose; PER: single application

Das 2006 and Rohatgi 2013 reported zero events per group, however the number of participants assessed at week four is unclear.

In the trial by Usha 2000, participants were evaluated after eight weeks. In the ivermectin group, three out of 40 participants experienced at least one adverse event, while none of the 45 analysed participants in the permethrin group experienced an event.

\section{Number of participants withdrawn from study due to adverse event}

\section{Four weeks' follow-up}

In three studies with 305 randomized participants (Usha 2000; Manjhi 2014; Wankhade 2016), no withdrawals due to adverse events occurred (Analysis 1.7). We rated the certainty of the evidence as moderate (Summary of findings for the main comparison).

\section{Ivermectin $200 \mu \mathrm{g} / \mathrm{kg}$ body weight (1 to 2 doses) versus permethrin 5\% lotion (1 or 5 applications) (227 participants, 2 trials)}

Two studies compared oral ivermectin $200 \mu \mathrm{g} / \mathrm{kg}$ body weight with permethrin 5\% lotion (Saqib 2012; Abdel-Raheem 2016). In the study by Abdel-Raheem 2016, children randomized to the permethrin group below the age of 10 were treated with permethrin $2.5 \%$ lotion.

\section{Complete clearance}

\section{One and two weeks' follow-up}

In Saqib 2012, participants were treated with either a single dose of ivermectin or a single application of permethrin $5 \%$ lotion. Complete clearance was defined as no itching, cutaneous lesions/burrows, and negative microscopy. There was no difference between study groups (week one: RR $0.93,95 \% \mathrm{Cl} 0.74$ to 1.17 ; Analysis 2.1: subgroup 1; week two: RR $1.00,95 \% \mathrm{Cl} 0.78$ to 1.29; Analysis 2.2: subgroup 1; 120 participants each). We rated the certainty of the evidence as moderate and low, respectively (Summary of findings 2).

In the study by Abdel-Raheem 2016, 107 participants were treated either with a single dose of ivermectin or with permethrin $5 \%$ lotion on five consecutive nights. Complete clearance was defined as negative parasitological examination of the participant with complete absence of new lesions. After one week, permethrin may have lead to slightly more participants with complete clearance (RR $0.70,95 \% \mathrm{Cl} 0.47$ to 1.03; Analysis 2.1: subgroup 2). After two weeks, no difference was found (RR $0.97,95 \% \mathrm{Cl} 0.81$ to 1.17 ; Analysis 2.2: subgroup 2). We rated the certainty of the evidence as low and moderate, respectively (Summary of findings 2).

\section{Number of participants re-treated}

The two studies comparing ivermectin $200 \mu \mathrm{g} / \mathrm{kg}$ with permethrin $5 \%$ lotion had different treatment schedules, as shown in Appendix 3. 
Number of participants with at least one adverse event

\section{Two weeks' follow-up}

Abdel-Raheem 2016 found no difference between groups in number of participants with at least one adverse event (RR 5.00, $95 \% \mathrm{Cl} 0.25$ to 101.58 ; 100 participants; Analysis 2.3). We rated the certainty of the evidence as very low (Summary of findings 2).

\section{Number of participants withdrawn from study due to adverse event}

Two weeks' follow-up

Saqib 2012 reported that no participants withdrew from the study due to adverse events in either group (120 participants; Analysis 2.4). We rated the certainty of the evidence as moderate (Summary of findings 2).

\section{Ivermectin $200 \mu \mathrm{g} / \mathrm{kg}$ body weight (1 dose) versus permethrin 5\%} (1 application) (100 participants, 1 trial)

We identified only one study, Wankhade 2013, whose data were published as an abstract only.

\section{Complete clearance}

Wankhade 2013 investigated ivermectin $200 \mu \mathrm{g} / \mathrm{kg}$ body weight and permethrin $5 \%$ of unknown ointment base. Participants were evaluated one and two weeks' post-treatment initiation. The authors state that "Permethrin had significantly better cure rate than ivermectin" (Wankhade 2013). The number of randomized participants per group, the definition of 'cure', and the time point of evaluation were not reported.

\section{Number of participants re-treated}

Wankhade 2013 stated that participants with no sign of cure received the same treatments again after one week (Appendix 3).

\section{Oral ivermectin versus topical ivermectin}

Ivermectin $200 \mu \mathrm{g} / \mathrm{kg}$ body weight (1 to 3 doses) versus ivermectin 1\% lotion/solution (1 to 3 applications) (272 participants, 2 trials)

Two studies compared ivermectin oral with ivermectin $1 \%$ lotion, Chhaiya 2012, or 1\% solution, Ahmad 2016.

\section{Complete clearance}

\section{One-week follow-up}

In Ahmad 2016, there was no difference between study groups after one week of follow-up (RR 0.84, 95\% $\mathrm{Cl} 0.65$ to 1.08; 62 participants; Analysis 3.1). We rated the certainty of evidence as low (Summary of findings 3 ).

In Chhaiya 2012, 30.0\% of participants treated with ivermectin $200 \mu \mathrm{g} / \mathrm{kg}$ body weight and $69.3 \%$ of participants treated with ivermectin $1 \%$ lotion achieved 'complete clearance' after one week. Reported data were insufficient for calculating an effect estimate.

\section{Two weeks' follow-up}

In Ahmad 2016, there was no difference between study groups after two weeks of follow-up (RR 1.00, 95\% Cl 0.94 to 1.06; 62 participants; Analysis 3.2). We rated the certainty of evidence as moderate (Summary of findings 3 ).
In Chhaiya 2012, 63.0\% of participants treated with ivermectin 200 $\mu \mathrm{g} / \mathrm{kg}$ body weight achieved 'complete clearance', whereas $100.0 \%$ of participants treated with ivermectin $1 \%$ lotion were cleared after two weeks of follow-up. Absolute numbers of participants were not reported (Chhaiya 2012).

\section{Four weeks' follow-up}

Pooled data from Chhaiya 2012 and Ahmad 2016 revealed no difference between study groups for 'complete clearance' after four weeks of follow-up (RR 0.99, 95\% Cl 0.95 to 1.03; 272 participants; Analysis 3.3). We rated the certainty of evidence as moderate (Summary of findings 3 ).

\section{Number of participants re-treated}

Ahmad 2016 re-treated non-responders after one week. Four out of 32 participants in the topical ivermectin group and eight out of 30 participants in the systemic ivermectin group were re-treated. Chhaiya 2012 re-treated those participants who were not cured at week one and week two. Non-responders at week three switched to permethrin. Absolute numbers were not reported (Appendix 3).

Number of participants with at least one adverse event

Four weeks' follow-up

We found no difference between groups for the number of participants with at least one adverse event within four weeks of follow-up (RR 5.05, 95\% Cl 0.25 to 103.87; 201 participants; Analysis 3.4). We rated the certainty of the evidence as very low (Summary of findings 3 ).

\section{Number of participants withdrawn from study due to adverse event}

\section{Four weeks' follow-up}

None of the 62 randomized participants in Ahmad 2016 withdrew due to an adverse event (Analysis 3.5). We rated the certainty of evidence as moderate (Summary of findings 3 ).

\section{Topical ivermectin versus topical permethrin}

Ivermectin 1\% lotion (1 to 3 applications) versus permethrin 5\% cream (1 to 3 applications) (210 participants, 1 trial)

\section{Complete clearance}

One-week follow-up

In Chhaiya 2012, 69.3\% of participants treated with ivermectin $1 \%$ lotion and $74.8 \%$ of participants treated with permethrin $5 \%$ cream achieved 'complete clearance' after one week. Reported data were insufficient to calculate an effect estimate.

\section{Two weeks' follow-up}

After two weeks of follow-up, $100.0 \%$ of the participants treated with ivermectin 1\% lotion achieved 'complete clearance' and 99.0\% of the participants treated with permethrin $5 \%$ cream were cleared. Absolute numbers of participants were not reported.

\section{Four weeks' follow-up}

Data reported by Chhaiya 2012 showed no difference between the study groups after four weeks of follow-up for complete clearance (RR 1.02, 95\% Cl 0.96 to 1.08; 210 participants; Analysis 4.1). We rated the certainty of the evidence as moderate (Summary of findings 4). 


\section{Number of participants re-treated}

Chhaiya 2012 re-treated those participants who were not cured at week one and week two. Non-responders at week three were switched to permethrin. Absolute numbers were not reported (Appendix 3).

\section{Number of participants with at least one adverse event}

\section{Four weeks' follow-up}

We could find no difference between the groups for the number of participants with at least one adverse event within four weeks of follow-up (RR 0.33, 95\% Cl 0.01 to 7.93; 200 participants; Analysis 4.2). We rated the certainty of the evidence as very low (Summary of findings 4 ).

\section{Oral ivermectin versus oral ivermectin in different doses}

Ivermectin $200 \mu \mathrm{g} / \mathrm{kg}$ body weight (1 dose) versus ivermectin 200 $\mu \mathrm{g} / \mathrm{kg}$ body weight (2 doses) (80 participants, 1 trial)

\section{Complete clearance}

\section{Four weeks' follow-up}

Sharma 2011, which included 80 participants, found no difference between one and two doses of oral ivermectin for 'complete clearance' after four weeks of follow-up (RR $0.97,95 \% \mathrm{Cl} 0.83$ to 1.14; Analysis 5.1; Summary of findings 5). We rated the certainty of the evidence as high.

\section{Number of participants re-treated}

As planned by Sharma 2011, none of the participants were retreated, except as defined in the study protocol (Appendix 3).

Ivermectin $250 \mu \mathrm{gg} / \mathrm{kg}$ body weight (1 dose) versus ivermectin 250 $\mu \mathrm{g} / \mathrm{kg}$ body weight ( 3 doses) (273 participants, 1 trial)

\section{Complete clearance}

Macotela-Ruiz 1996, which involved 273 participants, investigated a single dose ivermectin at day 1 versus three doses of ivermectin on day 1,3 , and 10 . Absolute numbers were not reported. All participants were cured within 45 days of follow-up. 'Cure' was defined as considerable improvement of dermatosis, no pruritus, and no new lesions. The exact time point of evaluation is unclear.

\section{Number of participants re-treated}

Macotela-Ruiz 1996 did not report on additional re-treatment of participants, except as stipulated in the study protocol (Appendix 3).

\section{Number of participants with at least one adverse event}

The authors reported that there were no adverse drug reactions (Macotela-Ruiz 1996).

\section{DISCUSSION}

\section{Summary of main results}

Fifteen trials, comprising 1896 participants treated with ivermectin or permethrin, met our inclusion criteria. Nearly all studies were conducted in South Asia or North Africa, where many people live in poor, overcrowded conditions. We have presented our findings in five 'Summary of findings' tables (Summary of findings for the main comparison; Summary of findings 2; Summary of findings 3; Summary of findings 4; Summary of findings 5).

The differences in the efficacy results, the number of participants with adverse events, and the number of participants withdrawn due to adverse events were small.

\section{Efficacy}

We analysed 13 studies comprising 1456 participants evaluating systemic ivermectin versus permethrin. Oral ivermectin at a standard dose of $200 \mu \mathrm{g} / \mathrm{kg}$ may lead to slightly lower rates of complete clearance after one week compared to permethrin $5 \%$ cream (extrapolated cure rates based on anticipated absolute effects: permethrin $65 \%$, ivermectin 43\%; RR $0.65,95 \% \mathrm{Cl} 0.54$ to 0.78; 613 participants, 6 studies; low-certainty evidence), but may lead to little or no difference in rates of complete clearance by week two (extrapolated cure rates based on anticipated absolute effects: permethrin $74 \%$, ivermectin $68 \%$; RR $0.91,95 \% \mathrm{Cl} 0.76$ to 1.08 ; 459 participants, 5 studies; low-certainty evidence).

In two out of 13 studies (Saqib 2012; Manjhi 2014), the re-treatment of participants was not planned. Uncured participants in seven studies were re-treated (Usha 2000; Bachewar 2009; Mushtaq 2010; Chhaiya 2012; Rohatgi 2013; Wankhade 2013; Wankhade 2016); however, only two of these studies reported numbers (Usha 2000; Bachewar 2009), finding that more participants in the systemic ivermectin groups were re-treated than in the permethrin groups. It is unclear whether the re-treatment of participants in these seven studies who did not show complete clearance had been planned or not. Additionally, three studies reported that all participants in the ivermectin group were re-treated after one or two weeks, irrespective of treatment response (Das 2006; Sharma 2011; Abdel-Raheem 2016). Meenakshi 2014 repeated treatment in all participants.

Study investigators may have chosen to repeat the treatment because ivermectin, unlike permethrin, only affects the mite and not the egg. After one dose, considering the life cycle of the scabies mite (10 to 17 days), a second treatment with ivermectin might be necessary. Alternatively, ivermectin might have a slower onset of action. Studies that included some form of re-treatment (see Appendix 3) comparing permethrin cream and oral ivermectin may lead to little or no difference in rates of complete clearance after four weeks (extrapolated cure rates based on anticipated absolute effects: 1 to 3 applications of permethrin 93\%, 1 to 3 doses of ivermectin $86 \%$; RR $0.92,95 \% \mathrm{Cl} 0.82$ to 1.03 ; 581 participants, 5 studies; low-certainty evidence). Considering the cure rates after one or two weeks of treatment, we assume that the number of participants needing re-treatment was low to medium. However, suboptimal reporting precludes further judgement.

Likewise, after four weeks ivermectin lotion probably leads to little or no difference in rates of complete clearance when compared to permethrin cream (extrapolated cure rates based on anticipated absolute effects: permethrin cream 94\%, ivermectin lotion $96 \%$; RR $1.02,95 \% \mathrm{Cl} 0.96$ to $1.08 ; 210$ participants, 1 study; moderate-certainty evidence, up to two re-treatments of non-responders, numbers unclear; Chhaiya 2012), which may support the above mentioned assumptions. Furthermore, there is probably little or no difference in rates of complete clearance between oral ivermectin at standard dose and topical ivermectin $1 \%$ lotion four weeks after initiation of treatment (extrapolated 
cure rates based on anticipated absolute effects: oral ivermectin $97 \%$, ivermectin lotion $96 \%$; RR $0.99,95 \% \mathrm{Cl} 0.95$ to $1.03 ; 272$ participants, 2 studies; moderate-certainty evidence; up to two re-treatments of non-responders, numbers unclear; Chhaiya 2012 and Ahmad 2016). The dose comparison study showed that one dose of systemic ivermectin led to little or no difference in rates of complete clearance compared to two doses of systemic ivermectin (extrapolated cure rates based on anticipated absolute effects: 2 doses 90\%, 1 dose $87 \%$; RR $0.97,95 \% \mathrm{Cl} 0.83$ to 1.14 ; 80 participants, 1 study; high-certainty evidence). This finding weakens our assumptions as described above. While this study had one of the smallest sample sizes, the methodological conduct and reporting appeared best, giving it more weight.

We did not identify any differences in efficacy between permethrin and ivermectin other than after one week of treatment. Our findings do not allow for a conclusion about the onset of action in topical treatments compared to systemic treatments, as this was not directly assessed.

\section{Safety}

Generally, systemic and topical drugs can lead to different types of events, endangering blinding. Only two of the studies included in this review were blinded. While the reporting of adverse events in the included studies was suboptimal, it appears that very few adverse events occurred. Two weeks after treatment initiation, there is probably little or no difference in the proportion of participants treated with systemic ivermectin or permethrin cream who experienced at least one adverse event (55 participants, 1 study; moderate-certainty evidence). After four weeks, ivermectin may lead to a slightly larger proportion of participants with at least one adverse event (extrapolated rates: permethrin $4 \%$, ivermectin 5\%; RR $1.30,95 \% \mathrm{Cl} 0.35$ to $4.83 ; 502$ participants, 4 studies; low-certainty evidence). In scabies treatment, medications are sometimes given more than once. However, even the studies with repeated applications did not report more adverse events. To add, no withdrawals due to adverse events occurred in either the systemic ivermectin or the permethrin group (moderate-certainty evidence). In most studies in which participants were treated only once, a possible explanation for zero withdrawals could be that participants who experienced adverse events after their first (and only) treatment remained in study because they had already had their treatment.

The studies analysed for this review reported severe itching, secondary bacterial infections, headache, and nausea in people treated with systemic ivermectin (Mushtaq 2010; Sharma 2011).

Regarding permethrin, the analysed studies in this review rarely stated the frequency of adverse events and did not designate their types. Only erythema, burning, and pruritus were reported during permethrin treatment (Mushtaq 2010; Sharma 2011).

Two analysed studies evaluating systemic versus topical ivermectin reported that adverse events were rare and of mild intensity and comparable in both study groups (Chhaiya 2012; Ahmad 2016). It is uncertain whether there was any difference in the proportion of participants with at least one adverse event (very low-certainty evidence). No withdrawals due to adverse events occurred, which supports these findings (62 participants, 1 study; moderate-certainty evidence).
Furthermore, it is uncertain whether topical ivermectin or permethrin differ in the number of participants with at least one adverse event (very low-certainty evidence). We found no studies comparing systemic ivermectin in different doses that assessed our predefined safety outcomes.

\section{Overall completeness and applicability of evidence}

Applicability to Western countries and external validity - apart from the obvious differences between RCT conditions and realworld conditions - is limited due to studies being conducted in regions with a high prevalence of scabies. Most included trials were conducted in lower-middle-income countries (India, Pakistan, and Egypt). Only one study was undertaken in Mexico in the beginning of the 1990s (middle-income country). All studies were conducted in resource-poor countries.

We identified only single-centre studies that included predominately small numbers of participants per study group. The included studies were inconsistent in their descriptions, definitions, and assessments of cure as well as in the frequencies of treatment application. Pooling data or comparing data across participant groups was therefore difficult or inappropriate.

Although permethrin is an ovicidal medication, in some of the included studies it was applied twice. Conversely, in some studies evaluating ivermectin, a non-ovicidal medication, the drug was administered only once. None of these studies explained the scientific rationale behind these a priori defined dosages, although permethrin is often administered twice due to compliance and reinfestation issues (see How the intervention might work).

\section{Quality of the evidence}

We assessed the certainty of the evidence according to the GRADE approach and presented it in five 'Summary of findings' tables (Summary of findings for the main comparison; Summary of findings 2; Summary of findings 3; Summary of findings 4; Summary of findings 5).

The main reasons for downgrading the certainty of the evidence were the quality of the trials and imprecision in the results. In general, the methodological quality of the trials included in this review was moderate. We assessed most of the studies as having a high risk of performance and detection bias. We rated attrition bias as high in nearly half of the included studies. We downgraded certainty for imprecision, mainly because minimal clinically important difference thresholds were crossed by the Cls or the Cls were wide.

Substantial heterogeneity between trials became apparent in two meta-analyses (Analysis 1.2 and Analysis 1.3). This could be explained by variations in the numbers of re-treated participants, which were not stated in most studies. However, the sensitivity analyses (Appendix 2) did not help to further explain this, and it restricts our confidence in the results.

\section{Potential biases in the review process}

While we considered publication bias to be undetected, we cannot rule it out. Nearly all included studies were conducted in resource-poor nations. It is unknown if studies were conducted but not published or not identified through our comprehensive searches. One-fifth of the included studies were not identified 
via the systematic searches of academic, trial, and grey literature repositories, but through web searches $(n=1)$ and through screening of reference lists $(n=2)$. We did not consult experts.

It should be noted that it is not clear what impact the three excluded studies - whose validity is questionable (see Excluded studies) would have on the overall findings of this review.

Despite clear inclusion criteria, individual interpretation or human mistakes may lead to different results in data extraction. We attempted to preclude this potential bias by ensuring that two review authors read all full texts and extracted data independently. All disagreements were discussed fully.

In some cases, we were unable to extract all relevant data because reporting was poor or incomplete (for example, absolute numbers of evaluated participants) in publications. We contacted study authors in an effort to overcome these issues. However, most authors did not respond to our inquiries.

In order to avoid the issue of multiplicity, we chose only one primary outcome at three time points and only reported effects measures/Cls instead of testing for significance.

\section{Agreements and disagreements with other studies or reviews}

Our results comparing permethrin and systemic ivermectin are similar to our recently published comprehensive systematic review considering several scabies treatments (Dressler 2016a). Dressler 2016 a concluded that there is no difference between a single dose of permethrin $5 \%$ and systemic ivermectin.

Of interest is also a larger study by Romani 2015b, who randomized three island communities in Fiji to either permethrin for only affected patients and their contacts (standard treatment) or permethrin for all island inhabitants or ivermectin for all inhabitants. After 12 months, systemic ivermectin was found to be superior to topical permethrin (Dressler 2016a). Romani 2015b reported that the prevalence declined by $49 \%$ in the standard treatment group, $62 \%$ in the permethrin group, and $94 \%$ in the ivermectin group after one year.

\section{A U THORS' CONCLUSIONS}

\section{Implications for practice}

Topical permethrin, topical ivermectin, and systemic ivermectin all lead to high clearance rates in the treatment of scabies. Highly relevant differences could not be seen in the identified trials.

The choice of one of these three treatments can be guided by considerations of practicability, availability, drug licensing, and costs depending on the individual setting.

Permethrin and ivermectin as topical treatments are appropriate for patients in which the correct application to the whole body can be properly ensured. Systemic ivermectin may be given preference if proper application cannot be ensured or if very large groups of patients need to be treated and proper instructions and topical application is not feasible.
Further limitations apply with regard to the age of the patients and in case of pregnancy and breastfeeding. Systemic ivermectin is not indicated during pregnancy or for children weighing less than $15 \mathrm{~kg}$.

The need for a single versus a repeated application cannot be properly answered based on the identified trial results. For most patients, a single treatment is likely sufficient. The treating physician may take into account the extent of the disease, the number of contact persons affected, the likeliness of correct application, the immune status, and the clinical response during follow-up as an indicator for the need of a second application.

\section{Implications for research}

Due to suboptimal study conduct, design, or reporting and, for example, the small sample sizes, the certainty of the level of evidence is restricted, which limits our confidence in the effect estimates. Randomized controlled trials of good methodological quality complying with current reporting standards (for example, CONSORT) are necessary to reduce risk of bias and and improve the evidence base.

The question of repeated treatment, that is when and how often, cannot be answered conclusively. Further studies with clear and strict treatment regimens are needed.

Adverse events were rare and poorly reported in the included studies. Studies with a larger sample size and better documentation and classification of adverse events could overcome this issue.

The proportion of participants withdrawn due to non-response or adverse events is poorly reported. It is unlikely that new studies from middle-income countries investigating systemic ivermectin versus topical permethrin will change the results (Mounsey 2009).

Discussions on resistance to scabious treatments have emerged, however such cases have been regionally limited, and the overall evidence is scarce. Studies focusing on a possible development of resistance may become necessary in the future.

Public health questions like mass drug interventions for prevention and treatment of scabies were not addressed in this review but could be part of further research and other reviews (Romani 2015b).

\section{ACKNOWLEDGEMENTS}

We thank Mark Strong and Paul Johnstone, authors of the Cochrane Review 'Interventions for treating scabies' (Strong 2007), which served as a basis for this review. We are heavily indebted to both of them for passing the topic on to us and for preparing the 'Background' section. We are also grateful to Anne-Marie Stephani and Paul Garner of the editorial office of the Cochrane Infectious Diseases Group (CIDG) for their administrative support. We thank Vittoria Lutje for preparing and running the searches in online databases and trial registries.

The CIDG editorial base is funded by the UK Department for International Development (DFID) for the benefit of low- and middle-income countries (Grant: 5242).

We are also grateful to Ricardo Niklas Werner for the translation, data extraction, and evaluation of the study published in Spanish. 


\section{RE F E R E N C E S}

\section{References to studies included in this review}

Abdel-Raheem 2016 \{published data only\}

Abdel-Raheem TA, Meabed EM, Nasef GA, Abdel Wahed WY, Rohaim RM. Efficacy, acceptability and cost effectiveness of four therapeutic agents for treatment of scabies. Journal of Dermatological Treatment 2016;27(5):473-9. [DOI: 10.3109/09546634.2016.1151855; PUBMED: 27027929]

\section{Ahmad 2016 \{published data only\}}

Ahmad HM, Abdel-Azim ES, Abdel-Aziz RT. Clinical efficacy and safety of topical versus oral ivermectin in treatment of uncomplicated scabies. Dermatolologic Therapy 2016;29(1):58-63. [DOI: 10.1111/dth.12310; PUBMED: 26555785]

\section{Bachewar 2009 \{published data only\}}

Bachewar NP, Thawani VR, Mali SN, Gharpure KJ, Shingade VP, Dakhale GN. Comparison of safety, efficacy, and cost effectiveness of benzyl benzoate, permethrin, and ivermectin in patients of scabies. Indian Journal of Pharmacology 2009;41(1):9-14. [DOI: 10.4103/0253-7613.48882]

\section{Chhaiya 2012 \{published data only\}}

Chhaiya SB, Patel VJ, Dave JN, Mehta DS, Shah HA. Comparative efficacy and safety of topical permethrin, topical ivermectin, and oral ivermectin in patients of uncomplicated scabies. Indian Journal of Dermatology, Venereology and Leprology 2012;78(5):605-10. [DOI: 10.4103/0378-6323.100571; PUBMED: 22960817]

\section{Das 2006 \{published data only\}}

Das S, Chatterjee T, Banerji G, Biswas I. Evaluation of the commonest site, demographic profile and most effective therapy in scabies. Indian Journal of Dermatology 2006;51(3):186-8. [DOI: 10.4103/0019-5154.27981]

\section{Macotela-Ruiz 1996 \{published data only\}}

Macotela-Ruiz E, Mendez Islas CC, Nochebuena Ramos E. Treatment of scabies with oral ivermectin in an enclosed rural community [Tratamiento de escabiasis con Ivermectina por via oral en una comunidad rural cerrada. Implicaciones epidemiologicas]. Dermatologia Revista Mexicana 1996;40(3):179-84

\section{Manjhi 2014 \{published data only\}}

Manjhi PK, Sinha RI, Kumar M, Sinha KI. Comparative study of efficacy of oral ivermectin versus some topical antiscabies drugs in the treatment of scabies. Journal of Clinical and Diagnostic Research 2014;8(9):HC01-4. [DOI: 10.7860/ jcdr/2014/9092.4878; PUBMED: 25386453]

\section{Meenakshi 2014 \{published data only\}}

Meenakshi M, Sadhna K, Neeraj S, Deepak V, Renu P. An open label, randomized, comparative study of antiscabietic drugs permethrin, gamma benzene hexachloride and ivermectin in patients of uncomplicated scabies. International Journal of Pharmacology and Clinical Sciences 2014;3(2):15-21.
Mushtaq 2010 \{published data only\}

Mushtaq A, Khurshid K, Pal SS. Comparison of efficacy and safety of oral ivermectin with topical permethrin in treatment of scabies. Journal of Pakistan Association of Dermatologists 2010;20(4):227-31.

Rohatgi 2013 \{published and unpublished data\} Rohatgi V, Narayana Reddy S, Vagge DS. A prospective, randomized, open labelled, comparative study of efficacy and cost effectiveness of permethrin and ivermectin in 5-15 years age group patients with scabies in a tertiary care hospital. Indian Journal of Pharmacology 2013;45:S45.

* Rohatgi, V. Doctoral thesis (as supplied 31 January 2017). Data on file.

\section{Saqib 2012 \{published data only\}}

Saqib M, Malik LM, Jahangir M. A comparison of efficacy of single topical permethrin and single oral ivermectin in the treatment of scabies. Journal of Pakistan Association of Dermatologists 2012;22(1):45-9.

Sharma 2011 \{published data only\}

Sharma R, Singal A. Topical permethrin and oral ivermectin in the management of scabies: a prospective, randomized, double blind, controlled study. Indian Journal of Dermatology, Venereology and Leprology 2011;77(5):581-6. [DOI: 10.4103/0378-6323.84063]

Usha 2000 \{published data only\}

Usha V, Gopalakrishnan Nair TV. A comparative study of oral ivermectin and topical permethrin cream in the treatment of scabies. Journal of the American Academy of Dermatology 2000;42(2 Pt 1):236-40. [DOI: 10.1016/S0190-9622(00)90131-2]

Wankhade 2013 \{published data only\}

Wankhade PA, Tamboli SB, Rathod P, Deshmukh JB, Shirure PA, Ghadlinge MS. Comparison of safety, efficacy, cost effectiveness of permethrin and ivermectin in patients of scabies. Indian Journal of Pharmacology 2013;45:S202.

Wankhade 2016 \{published data only\}

Wankhade P, Tamboli SB, Deshmukh JB, Rathode PS, Domple VK, Dagar V. A comparative study of topical permethrin, oral ivermectin and combination of permethrin with ivermectin in patients of scabies. IOSR Journal of Dental and Medical Sciences 2016;15(5):67-72. [DOI: 10.9790/0853-1505016772]

\section{References to studies excluded from this review}

Chhaiya 2013 \{published data only\}

Chhaiya SB, Patel VJ, Dave JN, Mehta DS. To study cost effectiveness of topical permethrin versus oral ivermectin in patients of uncomplicated scabies. International Journal of Basic \& Clinical Pharmacology 2013;2(6):799-803. [DOI: 10.5455/2319-2003.ijbcp20131224] 
Goldust 2012 \{published data only\}

Goldust M, Rezaee E, Hemayat S. Treatment of scabies: comparison of permethrin $5 \%$ versus ivermectin. Journal of Dermatology 2012;39(6):545-7. [DOI: 10.1111/ j.1346-8138.2011.01481.x; PUBMED: 22385121]

Goldust 2013 \{published data only\}

Goldust M, Rezaee E, Raghifar R, Hemayat S. Treatment of scabies: the topical ivermectin vs. permethrin $2.5 \%$ cream. Annals of Parasitology 2013;59(2):79-84. [PUBMED: 24171301]

\section{NCT02841215 \{published data only\}}

NCT02841215. Efficacy study between two different dosages of an antiparasitic in patients with crusted scabies (GALECRUSTED). clinicaltrials.gov/ct2/show/NCT02841215 (first received 26 November 2016).

Ranjkesh 2013 \{published data only\}

Ranjkesh MR, Naghili B, Goldust M, Rezaee E. The efficacy of permethrin $5 \%$ vs. oral ivermectin for the treatment of scabies. Annals of Parasitology 2013;59(4):189-94. [PUBMED: 24791346]

\section{References to ongoing studies}

NCT02407782 \{published data only\}

NCT02407782. Oral ivermectin versus topical permethrin to treat scabies in children (SCRATCH). clinicaltrials.gov/show/ NCT02407782 (first received 3 April 2015).

\section{Additional references}

\section{Alebiosu 2003}

Alebiosu CO, Ogunledun A, Ogunleye DS. A report of clinical trial conducted on Toto ointment and soap products. Journal of the National Medical Association 2003;95(1):95-105.

\section{Alexander 1984}

Alexander JO. Scabies. Arthropods and Human Skin. 1st Edition. Berlin: Springer-Verlag, 1984:227-92. [DOI: 10.1007/978-1-4471-1356-0_15; 9781447113584]

\section{Arlian 1989}

Arlian LG. Biology, host relations, and epidemiology of Sarcoptes scabiei. Annual Review of Entomology 1989;34:139-61. [DOI: 10.1146/annurev.en.34.010189.001035; PUBMED: 2494934]

\section{AusPAR 2013}

Therapeutic Goods Administration. Australian Public Assessment Report for Ivermectin. www.tga.gov.au/auspar/ auspar-ivermectin (accessed 25 May 2017).

\section{Banerji 2015}

Banerji A, Canadian Paediatric Society First Nations Inuit and Métis Health Committee. Scabies. Paediatrics and Child Health 2015;20(7):395-8. [PUBMED: 26527041]

\section{Banez 1999}

Banez JA, Nazareno RC, Medel RB. Clinical trial on the effectiveness of Gliricidia sepium (Kakawati) in treating patients with scabies in the antipolo CBHP. Philippine Journal of Microbiology and Infectious Diseases 1999;28(4):147-53.

\section{Barkwell 1997}

Barkwell R, Shields S. Deaths associated with ivermectin treatment of scabies. Lancet 1997;349(9059):1144-5. [DOI: 10.1016/S0140-6736(05)63020-6; PUBMED: 9113017]

\section{Bloch-Infanger 2017}

Bloch-Infanger C, Battig V, Kremo J, Widmer AF, Egli A, Bingisser R, et al. Increasing prevalence of infectious diseases in asylum seekers at a tertiary care hospital in Switzerland. PLOS ONE 2017;12(6):e0179537. [DOI: 10.1371/journal.pone.0179537; PUBMED: 28617860]

\section{Bredal 1997}

Bredal WP. Deaths associated with ivermectin for scabies. Lancet 1997;350(9072):216. [DOI: 10.1016/ S0140-6736(05)62380-X; PUBMED: 9250203]

\section{Buffet 2003}

Buffet M, Dupin N. Current treatments for scabies. Fundamental \& Clinical Pharmacology 2003;17(2):217-25.

\section{CDC 2015}

Centers for Disease Control and Prevention. 2015 Sexually Transmitted Diseases Treatment Guidelines (4 August 2015). www.cdc.gov/std/tg2015/ectoparasitic.htm (accessed 25 November 2017).

\section{CDC 2017a}

Centers for Disease Control and Prevention. Scabies prevention \& control (12 May 2017). www.cdc.gov/parasites/ scabies/prevent.html (accessed 4 June 2017).

\section{CDC 2017b}

Centers for Disease Control and Prevention. Scabies medications (21 March 2017). www.cdc.gov/parasites/scabies/ health_professionals/meds.html (accessed 25 May 2017).

\section{CDSCO}

Central Drugs Standard Control Organization. List of new drugs approved in India from 1991 to 2000. www.cdsco.nic.in/ writereaddata/1991-2000.pdf (accessed 11 June 2017).

\section{Chosidow 2000}

Chosidow 0 . Scabies and pediculosis. Lancet 2000;355(9206):819-26.

\section{Christensen 2006}

Christensen PM, Kristiansen IS. Number-needed-totreat (NNT) - needs treatment with care. Basic \& Clinical Pharmacology \& Toxicology 2006;99(1):12-6. [DOI: 10.1111/ j.1742-7843.2006.pto_412.x; PUBMED: 16867164]

\section{Coleman 2005}

Coleman $\mathrm{Cl}$, Gillespie EL, White CM. Probable topical permethrin-induced neck dystonia. Pharmacotherapy 2005;25(3):448-50. [DOI: 10.1592/phco.25.3.448.61596; PUBMED: 15843294$]$ 


\section{Coyne 1997}

Coyne PE, Addiss DG. Deaths associated with ivermectin for scabies. Lancet 1997;350(9072):215-6; author reply 216. [DOI: 10.1016/S0140-6736(05)62378-1; PUBMED: 9250202]

\section{Currie 2010}

Currie BJ, McCarthy JS. Permethrin and ivermectin for scabies. New England Journal of Medicine 2010;362(8):717-25. [DOI: 10.1056/NEJMct0910329; PUBMED: 20181973]

\section{DerSimonian 1986}

DerSimonian R, Laird N. Meta-analysis in clinical trials. Controlled Clinical Trials 1986;7(3):177-88. [PUBMED: 3802833]

\section{Diazgranados 1997}

Diazgranados JA, Costa JL. Deaths after ivermectin treatment. Lancet 1997;349(9066):1698. [DOI: 10.1016/ s0140-6736(05)62668-2; PUBMED: 9186403]

\section{Downs 1999}

Downs AM, Harvey I, Kennedy CT. The epidemiology of head lice and scabies in the UK. Epidemiology and Infection 1999;122(3):471-7. [PUBMED: 10459652]

\section{Dressler 2016a}

Dressler C, Rosumeck S, Sunderkotter C, Werner RN, Nast A. The treatment of scabies. Deutsches Ärzteblatt International 2016;113(45):757-62. [DOI: 10.3238/arztebl.2016.0757; PUBMED: 27974144]

\section{Dressler 2016b}

Dressler C, Rosumeck S, Nast A. Reporting in the clinical trials evaluating scabies treatments. Annals of Parasitology 2016;62(2):153-5. [DOI: 10.17420/ap6202.48; PUBMED: 27614482]

\section{Engauge Digitizer [Computer program]}

Mitchell M. Engauge Digitizer. Version 9.8. Mitchell M, 2016. [DOI: 10.5281/zenodo.200196]

\section{Fain 1978}

Fain A. Epidemiological problems of scabies. International Journal of Dermatology 1978;17(1):20-30. [PUBMED: 415012]

\section{Fawcett 2003}

Fawcett RS. Ivermectin use in scabies. American Family Physician 2003;68(6):1089-92. [PUBMED: 14524395]

\section{FDA 2012}

US Food, Drug Administration. Drugs@FDA: FDA Approved Drug Products: Sklice (7 February 2012). www.accessdata.fda.gov/scripts/cder/daf/index.cfm? event $=$ overview.process\&applno $=202736$ (accessed 28 May 2017).

\section{FDA 2014}

US Food, Drug Administration. Drugs@FDA: FDA Approved Drug Products: Soolantra (19 December 2014). www.accessdata.fda.gov/scripts/cder/daf/index.cfm? event $=$ overview.process\&varApplNo=206255 (accessed 28 May 2017).

\section{GRADEpro GDT [Computer program]}

McMaster University (developed by Evidence Prime, Inc.), accessed 5 June 2017. GRADEpro GDT. Evidence Prime, Inc., 2015.

\section{Green 1989}

Green M. Epidemiology of scabies. Epidemiologic Reviews 1989;11:126-50. [PUBMED: 2509232]

\section{Guyatt 2011a}

Guyatt GH, Oxman AD, Vist G, Kunz R, Brozek J, Alonso-Coello P, et al. GRADE guidelines: 4 . Rating the quality of evidence study limitations (risk of bias). Journal of Clinical Epidemiology 2011;64(4):407-15. [DOI: 10.1016/j.jclinepi.2010.07.017; PUBMED: 21247734$]$

\section{Guyatt 2011b}

Guyatt GH, Oxman AD, Montori V, Vist G, Kunz R, Brozek J, et al. GRADE guidelines: 5 . Rating the quality of evidence - publication bias. Journal of Clinical Epidemiology 2011;64(12):1277-82. [DOI: 10.1016/j.jclinepi.2011.01.011; PUBMED: 21802904]

\section{Guyatt 2011c}

Guyatt GH, Oxman AD, Kunz R, Brozek J, Alonso-Coello P, Rind $D$, et al. GRADE guidelines 6 . Rating the quality of evidence - imprecision. Journal of Clinical Epidemiology 2011;64(12):1283-93. [DOI: 10.1016/j.jclinepi.2011.01.012; PUBMED: 21839614]

\section{Guyatt 2011d}

Guyatt GH, Oxman AD, Kunz R, Woodcock J, Brozek J, Helfand M, et al. GRADE guidelines: 7 . Rating the quality of evidence - inconsistency. Journal of Clinical Epidemiology 2011;64(12):1294-302. [DOI: 10.1016/j.jclinepi.2011.03.017; PUBMED: 21803546]

\section{Guyatt 2011e}

Guyatt GH, Oxman AD, Kunz R, Woodcock J, Brozek J, Helfand M, et al. GRADE guidelines: 8 . Rating the quality of evidence - indirectness. Journal of Clinical Epidemiology 2011;64(12):1303-10. [DOI: 10.1016/j.jclinepi.2011.04.014; PUBMED: 21802903]

\section{Hamm 2006}

Hamm H, Beiteke U, Hoger PH, Seitz CS, Thaci D, Sunderkotter C. Treatment of scabies with 5\% permethrin cream: results of a German multicenter study. Journal der Deutschen Dermatologischen Gesellschaft [Journal of the German Society of Dermatology] 2006;4(5):407-13. [DOI: 10.1111/j.1610-0387.2006.05941.x; PUBMED: 16686608]

\section{Hay 2004}

Hay RJ. Scabies - learning from the animals. Journal of the European Academy of Dermatology and Venereology 2004;18:129-30. [PUBMED: 15009287]

\section{Hay 2012}

Hay RJ, Steer AC, Engelman D, Walton S. Scabies in the developing world - its prevalence, complications, and management. Clinical Microbiology and Infection: the official 
publication of the European Society of Clinical Microbiology and Infectious Diseases 2012;18(4):313-23. [DOI: 10.1111/ j.1469-0691.2012.03798.x; PUBMED: 22429456]

\section{Hay 2013}

Hay RJ, Steer AC, Chosidow O, Currie BJ. Scabies: a suitable case for a global control initiative. Current Opinion in Infectious Diseases 2013;26(2):107-9. [DOI: 10.1097/ QCO.0b013e32835e085b; PUBMED: 23302759]

\section{Higgins 2011}

Higgins JP, Green S, editor(s). Cochrane Handbook for Systematic Reviews of Interventions Version 5.1.0 (updated March 2011). The Cochrane Collaboration, 2011. Available from handbook.cochrane.org.

\section{Hoy 2012}

Hoy WE, White AV, Dowling A, Sharma SK, Bloomfield H, Tipiloura B, et al. Post-streptococcal glomerulonephritis is a strong risk factor for chronic kidney disease in later life. Kidney International 2012;81(10):1026-32. [DOI: 10.1038/ki.2011.478; PUBMED: 22297679]

\section{InfectoScab 2016}

InfectoPharm Arzneimittel und Consilium GmbH. InfectoScab $5 \%$ Cream (September 2016) [InfectoScab 5\% Creme (September 2016)]. www.infectopharm.com (login required) (accessed 25 November 2017).

\section{Karimkhani 2017}

Karimkhani C, Colombara DV, Drucker AM, Norton SA, Hay R, Engelman D, et al. The global burden of scabies: a crosssectional analysis from the Global Burden of Disease Study 2015. Lancet Infectious Diseases 2017;17(12):1247-54. [DOI: 10.1016/S1473-3099(17)30483-8; PUBMED: 28941561]

\section{Kühne 2016}

Kühne A, Gilsdorf A. Infectious disease outbreaks in centralized homes for asylum seekers in Germany from 2004-2014 [Ausbrüche von Infektionskrankheiten in Gemeinschaftsunterkünften für Asylsuchende 2004-2014 in Deutschland]. Bundesgesundheitsblatt Gesundheitsforschung Gesundheitsschutz [Federal Health Bulletin Health Research Health Protection] 2016;59(5):570-7. [DOI: 10.1007/ s00103-016-2332-9; PUBMED: 27072500]

\section{Lefebvre 2011}

Lefebvre C, Manheimer E, Glanville J. Chapter 6: Searching for studies. In: Higgins JP, Green S, editor(s). Cochrane Handbook for Systematic Reviews of Interventions Version 5.1.0 (updated March 2011). The Cochrane Collaboration, 2011. Available from handbook.cochrane.org.

\section{Meinking 1995}

Meinking TL, Taplin D. Infestations. In: Schachner LA, Hansen RC editor(s). Pediatric Dermatology. New York: Churchill Livingstone, 1995:1347-92.

\section{Merck 2015}

Merck Sharp, Dohme BV. Package leaflet: Information for the user, Stromectol 3 mg, tablets (September 2015) [Bijsluiter: informatie voor de gebruiker, Stromectol $3 \mathrm{mg}$, tabletten] db.cbg-meb.nl/Bijsluiters/h28341.pdf (accessed 4 June 2017).

\section{Mimouni 1998}

Mimouni D, Gdalevich M, Mimouni FB, Haviv J, Ashkenazi I. The epidemiologic trends of scabies among Israeli soldiers: a 28-year follow-up. International Journal of Dermatology 1998;37(8):586-7. [PUBMED: 9732002]

\section{Mimouni 2003}

Mimouni D, Ankol OE, Davidovitch N, Gdalevich M, Zangvil E, Grotto I. Seasonality trends of scabies in a young adult population: a 20-year follow-up. British Journal of Dermatology 2003;149(1):157-9. [PUBMED: 12890210]

\section{Mounsey 2009}

Mounsey KE, Holt DC, McCarthy JS, Currie BJ, Walton SF. Longitudinal evidence of increasing in vitro tolerance of scabies mites to ivermectin in scabies-endemic communities. Archives of Dermatology 2009;145(7):840-1. [DOI: 10.1001/ archdermatol.2009.125; PUBMED: 19620572]

\section{Oladimeji 2000}

Oladimeji FA, Orafidiya OO, Ogunniyi TA, Adewunmi TA. Pediculocidal and scabicidal properties of Lippia multiflora essential oil. Journal of Ethnopharmacology 2000;72(1-2):305-11. [PUBMED: 10967487]

\section{Oladimeji 2005}

Oladimeji FA, Orafidiya LO, Ogunniyi TA, Adewunmi TA, Onayemi O. A comparative study of the scabicidal activities of formulations of essential oil of Lippia multiflora Moldenke and benzyl benzoate emulsion BP. International Journal of Aromatherapy 2005;15(2):87-93. [DOI: 10.1016/ j.ijat.2005.03.005]

\section{Reintjes 1997}

Reintjes R, Hoek C. Deaths associated with ivermectin for scabies. Lancet 1997;350(9072):215; author reply 216. [DOI: 10.1016/S0140-6736(05)62377-X; PUBMED: 9250201]

\section{RevMan 2014 [Computer program]}

Nordic Cochrane Centre, The Cochrane Collaboration. Review Manager 5 (RevMan 5). Version 5.3. Copenhagen: Nordic Cochrane Centre, The Cochrane Collaboration, 2014.

\section{RKI 2016}

Robert-Koch-Institut. Skabies (Krätze), RKI-Ratgeber für Ärzte. www.rki.de/DE/Content/Infekt/EpidBull/Merkblaetter/ Ratgeber_Skabies.html. Robert Koch-Institut, Abteilung für Infektionsepidemiologie, (last updated 2 June 2016, accessed 25 May 2017).

\section{Romani 2015a}

Romani L, Steer AC, Whitfeld MJ, Kaldor JM. Prevalence of scabies and impetigo worldwide: a systematic review. Lancet Infectious Diseases 2015;15(8):960-7. [DOI: 10.1016/ S1473-3099(15)00132-2; PUBMED: 26088526] 


\section{Romani 2015b}

Romani L, Whitfeld MJ, Koroivueta J, Kama M, Wand H, Tikoduadua $\mathrm{L}$, et al. Mass drug administration for scabies control in a population with endemic disease. New England Journal of Medicine 2015;373(24):2305-13. [DOI: 10.1056/ NEJMoa1500987; PUBMED: 26650152]

\section{Salavastru 2017}

Salavastru CM, Chosidow O, Boffa MJ, Janier M, Tiplica GS. European guideline for the management of scabies. Journal of the European Academy of Dermatology and Venereology: JEADV 2017;31(8):1248-53. [DOI: 10.1111/jdv.14351; PUBMED: 28639722]

\section{Scabioral 2016}

InfectoPharm Arzneimitel und Consilium GmbH. Scabioral $3 \mathrm{mg}$ Tablets (May 2016) [Scabioral 3 mg Tabletten (Mai 2016)]. www.infectopharm.com/images/newsletter/1216/fiscabioral.pdf (accessed 28 May 2017).

\section{Scheinfeld 2004}

Scheinfeld N. Controlling scabies in institutional settings: a review of medications, treatment models and implementation. American Journal of Clinical Dermatology 2004;5(1):31-7. [PUBMED: 14979741]

\section{Schünemann 2013}

Schünemann H, Brożek J, Oxman A, editors. GRADE Handbook - Handbook for grading the quality of evidence and the strength of recommendations using the GRADE approach. gdt.guidelinedevelopment.org/app/handbook/handbook.html (updated October 2013, accessed 25 May 2017).

\section{Sunderkötter 2016}

Sunderkötter C, Feldmeier H, Fölster-Holst R, Geisel B, KlinkeRehbein S, Nast A, et al. S1 guidelines on the diagnosis and treatment of scabies - short version [S1-Leitlinie zur Diagnostik und Therapie der Skabies - Kurzfassung]. Journal der Deutschen Dermatologischen Gesellschaft [Journal of the German Society of Dermatology] 2016;14(11):1160-71. [DOI: 10.1111/ddg.13130_g; PUBMED: 27879080]

\section{Walton 2004a}

Walton SF, Dougall A, Pizzutto S, Holt D, Taplin D, Arlian LG, et al. Genetic epidemiology of Sarcoptes scabiei (Acari: Sarcoptidae) in northern Australia. International Journal for Parasitology 2004;34(7):839-49. [DOI: 10.1016/j.ijpara.2004.04.002; PUBMED: 15157767]

\section{Walton 2004b}

Walton SF, McKinnon M, Pizzutto S, Dougall A, Williams E, Currie BJ. Acaricidal activity of Melaleuca alternifolia (tea tree) oil. Archives of Dermatology 2004;140:563-6. [DOI: 10.1001/ archderm.140.5.563; PUBMED: 15148100]

\section{References to other published versions of this review Rosumeck 2016}

Rosumeck S, Dressler C, Nast A. Ivermectin and permethrin for treating scabies. PROSPERO 2016:CRD42016048685. www.crd.york.ac.uk/PROSPERO/display_record.asp? ID=CRD42016048685 (accessed 10 October 2016).

\section{Strong 2007}

Strong M, Johnstone P. Interventions for treating scabies. Cochrane Database of Systematic Reviews 2007, Issue 3. [DOI: 10.1002/14651858.CD000320.pub2]

\section{Walker 1997}

Walker GJ, Johnstone PW. Drug treatment for scabies. Cochrane Database of Systematic Reviews 1997, Issue 4. [DOI: 10.1002/14651858.CD000320]

\section{Walker 1999a}

Walker GJ, Johnstone PW. Interventions for treating scabies. Cochrane Database of Systematic Reviews 1999, Issue 1. [DOI: 10.1002/14651858.CD000320]

\section{Walker 1999b}

Walker GJ, Johnstone PW. Interventions for treating scabies. Cochrane Database of Systematic Reviews 1999, Issue 3. [DOI: 10.1002/14651858.CD000320]

\section{Walker 2000}

Walker GJA, Johnstone PW. Interventions for treating scabies. Cochrane Database of Systematic Reviews 2000, Issue 3. [DOI: 10.1002/14651858.CD000320]

* Indicates the major publication for the study

\section{CHARACTERISTICS OF STUDIES}

Characteristics of included studies [ordered by study ID]

Abdel-Raheem 2016

\begin{tabular}{ll} 
Methods & Single-centre, parallel-group randomized trial \\
& Duration: 7 months, from November 2012 to May 2013 \\
\hline Participants & Inclusion criteria \\
- & Aged 5 to 50 years \\
- Clinical presentation of scabies: people experiencing itching and had characteristic lesions (that is, \\
burrows, vesicles, papules, nodules or pustules) on anatomical sites of predilection for scabies (that
\end{tabular}


is, the interdigital folds of the hands, the elbows, the wrists, the buttocks, the axillary folds, the nipple areolas in women and the male external genitalia); detailed physical and dermatological examination was done including description of the lesions and their distribution on the body and assessment of the degree of pruritus

- Identification of a mite: parasitological examination of lesions was performed by low-power microscopy; at least 4 to 6 scrapings per participant from separate locations were obtained, placed in a drop of $10 \%$ potassium hydroxide solution on a glass slide, and examined for the presence of living Sarcoptes scabiei (that is, adult forms), eggs, or faecal pellets

\section{Exclusion criteria}

- Pregnant or lactating women

- Body weight less than $15 \mathrm{~kg}$

- People with a systemic condition such as abnormal liver and kidney functions, known thyroid disease, cardiac disorders, nervous system disorders and psychiatric illnesses

- People with history of diabetes mellitus, hypertension, or chronic infectious diseases

- People having any other associated skin disease that could alter the picture of scabies

- Immunocompromised individuals

- Atypical presentations like crusted scabies

- People with any antiscabietic treatment in the preceding month

Baseline characteristics ( $\mathrm{n}=50$ completers in each group)

- Age (mean \pm SD): group A: $27.84 \pm 9.46$, B: $25.28 \pm 13.73$, C: $22.52 \pm 12.77$, D: $28.40 \pm 13.42$

- Males/females: group A: 26/24, B: 14/36, C: 24/26, D: 20/30

A: Oral ivermectin $200 \mu \mathrm{g} / \mathrm{kg}$ body weight at day 1 and 7 , taken with meals; tablets were taken in the presence of the physician ( $n=53$ participants)

B: Permethrin $2.5 \%$ (for children below 10 years) or $5 \%$ (for adults) lotion applied by participant and left overnight to the whole body below neck for 5 consecutive nights ( $n=54$ participants)

Not included in this review:

C: Benzyl benzoate $20 \%$ cream applied by participant and left overnight to the whole body below neck for 5 consecutive nights ( $n=55$ participants)

D: Sulfur ointment, $5 \%$ (for children below 10 years) or $10 \%$ (for adults) applied by participant and left overnight to the whole body below neck for 5 consecutive nights ( $n=54$ participants)

- Participants were first treated from secondary bacterial infection, if present, with azithromycin once daily for 3 days.

- Cured participants were prescribed antihistaminic for symptomatic treatment of remaining pruritus and/or nodules, and the uncured participants were prescribed repeated intervention along with antihistaminic.

- Members of the same family not enrolled in the study were given the same drugs according to their age or any other suitable regimen.

- Complete cure (negative parasitological examination of the participant with complete absence of new lesions; residual and all new lesions were scraped for detection of mites; if only 1 mite was detected, this was considered as treatment failure; week 1 and 2)

- Number of participants re-treated (week 1 )

- Number of participant with $\geq 1$ adverse event

Funding source

Quote (page 478): "This research was funded by authors themselves, and received support From Faculty of Medicine Fayoum University."

Declarations of interest Quote (page 478): "The authors report no conflicts of interest."


Abdel-Raheem 2016 (Continued)

Clinical trial registry: PACTR201505001116484

\section{Risk of bias}

\begin{tabular}{|c|c|c|}
\hline Bias & Authors' judgement & Support for judgement \\
\hline $\begin{array}{l}\text { Random sequence genera- } \\
\text { tion (selection bias) }\end{array}$ & Low risk & Quote (page 474): "random allocation number generated through computer" \\
\hline $\begin{array}{l}\text { Allocation concealment } \\
\text { (selection bias) }\end{array}$ & Low risk & $\begin{array}{l}\text { Quote (page 474): "randomly allocated" } \\
\text { Quote from Pan African Clinical Trials Registry: "Sealed opaque envelopes" }\end{array}$ \\
\hline $\begin{array}{l}\text { Blinding of participants } \\
\text { and personnel (perfor- } \\
\text { mance bias) } \\
\text { Efficacy }\end{array}$ & High risk & $\begin{array}{l}\text { Quote from Pan African Clinical Trials Registry: "Open-label (masking not } \\
\text { used)" }\end{array}$ \\
\hline $\begin{array}{l}\text { Blinding of participants } \\
\text { and personnel (perfor- } \\
\text { mance bias) } \\
\text { Safety }\end{array}$ & High risk & $\begin{array}{l}\text { Quote from Pan African Clinical Trials Registry: "Open-label (masking not } \\
\text { used)" }\end{array}$ \\
\hline $\begin{array}{l}\text { Blinding of outcome as- } \\
\text { sessment (detection bias) } \\
\text { Efficacy }\end{array}$ & High risk & $\begin{array}{l}\text { Quote from Pan African Clinical Trials Registry: "Open-label (masking not } \\
\text { used)" }\end{array}$ \\
\hline $\begin{array}{l}\text { Blinding of outcome as- } \\
\text { sessment (detection bias) } \\
\text { Safety }\end{array}$ & High risk & $\begin{array}{l}\text { Quote from Pan African Clinical Trials Registry: "Open-label (masking not } \\
\text { used)" }\end{array}$ \\
\hline $\begin{array}{l}\text { Incomplete outcome data } \\
\text { (attrition bias) } \\
\text { Efficacy }\end{array}$ & Low risk & $\begin{array}{l}\text { 16/216 participants lost to follow-up (permethrin group: 4; oral ivermectin } \\
\text { group: 3; benzoyl benzoate group: 5; sulfur group: } 4 \text { ) } \\
\text { No intention-to-treat analysis performed. } \\
\text { Quote (page } 475 \text {, Figure } 1 \text { ) }\end{array}$ \\
\hline $\begin{array}{l}\text { Incomplete outcome data } \\
\text { (attrition bias) } \\
\text { Safety }\end{array}$ & Low risk & $\begin{array}{l}\text { 16/216 participants lost to follow-up (permethrin group: 4; oral ivermectin } \\
\text { group: 3; benzoyl benzoate group: 5; sulfur group: 4) } \\
\text { Quote (page } 475, \text { Figure } 1 \text { ) }\end{array}$ \\
\hline $\begin{array}{l}\text { Selective reporting (re- } \\
\text { porting bias) }\end{array}$ & Unclear risk & $\begin{array}{l}\text { Outcomes stated in Pan African Clinical Trials Registry, but registration was on } \\
25 \text { April } 2015 \text { (after completion of study). }\end{array}$ \\
\hline Other bias & Unclear risk & - \\
\hline
\end{tabular}

Ahmad 2016

\begin{tabular}{ll} 
Methods & Single-centre, randomized trial \\
& Duration: not stated \\
\hline
\end{tabular}

Participants

Inclusion criteria

- Age $\geq 5$ years and $>15 \mathrm{~kg}$ body weight 
Ahmad 2016 (Continued)

- Clinically and laboratory diagnosed scabies:

- Clinical diagnosis was based on the presence of $\geq 3$ out of 4 criteria: nocturnal pruritus, family history of similar illness, clinical demonstration of burrows, scabies lesions at typical sites

- Laboratory diagnosis: demonstration of mites and/or mite products (eggs, larva, or faecal pellets) in scrapings from skin lesions (burrows or scabetic papules from classical sites) using light microscopy after incubation in $15 \%$ potassium hydroxide

\section{Exclusion criteria}

- Pregnant and lactating women

- People with crusted (Norwegian) scabies

- People with history of epileptic fits, immunodeficiency, secondary cutaneous infection or eczematization, and coexisting skin disease that could interfere with treatment evaluation

- People with history of recent scabetic treatment

- Known hypersensitivity to ivermectin

\section{Baseline characteristics}

- Age (mean $\pm \mathrm{SD}): 21.8 \pm 15$

- Males/females: $26 / 36$
A: Ivermectin $1 \%$ solution applied once to entire body below neck at night ( $\mathrm{n}=32$ participants)

B: Oral ivermectin $200 \mu \mathrm{g} / \mathrm{kg}$ body weight after food on day 1 ( $\mathrm{n}=30$ participants)

- Treatment was repeated after 1 week only in participants with persistent symptoms.

- Treatment of contacts and proper hygienic measures were emphasized.
Outcomes

- Cure ('effective' = marked to excellent improvement in pruritus (score 0 ) and no lesions, absence of mites and their products on microscopy; score: $0=$ no pruritus, no skin lesions; $1=$ mild pruritus, $\leq 10$ lesions; 2 = moderate pruritus, 11 to 49 lesions; 3 = marked pruritus, $\geq 50$ lesions; week 1, 2, and 4)

- Number of participants withdrawn from study due to adverse event

\begin{tabular}{ll}
\hline Funding source & Not stated \\
\hline Declarations of interest & Not stated \\
\hline Notes & Location: Minia, Egypt \\
\hline
\end{tabular}

\section{Risk of bias}

\begin{tabular}{lll}
\hline Bias & Authors' judgement & Support for judgement \\
\hline $\begin{array}{l}\text { Random sequence genera- } \\
\text { tion (selection bias) }\end{array}$ & Low risk & Quote (page 59): "adaptive biased-coin randomization" \\
\hline $\begin{array}{l}\text { Allocation concealment } \\
\text { (selection bias) }\end{array}$ & Unclear risk & Insufficient information \\
\hline $\begin{array}{l}\text { Blinding of participants } \\
\text { and personnel (perfor- } \\
\text { mance bias) }\end{array}$ & High risk & No information \\
Efficacy & \\
\hline $\begin{array}{l}\text { Blinding of participants } \\
\text { and personnel (perfor- } \\
\text { mance bias) }\end{array}$ & High risk & No information \\
$\begin{array}{l}\text { Safety } \\
\end{array}$ & \\
\hline
\end{tabular}


Ahmad 2016 (Continued)

$\begin{array}{lll}\text { Blinding of outcome as- } & \text { High risk } & \text { No information } \\ \text { sessment (detection bias) } & \end{array}$

Efficacy

\begin{tabular}{lll}
\hline $\begin{array}{l}\text { Blinding of outcome as- } \\
\text { sessment (detection bias) } \\
\text { Safety }\end{array}$ & High risk & No information \\
\hline $\begin{array}{l}\text { Incomplete outcome data } \\
\text { (attrition bias) }\end{array}$ & Low risk & All data reported, no loss to follow-up. \\
Efficacy & &
\end{tabular}

\begin{tabular}{lll}
\hline $\begin{array}{l}\text { Incomplete outcome data } \\
\text { (attrition bias) } \\
\text { Safety }\end{array}$ & Unclear risk & No numerical data on participants with adverse events per study group \\
\hline $\begin{array}{l}\text { Selective reporting (re- } \\
\text { porting bias) }\end{array}$ & Unclear risk & Insufficient information \\
\hline Other bias & Unclear risk & - \\
\hline
\end{tabular}

\section{Bachewar 2009}

\begin{tabular}{ll}
\hline Methods & Single-centre, parallel-group randomized trial \\
& Duration: 5 months, from March to July 2007 \\
\hline
\end{tabular}

\section{Participants}

\section{Inclusion criteria}

- Above 12 years of age

- Newly diagnosed with scabies (diagnosis was based on clinical symptoms and clinical history)

- Person had to satisfy $\geq 3$ of following criteria: history of contact with a person with scabies, complaint of nocturnal itching, history of involvement of family members, presence of classical burrows on clinical examination, presence of typical scabetic lesions like papules, nodules, or vesicles

\section{Exclusion criteria}

- Pregnant or lactating women; women of childbearing age or planning for conception in near future

- Abnormal liver and kidney functions, known thyroid disease, cardiac disorders, nervous system disorders, and psychiatric illnesses; people with history of diabetes mellitus, hypertension, or chronic infectious diseases

- Any concurrent medication for other illness, consuming tobacco in any form, alcohol, or any substance of abuse

- Any other associated skin disease that could alter the picture of scabies

- Known/suspected immunocompromised individuals

- Scabies with atypical presentations

- Intake of any antiscabetic treatment in the preceding week

- Noncompliant participants

\section{Baseline characteristics}

- Males/females: group A: 22/12, B: $18 / 16, \mathrm{C}: 23 / 12$

\footnotetext{
Interventions
}
A: Permethrin 5\% cream applied once to whole body below neck, left overnight ( $n=34$ participants)
B: Oral ivermectin $200 \mu \mathrm{g} / \mathrm{kg}$ body weight as single dose, given as supervised medication along with printed handouts of "do's" in the local vernacular language $(n=34$ participants)


Bachewar 2009 (Continued)

- Same treatment was repeated if there were no signs of cure after 1 week.

- All participants were issued $25 \%$ benzyl benzoate lotion for topical application for family members and close contacts.

Not included in this review:

C: Benzyl benzoate $25 \%$ lotion applied to whole body below neck, left overnight, on 2 consecutive nights ( $\mathrm{n}=35$ participants)

\begin{tabular}{ll}
\hline Outcomes & $\begin{array}{l}\text { Cure (no new lesions (papules, vesicles, and classical burrows), examined by dermatologist and prin- } \\
\text { cipal investigator; week } 1 \text { and } 2 \text { ) } \\
\text { - Number of participants with } \geq 1 \text { adverse event }\end{array}$ \\
\hline Funding source & Not stated \\
\hline Declarations of interest & Not stated \\
\hline Notes & Location: Nagpur, India
\end{tabular}

\section{Risk of bias}

\begin{tabular}{|c|c|c|}
\hline Bias & Authors' judgement & Support for judgement \\
\hline $\begin{array}{l}\text { Random sequence genera- } \\
\text { tion (selection bias) }\end{array}$ & Low risk & Quote: "random allocation number generated through computer" \\
\hline $\begin{array}{l}\text { Allocation concealment } \\
\text { (selection bias) }\end{array}$ & Low risk & $\begin{array}{l}\text { Quote: "number [...] provided with any one of the chosen three therapeutic in- } \\
\text { terventions" }\end{array}$ \\
\hline $\begin{array}{l}\text { Blinding of participants } \\
\text { and personnel (perfor- } \\
\text { mance bias) } \\
\text { Efficacy }\end{array}$ & High risk & $\begin{array}{l}\text { Quote: "our study was biased due to nonblinding" } \\
\text { Not blinded }\end{array}$ \\
\hline $\begin{array}{l}\text { Blinding of participants } \\
\text { and personnel (perfor- } \\
\text { mance bias) } \\
\text { Safety }\end{array}$ & High risk & $\begin{array}{l}\text { Quote: "our study was biased due to nonblinding" } \\
\text { Not blinded }\end{array}$ \\
\hline $\begin{array}{l}\text { Blinding of outcome as- } \\
\text { sessment (detection bias) } \\
\text { Efficacy }\end{array}$ & High risk & $\begin{array}{l}\text { Quote: "our study was biased due to nonblinding" } \\
\text { Not blinded }\end{array}$ \\
\hline $\begin{array}{l}\text { Blinding of outcome as- } \\
\text { sessment (detection bias) } \\
\text { Safety }\end{array}$ & High risk & $\begin{array}{l}\text { Quote: "our study was biased due to nonblinding" } \\
\text { Not blinded }\end{array}$ \\
\hline $\begin{array}{l}\text { Incomplete outcome data } \\
\text { (attrition bias) } \\
\text { Efficacy }\end{array}$ & High risk & $\begin{array}{l}\text { 23/103 participants lost to follow-up (permethrin group: 6; oral ivermectin } \\
\text { group: } 7 \text {; benzyl benzoate group: } 10 \text { ) } \\
\text { No intention-to-treat analysis performed. } \\
\text { Quote: Table } 1 \text { and } 2\end{array}$ \\
\hline $\begin{array}{l}\text { Incomplete outcome data } \\
\text { (attrition bias) } \\
\text { Safety }\end{array}$ & High risk & $\begin{array}{l}\text { 23/103 participants lost to follow-up (permethrin group: 6; oral ivermectin } \\
\text { group: 7; benzyl benzoate group: 10) } \\
\text { Quote: Table } 1 \text { and } 2\end{array}$ \\
\hline
\end{tabular}


Bachewar 2009 (Continued)
Selective reporting (re-
Unclear risk
Insufficient information porting bias)

Other bias

Unclear risk

Chhaiya 2012

$\begin{array}{ll}\text { Methods } & \text { Single-centre, parallel-group randomized trial } \\ & \text { Duration: } 1 \text { year and } 8 \text { months, from June } 2007 \text { to January } 2009\end{array}$

Participants

\section{Inclusion criteria}

- Aged 5 to 80 years

- Clinically diagnosed scabies:

- Microscopically diagnosed scabies (demonstration of egg, larvae, mite, or faecal material)

- In case of negative microscopic examination, person had to satisfy $\geq 3$ of following criteria: presence of typical scabietic lesions (papules, nodules, or vesicles at classical sites), presence of classical burrows on clinical examination, nocturnal pruritus, history of involvement of family member or similar symptoms in contacts

\section{Exclusion criteria}

- Pregnant women and lactating mothers

- Person treated with any topical scabicidal therapy in the month before entry

- People taking any topical or systemic antibiotic therapy in the week before entry into the study

- Immunologically compromised patients

- Having scabies with atypical presentation like crusted scabies or scabies incognito

- People with secondary bacterial infection

- History of allergy to any of the study drugs

- Blood pressure $<100 / 60 \mathrm{mmHg}$

\section{Baseline characteristics}

- Age (mean \pm SD): group A: $23.40 \pm 13.55$, B: $21.97 \pm 13.26, C: 22.52 \pm 12.69$

- Males/females: group A: 58/47, B: 58/47, C: 59/46

A: Permethrin 5\% cream applied once to whole body covering neck to toe, left for $\geq 8$ hours, along with printed information sheet in the local vernacular language ( $n=105$ participants)

B: Oral ivermectin $200 \mu \mathrm{g} / \mathrm{kg}$ body weight as single dose, self administered along with printed information sheet in the local vernacular language ( $n=105$ participants)

C: Ivermectin $1 \%$ lotion, left for $\geq 8$ hours, along with printed information sheet in the local vernacular language, containing details regarding application of drug and other instructions ( $n=105$ participants)

- Participants who were not cured were prescribed repeat intervention along with antihistaminic at each follow-up.

- Participants who were not cured at the end of 3 rd week were switched over to standard treatment with $5 \%$ permethrin.

- All participants received oral hydroxyzine $10 \mathrm{mg}$ or $25 \mathrm{mg}$ twice daily for symptomatic treatment of pruritus.

- Number of participants re-treated (week 1, 2, 3, and 4)

- Number of participants with $\geq 1$ adverse event 
Chhaiya 2012 (Continued)

\begin{tabular}{ll} 
Funding source & Quote: "Source of Support: None" \\
\hline Declarations of interest & Quote: "Conflict of Interest: None" \\
\hline Notes & Location: Surendranagar, India
\end{tabular}

\section{Risk of bias}

\begin{tabular}{|c|c|c|}
\hline Bias & Authors' judgement & Support for judgement \\
\hline $\begin{array}{l}\text { Random sequence genera- } \\
\text { tion (selection bias) }\end{array}$ & Low risk & Quote: "random allocation number generated through computer" \\
\hline $\begin{array}{l}\text { Allocation concealment } \\
\text { (selection bias) }\end{array}$ & Unclear risk & Insufficient information \\
\hline $\begin{array}{l}\text { Blinding of participants } \\
\text { and personnel (perfor- } \\
\text { mance bias) } \\
\text { Efficacy }\end{array}$ & High risk & $\begin{array}{l}\text { Quote: "The study was open-labeled.", "Possible variation, if any, due to differ- } \\
\text { ent formulations- lotion and cream, cannot be ruled out." }\end{array}$ \\
\hline $\begin{array}{l}\text { Blinding of participants } \\
\text { and personnel (perfor- } \\
\text { mance bias) } \\
\text { Safety }\end{array}$ & High risk & $\begin{array}{l}\text { Quote: "The study was open-labeled.", "Possible variation, if any, due to differ- } \\
\text { ent formulations- lotion and cream, cannot be ruled out." }\end{array}$ \\
\hline $\begin{array}{l}\text { Blinding of outcome as- } \\
\text { sessment (detection bias) } \\
\text { Efficacy }\end{array}$ & High risk & $\begin{array}{l}\text { Quote: "The study was open-labeled.", "Possible variation, if any, due to differ- } \\
\text { ent formulations- lotion and cream, cannot be ruled out." }\end{array}$ \\
\hline $\begin{array}{l}\text { Blinding of outcome as- } \\
\text { sessment (detection bias) } \\
\text { Safety }\end{array}$ & High risk & $\begin{array}{l}\text { Quote: "The study was open-labeled.", "Possible variation, if any, due to differ- } \\
\text { ent formulations- lotion and cream, cannot be ruled out." }\end{array}$ \\
\hline $\begin{array}{l}\text { Incomplete outcome data } \\
\text { (attrition bias) } \\
\text { Efficacy }\end{array}$ & Unclear risk & $\begin{array}{l}\text { 15/315 participants lost to follow-up (permethrin group: 6; oral ivermectin } \\
\text { group: 5; topical ivermectin group: } 4 \text { ) } \\
\text { Quote: Figure } 1 \\
\text { No intention-to-treat analysis performed. } \\
\text { Number of participants analysed in week } 2 \text { and } 3 \text { is unclear. }\end{array}$ \\
\hline $\begin{array}{l}\text { Incomplete outcome data } \\
\text { (attrition bias) } \\
\text { Safety }\end{array}$ & Low risk & $\begin{array}{l}\text { 15/315 participants lost to follow-up (permethrin group: } 6 \text {; oral ivermectin } \\
\text { group: 5; topical ivermectin group: } 4 \text { ) } \\
\text { Quote: Figure } 1\end{array}$ \\
\hline $\begin{array}{l}\text { Selective reporting (re- } \\
\text { porting bias) }\end{array}$ & Unclear risk & Insufficient information \\
\hline Other bias & Unclear risk & - \\
\hline
\end{tabular}


Das 2006 (Continued)

Duration: not stated

\begin{tabular}{|c|c|}
\hline Participants & $\begin{array}{l}\text { Inclusion criteria } \\
\text { - At least } 2 \text { years of age } \\
\text { - Scabies (microscopic and clinical confirmation) } \\
\text { Exclusion criteria } \\
\text { - Pregnant women } \\
\text { Baseline characteristics } \\
\text { - Age: } 3 \text { to } 71 \text { (age } 0 \text { to } 5: 9 \% \text {, age } 6 \text { to } 15: 22 \% \text {, age } 16 \text { to } 30: 22 \% \text {, age } 30 \text { to } 50: 9 \% \text {, age } \geq 51: 7 \% \text {; total } \\
\text { does not equal } 100 \% \text { ) } \\
\text { - Males/females: } 140 / 60\end{array}$ \\
\hline Interventions & $\begin{array}{l}\text { A: Permethrin } 5 \% \text { cream overnight, single application from neck to toes in all family members ( } n=50 \\
\text { participants) } \\
\text { B: Oral ivermectin } 200 \mu \mathrm{g} / \mathrm{kg} \text { body weight } \mathrm{d} 1 \text { and } \mathrm{d} 14 \text { ( } \mathrm{n}=50 \text { participants) } \\
\text { Not included in this review: } \\
\text { C: Gamma benzene hexachloride } 1 \% \text { for } 2 \text { consecutive overnight applications to all family members ( } \mathrm{n} \\
=50 \text { participants) } \\
\text { D: White soft paraffin in a manner similar to group A ( } n=50 \text { participants) }\end{array}$ \\
\hline Outcomes & - "Improvement clinically" (no definition; week 4) \\
\hline Funding source & Quote: "Source of Support: None" \\
\hline Declarations of interest & Quote: "Conflict of Interest: None" \\
\hline Notes & $\begin{array}{l}\text { Location: Kolkata, India } \\
\text { We contacted first author twice via e-mail but did not receive a response. }\end{array}$ \\
\hline
\end{tabular}

\section{Risk of bias}

\begin{tabular}{|c|c|c|}
\hline Bias & Authors' judgement & Support for judgement \\
\hline $\begin{array}{l}\text { Random sequence genera- } \\
\text { tion (selection bias) }\end{array}$ & Unclear risk & Quote: "randomly distributed" \\
\hline $\begin{array}{l}\text { Allocation concealment } \\
\text { (selection bias) }\end{array}$ & Unclear risk & Insufficient information \\
\hline $\begin{array}{l}\text { Blinding of participants } \\
\text { and personnel (perfor- } \\
\text { mance bias) } \\
\text { Efficacy }\end{array}$ & High risk & No information \\
\hline $\begin{array}{l}\text { Blinding of participants } \\
\text { and personnel (perfor- } \\
\text { mance bias) } \\
\text { Safety }\end{array}$ & High risk & No information \\
\hline $\begin{array}{l}\text { Blinding of outcome as- } \\
\text { sessment (detection bias) }\end{array}$ & High risk & No information \\
\hline
\end{tabular}


Das 2006 (Continued)

Efficacy

\begin{tabular}{lll}
\hline $\begin{array}{l}\text { Blinding of outcome as- } \\
\text { sessment (detection bias) } \\
\text { Safety }\end{array}$ & High risk & No information \\
\hline $\begin{array}{l}\text { Incomplete outcome data } \\
\text { (attrition bias) } \\
\text { Efficacy }\end{array}$ & High risk & Percentage of "improved clinically" reported, no definition. \\
\hline $\begin{array}{l}\text { Incomplete outcome data } \\
\text { (attrition bias) }\end{array}$ & Unclear risk & Quote: "We however did not experience any adverse effect in all four groups." \\
$\begin{array}{l}\text { Safety } \\
\text { Selective reporting (re- }\end{array}$ & Unclear risk & Unclear number of evaluated completers \\
\hline porting bias) & & Insufficient information \\
\hline \begin{tabular}{l} 
Other bias \\
\hline
\end{tabular} & Unclear risk & - \\
\hline
\end{tabular}

Macotela-Ruiz 1996

\begin{tabular}{ll}
\hline Methods & Single-centre, parallel-group randomized trial \\
& Duration: 3 years, from January 1993 to December 1995 \\
\hline
\end{tabular}

\section{Participants}

\section{Inclusion criteria}

- Scabies (indisputable, no information about methods of diagnosing scabies)

- No age limit

\section{Exclusion criteria}

- Pregnant or lactating women

- People with renal or hepatic insufficiency

- People with antiscabietic treatment in 6 weeks prior to study

\section{Baseline characteristics}

- Age (mean): group A: male: 12, female: 16; B: male: 18, female: 20

- Males/females: group A: 56/96, B: 53/32; unclear data, sum of males and females does not correspond to total number of included participants

\begin{tabular}{|c|c|}
\hline Interventions & $\begin{array}{l}\text { A: Oral ivermectin } 250 \mu \mathrm{g} / \mathrm{kg} \text { body weight on day } 1 \text { ( } \mathrm{n}=152 \text { participants) } \\
\text { B: Oral ivermectin } 250 \mu \mathrm{g} / \mathrm{kg} \text { body weight on day } 1,3 \text {, and } 10 \text { ( } \mathrm{n}=121 \text { participants) } \\
\text { - } 9 \text { participants in group A and } 10 \text { participants in group B with secondary infection received dicloxacillin } \\
75 \mathrm{mg} / \mathrm{kg} \text { body weight per day. } \\
\text { - } 95 \text { healthy contacts received an oral single dose of } 250 \mu \mathrm{g} / \mathrm{kg} \text { body weight ivermectin. }\end{array}$ \\
\hline Outcomes & - Cure (considerable improvement of dermatosis, no pruritus, no new lesions; up to 45 days) \\
\hline Funding source & Not stated \\
\hline Declarations of interest & Not stated \\
\hline Notes & Location: Santiago Yancuitlalpan, Mexico \\
\hline
\end{tabular}


Macotela-Ruiz 1996 (Continued)

Risk of bias

\begin{tabular}{|c|c|c|}
\hline Bias & Authors' judgement & Support for judgement \\
\hline $\begin{array}{l}\text { Random sequence genera- } \\
\text { tion (selection bias) }\end{array}$ & Unclear risk & Quote (page 179): "patients were randomized in two groups" \\
\hline $\begin{array}{l}\text { Allocation concealment } \\
\text { (selection bias) }\end{array}$ & Unclear risk & Insufficient information \\
\hline $\begin{array}{l}\text { Blinding of participants } \\
\text { and personnel (perfor- } \\
\text { mance bias) } \\
\text { Efficacy }\end{array}$ & High risk & $\begin{array}{l}\text { Quote (page 179): "An open therapeutic study" } \\
\text { Not blinded }\end{array}$ \\
\hline $\begin{array}{l}\text { Blinding of participants } \\
\text { and personnel (perfor- } \\
\text { mance bias) } \\
\text { Safety }\end{array}$ & High risk & $\begin{array}{l}\text { Quote (page 179): "An open therapeutic study" } \\
\text { Not blinded }\end{array}$ \\
\hline $\begin{array}{l}\text { Blinding of outcome as- } \\
\text { sessment (detection bias) } \\
\text { Efficacy }\end{array}$ & High risk & $\begin{array}{l}\text { Quote (page 179): "An open therapeutic study" } \\
\text { Not blinded }\end{array}$ \\
\hline $\begin{array}{l}\text { Blinding of outcome as- } \\
\text { sessment (detection bias) } \\
\text { Safety }\end{array}$ & High risk & $\begin{array}{l}\text { Quote (page 179): "An open therapeutic study" } \\
\text { Not blinded }\end{array}$ \\
\hline $\begin{array}{l}\text { Incomplete outcome data } \\
\text { (attrition bias) } \\
\text { Efficacy }\end{array}$ & High risk & $\begin{array}{l}\text { No information on dropouts, unclear time point of evaluation, no absolute } \\
\text { numbers }\end{array}$ \\
\hline $\begin{array}{l}\text { Incomplete outcome data } \\
\text { (attrition bias) } \\
\text { Safety }\end{array}$ & High risk & $\begin{array}{l}\text { No information on dropouts, unclear time point of evaluation, no absolute } \\
\text { numbers }\end{array}$ \\
\hline $\begin{array}{l}\text { Selective reporting (re- } \\
\text { porting bias) }\end{array}$ & High risk & $\begin{array}{l}\text { No data on defined outcomes such as pruritus, papules, excoriation, crusts, } \\
\text { etc. }\end{array}$ \\
\hline Other bias & Unclear risk & - \\
\hline
\end{tabular}

Manjhi 2014

\begin{tabular}{ll}
\hline Methods & Single-centre, parallel-group randomized trial \\
& Duration: 1 year, from April 2011 to March 2012 \\
\hline
\end{tabular}

Participants

\section{Inclusion criteria}

- Age above 5 and below 60 years

- People of both sexes

- People willing to receive either topical or oral therapy

- People willing to follow-up at 1 st and 6 th week or if any complaints in between

- Scabies (no information about methods of diagnosing)

\section{Exclusion criteria}


Manjhi 2014 (Continued)

- Pregnant and lactating women

- People who were not willing to come for follow-up

- Any serious systemic illness

\section{Baseline characteristics}

- Not stated

A: Oral ivermectin $200 \mu \mathrm{g} / \mathrm{kg}$ body weight, single dose $(\mathrm{n}=60$ participants)
B: Permethrin $5 \%$ cream, single application below the jaw line after scrub bath and left overnight ( $\mathrm{n}=$
60 participants)
Not included in this review:
C: Gamma benzene hexachloride $1 \%$ lotion, single application ( $\mathrm{n}=60$ participants)
D: Benzyl benzoate $25 \%$ lotion, single application ( $\mathrm{n}=60$ participants)

Outcomes

- Complete improvement based on severity of pruritus or lesions (lesion count: < 10 - mild, 11 to 49 moderate, > 50 - severe; pruritus: 10-centimetre visual analogue scale: 0 - no pruritus, 1 to 3 - mild, 4 to 6 - moderate, 7 to 10 - severe; week 1 and 6)

- Number of participants withdrawn from study due to adverse event

\begin{tabular}{ll}
\hline Funding source & Not stated \\
\hline Declarations of interest & Not stated \\
\hline Notes & Location: Patna, India \\
& Children "below 5y" were excluded; unclear if children of 5 years of age were included or excluded. \\
& We contacted first author twice via e-mail but did not receive a response.
\end{tabular}

\section{Risk of bias}

\begin{tabular}{lll}
\hline Bias & Authors' judgement & Support for judgement \\
\hline $\begin{array}{l}\text { Random sequence genera- } \\
\text { tion (selection bias) }\end{array}$ & Unclear risk & Quote (page 1): "simple random sampling" \\
& & Insufficient information \\
\hline $\begin{array}{l}\text { Allocation concealment } \\
\text { (selection bias) }\end{array}$ & Unclear risk & Quote (page 2): "randomly allocated" \\
\hline $\begin{array}{l}\text { Blinding of participants } \\
\text { and personnel (perfor- } \\
\text { mance bias) } \\
\text { Efficacy }\end{array}$ & High risk & Insufficient information \\
\hline $\begin{array}{l}\text { Blinding of participants } \\
\begin{array}{l}\text { and personnel (perfor- } \\
\text { mance bias) }\end{array}\end{array}$ & High risk & \\
$\begin{array}{l}\text { Safety } \\
\text { Blinding of outcome as- } \\
\text { sessment (detection bias) } \\
\text { Efficacy }\end{array}$ & High risk & No information \\
\hline
\end{tabular}


Manjhi 2014 (Continued)

$\begin{array}{lll}\text { Blinding of outcome as- } & \text { High risk } & \text { No information } \\ \text { sessment (detection bias) } & \end{array}$

Safety

$\begin{array}{ll}\begin{array}{l}\text { Incomplete outcome data } \\ \text { (attrition bias) }\end{array} & \text { High risk } \\ \text { Efficacy } & \text { Results are reported for all } 60 \text { randomized participants per treatment group, } \\ & \begin{array}{l}\text { but actual results of the outcomes scales are not reported; clear explanation of } \\ \text { how 'improvement' is reflected in the scales is missing. }\end{array}\end{array}$

\section{Incomplete outcome data High risk} (attrition bias)

Quote (page 1): "The main objective of the study is to know the efficacy and

Safety safety of Oral Ivermectin in comparison to commonly used topical antiscabies drugs $[\ldots] "$

Quote (page 3): "Oral Ivermectin is well tolerated, non irritant to skin, does not show central nervous system side effects because it does not cross blood brain barrier."

No information about safety issues in other treatment groups; no numerical data on safety were reported

\begin{tabular}{lll}
\hline $\begin{array}{l}\text { Selective reporting (re- } \\
\text { porting bias) }\end{array}$ & Unclear risk & Insufficient information \\
\hline Other bias & Unclear risk & No information on baseline data \\
\hline
\end{tabular}

\section{Meenakshi 2014}

\begin{tabular}{ll}
\hline Methods & Single-centre, parallel-group randomized trial \\
& Duration: 10 months, from January to October 2011
\end{tabular}

\section{Participants}

\section{Inclusion criteria}

- Age was at least 12 years

- Newly diagnosed scabies: made on basis of history and clinical examination; presence of diffuse itching and visible lesions associated either with $\geq 2$ typical locations of scabies (interdigital folds, flexor aspect of wrist and elbow, genitals, anterior axillary folds) or with a household member with itching

\section{Exclusion criteria}

- Pregnant or lactating females

- Any history of diabetes, hypertension, or any chronic disease

- Any psychiatric illness or neurological disorder, any other associated skin disease which can affect the study due to same presentation like atopic dermatitis, dyshidrotic eczema, insect bite reaction, etc.

\section{Baseline characteristics}

- Age (mean): group A: 23.55, B: 27.74, C: 28.89

- Males/females: group A: 49/21, B: 41/29, C: 51/19

Interventions A: Permethrin $5 \%$ cream on day 1 and 7 , applied over whole body below neck and scrub bath taken 12 hours later ( $\mathrm{n}=70$ participants)

B: Oral ivermectin $200 \mu \mathrm{g} / \mathrm{kg}$ body weight on day 1 and 7 , applied any time of day ( $\mathrm{n}=70$ participants)

Not included in this review: 
C: Gamma benzene hexachloride $1 \%$ lotion on day 1 and 7 applied over whole body below neck and scrub bath taken 12 hours later ( $\mathrm{n}=70$ participants)

- Participants of group $\mathrm{A}$ and $\mathrm{C}$ were instructed to take warm-water bath before application of medicine and then after application of medicine next morning.

- They were advised about also treating the family members and prevention of transmission by washing all clothes and bedding that came in contact.

\section{Outcomes}

- Complete clinical cure (week 1 and 3; reduction in clinical grading score (up to grade 0 or 1 ) and itching grading score (up to grade 0,1 , or 2 ); "moderate or good improvement"):

- Clinical grading score: scale of 0 to 3: $0=$ free of lesions (no lesions), $1=10$ or fewer lesions (mild), $2=11$ to 49 lesions (moderate), $3=50$ or more lesions (severe)

- Itching grading score: participant was asked for reduction in pruritus, grading was done on given scale by the observer: scale of 0 to $4: 0=0 \%$ (no pruritus), $1=1 \%$ to $25 \%$ (mild pruritus), $2=26 \%$ to $50 \%$ (moderate pruritus), $3=51 \%$ to $75 \%$ (severe pruritus), $4=76 \%$ to $100 \%$ (very severe pruritus

- Number of participants with $\geq 1$ adverse event

\begin{tabular}{ll}
\hline Funding source & Quote (page 15): "Source of support: Nil" \\
\hline Declarations of interest & Quote (page 15): "Conflict of interest: Nil" \\
\hline Notes & Location: Jhansi, India
\end{tabular}

\section{Risk of bias}

\begin{tabular}{|c|c|c|}
\hline Bias & Authors' judgement & Support for judgement \\
\hline $\begin{array}{l}\text { Random sequence genera- } \\
\text { tion (selection bias) }\end{array}$ & Low risk & Quote (page 16): "randomly on basis of a computer generated random table" \\
\hline $\begin{array}{l}\text { Allocation concealment } \\
\text { (selection bias) }\end{array}$ & Unclear risk & Insufficient information \\
\hline $\begin{array}{l}\text { Blinding of participants } \\
\text { and personnel (perfor- } \\
\text { mance bias) } \\
\text { Efficacy }\end{array}$ & High risk & Quote (page 15): "open label" \\
\hline $\begin{array}{l}\text { Blinding of participants } \\
\text { and personnel (perfor- } \\
\text { mance bias) } \\
\text { Safety }\end{array}$ & High risk & Quote (page 15): "open label" \\
\hline $\begin{array}{l}\text { Blinding of outcome as- } \\
\text { sessment (detection bias) } \\
\text { Efficacy }\end{array}$ & High risk & Quote (page 15): "open label" \\
\hline $\begin{array}{l}\text { Blinding of outcome as- } \\
\text { sessment (detection bias) } \\
\text { Safety }\end{array}$ & High risk & Quote (page 15): "open label" \\
\hline $\begin{array}{l}\text { Incomplete outcome data } \\
\text { (attrition bias) } \\
\text { Efficacy }\end{array}$ & High risk & $\begin{array}{l}\text { 35/210 participants lost to follow-up or non-compliant (permethrin group: } 8 \text {; } \\
\text { oral ivermectin group: } 12 ; \text { GBH group: } 15 \text { ) } \\
\text { Quote (page } 18 \text { and Table 2): "several patients were lost during follow up" } \\
\text { No intention-to-treat analysis performed. }\end{array}$ \\
\hline
\end{tabular}


Meenakshi 2014 (Continued)

Incomplete outcome data High risk 35/210 participants lost to follow-up or non-compliant (permethrin group: 8; (attrition bias)

Safety

Selective reporting (re- High risk
porting bias)

Selective reporting (re- High risk

porting bias)

oral ivermectin group: 12 ; GBH group: 15$)$

Quote (page 18 and Table 2): "several patients were lost during follow up"

Cure (moderate or good improvement) and not cured (no or mild improvement) were defined but not reported.

Assessment of safety was planned, but not reported numerically.

Other bias Unclear risk -

\section{Mushtaq 2010}

\begin{tabular}{ll}
\hline Methods & Single-centre, parallel-group randomized trial \\
Duration: not stated
\end{tabular}

\section{Participants}

\section{Inclusion criteria}

- Aged 2 to 60 years

- Diagnosed as having scabies on history and examination; scraping for mite was performed in cases of doubt

\section{Exclusion criteria}

- Pregnant and lactating females

- Immunocompromised patients

- People having bacterial, fungal, or viral infections of skin

- People receiving any treatment for systemic disorders

- People who received treatment for scabies in last 4 weeks

Baseline characteristics (for completers only)

- Males/females: group A: 24/20, B: 20/22

\begin{tabular}{ll}
\hline Interventions & A: Oral ivermectin $200 \mu \mathrm{g} / \mathrm{kg}$ body weight as a single dose ( $\mathrm{n}=44$ participants completed) \\
B: Permethrin $5 \%$ cream at night on whole body for 12 hours, single application $(\mathrm{n}=42$ participants \\
completed) \\
- 100 participants randomized, number of randomized participants per study group unclear. \\
- Non-responders to first treatment were given second dose at second week in their respective group. \\
\hline Outcomes \\
- Cure of disease (no lesions; week 1,2 , and 4$)$ \\
- Number of participants re-treated (week 2)
\end{tabular}

\begin{tabular}{ll}
\hline Funding source & Not stated \\
\hline Declarations of interest & Not stated \\
\hline
\end{tabular}

Notes

Location: Lahore, Pakistan

Probably baseline differences: page 229: "more patients in the ivermectin group had moderate and severe lesions as compared to permethrin group" 


\section{Risk of bias}

\begin{tabular}{lll}
\hline Bias & Authors' judgement & Support for judgement \\
\hline $\begin{array}{l}\text { Random sequence genera- } \\
\text { tion (selection bias) }\end{array}$ & Low risk & Quote: "divided by using random number table into group A and group B" \\
\hline $\begin{array}{l}\text { Allocation concealment } \\
\text { (selection bias) }\end{array}$ & Unclear risk & Insufficient information \\
\hline $\begin{array}{l}\text { Blinding of participants } \\
\text { and personnel (perfor- } \\
\text { mance bias) }\end{array}$ & High risk & No information \\
$\begin{array}{l}\text { Efficacy } \\
\begin{array}{l}\text { Blinding of participants } \\
\text { and personnel (perfor- } \\
\text { mance bias) }\end{array}\end{array}$ & High risk & \\
Safety & & No information \\
\end{tabular}

\begin{tabular}{|c|c|c|}
\hline $\begin{array}{l}\text { Blinding of outcome as- } \\
\text { sessment (detection bias) } \\
\text { Efficacy }\end{array}$ & High risk & No information \\
\hline $\begin{array}{l}\text { Blinding of outcome as- } \\
\text { sessment (detection bias) } \\
\text { Safety }\end{array}$ & High risk & No information \\
\hline \multirow[t]{2}{*}{$\begin{array}{l}\text { Incomplete outcome data } \\
\text { (attrition bias) } \\
\text { Efficacy }\end{array}$} & High risk & $\begin{array}{l}\text { 14/100 participants lost to follow-up (unclear how many in each group, proba- } \\
\text { bly } 6 \text { in ivermectin group, } 8 \text { in permethrin group) } \\
\text { Quote: "14 participants lost to follow up" }\end{array}$ \\
\hline & & $\begin{array}{l}\text { No intention-to-treat analysis performed; number of randomized participants } \\
\text { per study group unclear. }\end{array}$ \\
\hline
\end{tabular}

\begin{tabular}{|c|c|c|}
\hline \multirow{3}{*}{$\begin{array}{l}\text { Incomplete outcome data } \\
\text { (attrition bias) } \\
\text { Safety }\end{array}$} & High risk & $\begin{array}{l}\text { 14/100 participants lost to follow-up (unclear how many in each group, proba- } \\
\text { bly } 6 \text { in ivermectin group, } 8 \text { in permethrin group) }\end{array}$ \\
\hline & & Quote: "14 participants lost to follow up" \\
\hline & & Unclear number of randomized participants per study group \\
\hline $\begin{array}{l}\text { Selective reporting (re- } \\
\text { porting bias) }\end{array}$ & Unclear risk & Insufficient information \\
\hline \multirow[t]{3}{*}{ Other bias } & High risk & Sex distribution in Table 1 seems to be reversed. \\
\hline & & $\begin{array}{l}\text { Probably baseline differences in severity: "more patients in the ivermectin } \\
\text { group had moderate and severe lesions as compared to permethrin group" }\end{array}$ \\
\hline & & $\begin{array}{l}\text { Inconsistent data for safety (page } 229 \text { and 300): } 8 \text { versus } 7 \text { participants with } \\
\text { adverse events }\end{array}$ \\
\hline
\end{tabular}


Rohatgi 2013

$\begin{array}{ll}\text { Methods } & \text { Single-centre, parallel-group randomized trial } \\ \text { Duration: } 1 \text { year and } 7 \text { months, from November } 2011 \text { to May } 2013\end{array}$

Participants

Inclusion criteria

- Aged 5 to 15 years

- Newly diagnosed with scabies

- Diagnosed by dermatologist: people with severity score 1, 2, or 3 were eligible; assessed by counting the number of lesions and assigning a score: 0 (free of lesions - no scabies), 1 (10 or fewer lesions mild), 2 (11 to 49 lesions - moderate), 3 (50 or more lesions - severe), 4 (crusty - very severe)

- Diagnosis confirmed by microscopic examination of mite in "many patients", by biopsy of the skin lesions in "few patients"

- Body weight $>15 \mathrm{~kg}$

\section{Exclusion criteria}

- Abnormal liver and kidney functions, known thyroid disease, cardiac disorders, nervous system disorders, psychiatric illnesses; people with history of diabetes mellitus, hypertension, or infectious diseases

- Any concurrent medication for other illness

- Any other associated skin disease that could alter the picture of scabies, or complications of scabies like pyoderma

- Known/suspected immunocompromised individuals or parents diagnosed as HIV, having scabies with atypical presentations

- Intake of any antiscabetic treatment in the preceding 4 weeks

- Intake of topical steroid in the previous 4 weeks

- Known hypersensitivity to oral or topical preparations

- People whose family/household members or classmates have scabies at the same time

- Noncompliant people/guardians

\section{Baseline characteristics}

- Males/females: group A: 31/19, group B: 30/20

- Age (mean): group A: 10.5, group B: 9.6

Interventions

A: Permethrin $5 \%$ cream, single application to whole body below neck, left overnight $(n=50$ participants)

B: Oral ivermectin $200 \mu \mathrm{g} / \mathrm{kg}$ body weight as a single dose ( $\mathrm{n}=50$ participants)

- All participants were given antipruritic or antihistaminic medication for pruritus.

- Participants who showed no signs of cure at first follow-up were given same treatment again only once.

- All family contacts received same treatment as the study participant (children $<5$ years of age and pregnant women were treated with $12.5 \%$ to $25 \%$ benzyl benzoate emulsion, supplied free of cost).

Outcomes

- Cure (absence of clinical lesions and no new lesions like papules, vesicles, and classical burrows suggestive of live parasite; week 1, 2, and 4)

- Number of participants re-treated (week 1)

- Number of participants with $\geq 1$ adverse event

Funding source Not stated

Declarations of interest Not stated

Notes

Location: Bangalore, India 
Rohatgi 2013 (Continued)

Abstract available, and first author provided unpublished data (doctoral thesis); not all questions were answered by contact author.

\section{Risk of bias}

\begin{tabular}{|c|c|c|}
\hline Bias & Authors' judgement & Support for judgement \\
\hline $\begin{array}{l}\text { Random sequence genera- } \\
\text { tion (selection bias) }\end{array}$ & Unclear risk & $\begin{array}{l}\text { Quote (doctoral thesis, page 42): "Simple random sampling" } \\
\text { Insufficient information }\end{array}$ \\
\hline $\begin{array}{l}\text { Allocation concealment } \\
\text { (selection bias) }\end{array}$ & Unclear risk & Insufficient information \\
\hline $\begin{array}{l}\text { Blinding of participants } \\
\text { and personnel (perfor- } \\
\text { mance bias) } \\
\text { Efficacy }\end{array}$ & High risk & Quote (abstract): "open labelled" \\
\hline $\begin{array}{l}\text { Blinding of participants } \\
\text { and personnel (perfor- } \\
\text { mance bias) } \\
\text { Safety }\end{array}$ & High risk & Quote (abstract): "open labelled" \\
\hline $\begin{array}{l}\text { Blinding of outcome as- } \\
\text { sessment (detection bias) } \\
\text { Efficacy }\end{array}$ & High risk & Quote (abstract): "open labelled" \\
\hline $\begin{array}{l}\text { Blinding of outcome as- } \\
\text { sessment (detection bias) } \\
\text { Safety }\end{array}$ & High risk & Quote (abstract): "open labelled" \\
\hline $\begin{array}{l}\text { Incomplete outcome data } \\
\text { (attrition bias) } \\
\text { Efficacy }\end{array}$ & Low risk & $\begin{array}{l}\text { 4/100 participants lost to follow-up (permethrin group: } 2 \text {; oral ivermectin } \\
\text { group: } 2 \text { ) } \\
\text { Intention-to-treat analysis performed. }\end{array}$ \\
\hline $\begin{array}{l}\text { Incomplete outcome data } \\
\text { (attrition bias) } \\
\text { Safety }\end{array}$ & Low risk & $\begin{array}{l}\text { 4/100 participants lost to follow-up (permethrin group: } 2 \text {; oral ivermectin } \\
\text { group: } 2 \text { ) }\end{array}$ \\
\hline $\begin{array}{l}\text { Selective reporting (re- } \\
\text { porting bias) }\end{array}$ & Unclear risk & Insufficient information \\
\hline Other bias & High risk & $\begin{array}{l}\text { Inconsistent data for male/female ratio (page 55/56: } 61 \text { males/39 females; } \\
\text { page } 76: 63 \text { males/37 females) } \\
\text { Inconsistent response data in abstract and doctoral thesis; conservative ap- } \\
\text { proach was followed }\end{array}$ \\
\hline
\end{tabular}

Saqib 2012

\begin{tabular}{ll}
\hline Methods & Single-centre, parallel-group randomized trial \\
& Duration: not stated
\end{tabular}


Saqib 2012 (Continued)

- Aged 18 to 60 years

- Confirmed diagnosis of scabies by burrow detection by ink method and microscopic evidence of Sarcoptes scabiei mite in any of its development stage or its faeces

\section{Exclusion criteria}

- Pregnant or lactating women

- Hypersensitivity to permethrin or ivermectin

- Prior use of topical or systemic scabicide in last 4 weeks

- People on radiotherapy, steroids or other immunosuppressive drugs for any systemic or cutaneous indication

- People with any chronic debilitating disorders, neoplasias, with neurological, hepatic, or renal dysfunction

\section{Baseline characteristics}

- Age (mean \pm SD): group A: $31.45 \pm 9.78$, B: $29.45 \pm 9.72$ (data from Table 1$)$

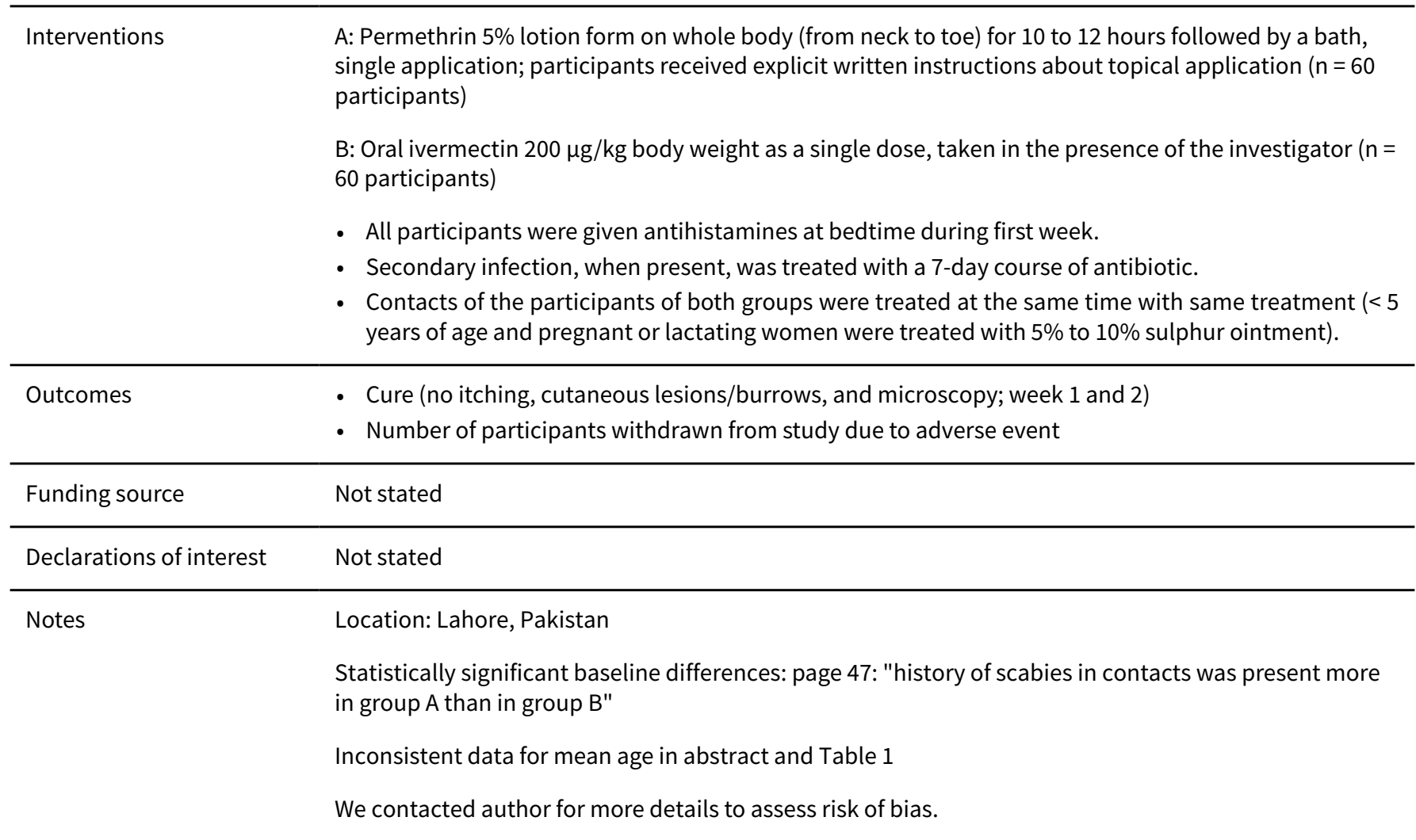

\section{Risk of bias}

\begin{tabular}{lll}
\hline Bias & Authors' judgement & Support for judgement \\
\hline $\begin{array}{l}\text { Random sequence genera- } \\
\text { tion (selection bias) }\end{array}$ & Low risk & $\begin{array}{l}\text { Quote: "randomly divided" } \\
\text { Author confirmed via e-mail: "random number table" }\end{array}$ \\
\hline $\begin{array}{ll}\text { Allocation concealment } \\
\text { (selection bias) }\end{array}$ & Low risk & $\begin{array}{l}\text { Author confirmed via e-mail: "assignment by nurse, treated by physician blind } \\
\text { to assignment" }\end{array}$ \\
\hline $\begin{array}{l}\text { Blinding of participants } \\
\begin{array}{l}\text { and personnel (perfor- } \\
\text { mance bias) }\end{array}\end{array}$ & Low risk & Author confirmed via e-mail: "treated by physician blind to assignment" \\
\hline
\end{tabular}


Saqib 2012 (Continued)

Efficacy

\begin{tabular}{|c|c|c|}
\hline $\begin{array}{l}\text { Blinding of participants } \\
\text { and personnel (perfor- } \\
\text { mance bias) } \\
\text { Safety }\end{array}$ & High risk & Probably not blinded \\
\hline $\begin{array}{l}\text { Blinding of outcome as- } \\
\text { sessment (detection bias) } \\
\text { Efficacy }\end{array}$ & Low risk & Author confirmed via e-mail: "treated by physician blind to assignment" \\
\hline $\begin{array}{l}\text { Blinding of outcome as- } \\
\text { sessment (detection bias) } \\
\text { Safety }\end{array}$ & High risk & Probably not blinded \\
\hline $\begin{array}{l}\text { Incomplete outcome data } \\
\text { (attrition bias) } \\
\text { Efficacy }\end{array}$ & Low risk & Quote: "All 120 patients completed the study." \\
\hline $\begin{array}{l}\text { Incomplete outcome data } \\
\text { (attrition bias) } \\
\text { Safety }\end{array}$ & Low risk & Quote: "All 120 patients completed the study." \\
\hline $\begin{array}{l}\text { Selective reporting (re- } \\
\text { porting bias) }\end{array}$ & Unclear risk & Insufficient information \\
\hline Other bias & High risk & $\begin{array}{l}\text { Inconsistent data for mean age in abstract and Table } 1 \\
\text { Statistically significant baseline differences: page } 47 \text { : "history of scabies in } \\
\text { contacts was present more in group A than in group B" }\end{array}$ \\
\hline
\end{tabular}

Sharma 2011

Methods Single-centre, parallel-group randomized trial

Duration: 1 year and 4 months, from December 2006 to March 2008

Participants

\section{Inclusion criteria}

- Age over 5 years and/or $>15 \mathrm{~kg}$

- Clinically diagnosed scabies: demonstration of eggs, larva, mites/mite products, or faecal pellets by light microscopy in the scrapings from multiple representative or suspected skin lesions in $10 \%$ potassium hydroxide and/or the presence of $\geq 3$ of the following clinical criteria: demonstration of burrow; presence of scabetic lesions at the classical sites; nocturnal pruritus; family history of similar illness

\section{Exclusion criteria}

- Pregnant and lactating women

- People with immunodeficiency or severe systemic disease or with heavily crusted or nodular lesions, secondary infection or eczematization and coexisting dermatological disease that could interfere with the diagnosis and subsequent monitoring of scabies

- Antiscabetic or topical steroid in the previous 4 weeks

- Known hypersensitivity to the trial drugs

Baseline characteristics

- Age (mean \pm SD): group A: $21.38 \pm 13.17$, B: $23.40 \pm 11.03$, C: $23.53 \pm 12.73$ 
Sharma 2011 (Continued)

- Males/females: group A: 19/21, B: 29/11, C: 24/16

Interventions $\quad$ A: Permethrin $5 \%$ cream, self applied on day 1 and placebo tablets of vitamin B-complex on day 1 and 15 ( $n=40$ participants)

B: Placebo cream, self applied on day 1 and oral ivermectin $200 \mu \mathrm{g} / \mathrm{kg}$ body weight on day 1 and placebo tablet of vitamin B-complex on day 15 ( $n=40$ participants)

C: Placebo cream, self applied on day 1 and oral ivermectin $200 \mu \mathrm{g} / \mathrm{kg}$ body weight on day 1 and $15(\mathrm{n}=$ 40 participants)

- Participants were instructed to apply the medication all over the body below the neck at night.

- All family contacts were provided with permethrin $5 \%$ cream for single overnight application, free of cost.

\section{Outcomes}

Complete clinical cure (defined as reduction in both the number of lesions as well as the grade of pruritus by more than or equal to $50 \%$ (that is, moderate and good improvement) and negative microscopy; week 1, 2, and 4)

- Number of participants with $\geq 1$ adverse event (data for group B and C combined)

\begin{tabular}{ll}
\hline Funding source & Not stated \\
\hline Declarations of interest & Not stated \\
\hline Notes & Location: New Delhi, India \\
\hline
\end{tabular}

\section{Risk of bias}

\begin{tabular}{|c|c|c|}
\hline Bias & Authors' judgement & Support for judgement \\
\hline $\begin{array}{l}\text { Random sequence genera- } \\
\text { tion (selection bias) }\end{array}$ & Low risk & Quote: "computer-generated random numbers" \\
\hline $\begin{array}{l}\text { Allocation concealment } \\
\text { (selection bias) }\end{array}$ & Low risk & $\begin{array}{l}\text { Quote: "dispensed by a trained staff nurse in identical pre-coded and num- } \\
\text { bered container" }\end{array}$ \\
\hline $\begin{array}{l}\text { Blinding of participants } \\
\text { and personnel (perfor- } \\
\text { mance bias) } \\
\text { Efficacy }\end{array}$ & Low risk & $\begin{array}{l}\text { Quote: "placebos were similar to the trial drugs in color, shape, size, and con- } \\
\text { sistency and were dispensed by a trained staff nurse in identical pre-coded and } \\
\text { numbered container" }\end{array}$ \\
\hline $\begin{array}{l}\text { Blinding of participants } \\
\text { and personnel (perfor- } \\
\text { mance bias) } \\
\text { Safety }\end{array}$ & Low risk & $\begin{array}{l}\text { Quote: "placebos were similar to the trial drugs in color, shape, size, and con- } \\
\text { sistency and were dispensed by a trained staff nurse in identical pre-coded and } \\
\text { numbered container" }\end{array}$ \\
\hline $\begin{array}{l}\text { Blinding of outcome as- } \\
\text { sessment (detection bias) } \\
\text { Efficacy }\end{array}$ & Low risk & $\begin{array}{l}\text { Quote: "neither the investigator nor the patients were aware of the composi- } \\
\text { tion of drugs allocated and the code was revealed only after the completion of } \\
\text { the study" }\end{array}$ \\
\hline $\begin{array}{l}\text { Blinding of outcome as- } \\
\text { sessment (detection bias) } \\
\text { Safety }\end{array}$ & Low risk & $\begin{array}{l}\text { Quote: "neither the investigator nor the patients were aware of the composi- } \\
\text { tion of drugs allocated and the code was revealed only after the completion of } \\
\text { the study" }\end{array}$ \\
\hline $\begin{array}{l}\text { Incomplete outcome data } \\
\text { (attrition bias) } \\
\text { Efficacy }\end{array}$ & Low risk & $\begin{array}{l}\text { 3/120 participants lost to follow-up (permethrin group: } 2 \text {; oral ivermectin - } 2 \\
\text { doses group: } 1 \text { ) } \\
\text { No withdrawal at } 1 \text { week follow-up; no intention-to-treat analysis for week } 2 \\
\text { and } 4\end{array}$ \\
\hline
\end{tabular}


Sharma 2011 (Continued)

Incomplete outcome data Unclear risk 3/120 participants lost to follow-up (permethrin group: 2; oral ivermectin - 2 (attrition bias) doses group: 1 )

Safety

Number of adverse events reported for ivermectin groups were combined.

\begin{tabular}{lll}
\hline $\begin{array}{l}\text { Selective reporting (re- } \\
\text { porting bias) }\end{array}$ & Unclear risk & Insufficient information \\
\hline Other bias & Unclear risk & -
\end{tabular}

Usha 2000

$\begin{array}{ll}\text { Methods } & \text { Single-centre, parallel-group randomized trial } \\ & \text { Duration: } 1 \text { year and } 5 \text { months, from August } 1996 \text { to December } 1997\end{array}$

Inclusion criteria
Participants
- $\begin{aligned} & \text { Scabies: diagnosed by the demonstration of eggs, larva, mites, or faecal pellets by light microscopy } \\ & \text { or by the presence of } \geq 3 \text { of the following clinical criteria confirmed independently by } 2 \text { consultants: } \\ & \text { demonstration of burrow, presence of scabietic lesions at the classical sites, nocturnal pruritus, family } \\ & \text { history of similar illness }\end{aligned}$

\section{Exclusion criteria}

- Pregnant and lactating women

- Any antiscabietic treatment in the previous month

- People with serious central nervous system, hepatic, cardiac, or renal disease

\section{Baseline characteristics}

- Age (mean \pm SD): group A: $21.28 \pm 13.44$, B: $22.4 \pm 12.6$

- Males/females: group A: 26/14, B: 33/12

B: Permethrin 5\% cream, single application overnight ( $n=45$ participants)

- All participants received standard instructions (about the mode of application, general measures, importance of treating the family contacts, prevention of fomite transmission).

- Participants with treatment failure (no improvement in pruritus and skin lesions, appearance of new lesions, or presence of mites or their products on microscopy) at week 2 received another dose of same treatment; at week 4 cross-over to other group.

- Secondary infection was treated with a 7-day course of erythromycin $250 \mathrm{mg} 4$ times daily.

- All family contacts received same treatment as the study participant (children $<5$ years of age and pregnant women were treated with $12.5 \%$ to $25 \%$ benzyl benzoate emulsion).

- Complete clearance (good improvement; week $1,2,4$, and 8)
- Number of participants re-treated (week 2 and 4 )
- Number of participants with $\geq 1$ adverse event
- Number of participants withdrawn from study due to adverse event

Funding source Not stated


Usha 2000 (Continued)
Notes
Location: Trivandrum, India

\section{Risk of bias}

\begin{tabular}{|c|c|c|}
\hline Bias & Authors' judgement & Support for judgement \\
\hline $\begin{array}{l}\text { Random sequence genera- } \\
\text { tion (selection bias) }\end{array}$ & Unclear risk & $\begin{array}{l}\text { Quote (page 237): "randomly allocated" } \\
\text { Insufficient information }\end{array}$ \\
\hline $\begin{array}{l}\text { Allocation concealment } \\
\text { (selection bias) }\end{array}$ & Unclear risk & $\begin{array}{l}\text { Quote (page 237): "randomly allocated" } \\
\text { Insufficient information }\end{array}$ \\
\hline $\begin{array}{l}\text { Blinding of participants } \\
\text { and personnel (perfor- } \\
\text { mance bias) } \\
\text { Efficacy }\end{array}$ & High risk & No information \\
\hline $\begin{array}{l}\text { Blinding of participants } \\
\text { and personnel (perfor- } \\
\text { mance bias) } \\
\text { Safety }\end{array}$ & High risk & No information \\
\hline $\begin{array}{l}\text { Blinding of outcome as- } \\
\text { sessment (detection bias) } \\
\text { Efficacy }\end{array}$ & High risk & No information \\
\hline $\begin{array}{l}\text { Blinding of outcome as- } \\
\text { sessment (detection bias) } \\
\text { Safety }\end{array}$ & High risk & No information \\
\hline $\begin{array}{l}\text { Incomplete outcome data } \\
\text { (attrition bias) } \\
\text { Efficacy }\end{array}$ & Low risk & No missing outcome data \\
\hline $\begin{array}{l}\text { Incomplete outcome data } \\
\text { (attrition bias) } \\
\text { Safety }\end{array}$ & Low risk & No missing outcome data \\
\hline $\begin{array}{l}\text { Selective reporting (re- } \\
\text { porting bias) }\end{array}$ & Unclear risk & Insufficient information \\
\hline Other bias & Unclear risk & $\begin{array}{l}\text { Data for 'complete clearance' reported in figure only; numerical data were ex- } \\
\text { tracted from chart for meta-analysis. }\end{array}$ \\
\hline
\end{tabular}

Wankhade 2013

\begin{tabular}{ll}
\hline Methods & Single-centre, parallel-group randomized trial \\
& Duration: not stated
\end{tabular}

Participants

\section{Inclusion criteria}

- People with scabies

\section{Exclusion criteria}

Ivermectin and permethrin for treating scabies (Review) 
Wankhade 2013 (Continued)

\section{- Not stated \\ Baseline characteristics}

- Not stated

\begin{tabular}{ll}
\hline Interventions & A: Permethrin $5 \%$ (type of formulation not stated; $\mathrm{n}=$ unclear) \\
& B: Oral ivermectin $200 \mu \mathrm{g} / \mathrm{kg}$ body weight as a single dose ( $\mathrm{n}=$ unclear) \\
& $\begin{array}{l}\text { - } 100 \text { participants were allocated. } \\
\text { If there was no sign of cure, same treatment was repeated. }\end{array}$ \\
\hline Outcomes & Cure rate (no definition; time point of evaluation unclear) \\
\hline Funding source & Not stated \\
\hline Notes & Lot stated \\
\hline & Only abstract available \\
& We contacted first author twice via e-mail but did not receive a response. \\
\hline
\end{tabular}

\section{Risk of bias}

\begin{tabular}{|c|c|c|}
\hline Bias & Authors' judgement & Support for judgement \\
\hline $\begin{array}{l}\text { Random sequence genera- } \\
\text { tion (selection bias) }\end{array}$ & Unclear risk & $\begin{array}{l}\text { Quote: "randomely allocated" } \\
\text { Insufficient information }\end{array}$ \\
\hline $\begin{array}{l}\text { Allocation concealment } \\
\text { (selection bias) }\end{array}$ & Unclear risk & $\begin{array}{l}\text { Quote: "randomely allocated" } \\
\text { Insufficient information }\end{array}$ \\
\hline $\begin{array}{l}\text { Blinding of participants } \\
\text { and personnel (perfor- } \\
\text { mance bias) } \\
\text { Efficacy }\end{array}$ & High risk & No information \\
\hline $\begin{array}{l}\text { Blinding of participants } \\
\text { and personnel (perfor- } \\
\text { mance bias) } \\
\text { Safety }\end{array}$ & High risk & No information \\
\hline $\begin{array}{l}\text { Blinding of outcome as- } \\
\text { sessment (detection bias) } \\
\text { Efficacy }\end{array}$ & High risk & No information \\
\hline $\begin{array}{l}\text { Blinding of outcome as- } \\
\text { sessment (detection bias) } \\
\text { Safety }\end{array}$ & High risk & No information \\
\hline $\begin{array}{l}\text { Incomplete outcome data } \\
\text { (attrition bias) } \\
\text { Efficacy }\end{array}$ & High risk & No numerical data given. \\
\hline
\end{tabular}


Wankhade 2013 (Continued)

Incomplete outcome data High risk No numerical data given. (attrition bias)

Safety

Selective reporting (re- Unclear risk Insufficient information
porting bias)

Other bias Unclear risk -

Wankhade 2016

$\begin{array}{ll}\text { Methods } & \text { Single-centre, parallel-group randomized trial } \\ \text { Duration: } 1 \text { year and } 1 \text { month, from March } 2013 \text { to March } 2014\end{array}$

Inclusion criteria
- Age between 5 to 60 years
- New patients of scabies as diagnosed by dermatologist
- History of involvement of family member or similar symptoms in contacts
- Presence of nocturnal itching
- For those whose microscopic examination was negative, inclusion in study was based on clinical cri-
Exclusion criteria
- Pregnant and lactating women
- People with any other associated skin disease that could alter the picture of scabies, or complications
- of scabies like pyoderma
- History of topical steroid use in the previous 4 weeks or use of topical or systemic antibiotic therapy
- in the week before entry into the study
- Received any antiscabetic treatment in the past 4 weeks
- People not willing to come for follow-up
- People having scabies with atypical presentation like crusted scabies or scabies incognito
- History of allergy to any of the study drugs

\section{Baseline characteristics}

- Age (mean \pm SD): group A: $16.74 \pm 9.90, B: 22.04 \pm 10.61$, C: $23.74 \pm 9.91$

- Males/females: group A: 30/20, B: 28/22, C: 29/21
A: Permethrin 5\% cream, single application ( $n=50$ participants)
B: Oral ivermectin $200 \mu \mathrm{g} / \mathrm{kg}$ body weight, single application ( $\mathrm{n}=50$ participants)

Not included in this review:

C: Combination of topical permethrin with oral ivermectin ( $n=50$ participants)

- If there were no signs of cure, the same intervention was repeated at the end of week 1 only once.

Outcomes

- Cure (no new clinical lesions and improvement in pruritus, no new lesions like papules, vesicles, and classical burrows suggestive of live parasite should be seen; week 1 and 4) 
Wankhade 2016 (Continued)

- Number of participants with $\geq 1$ adverse event

- Number of participants withdrawn due to adverse event

\begin{tabular}{ll}
\hline Funding source & Quote (page 71): "Funding: None" \\
\hline Declarations of interest & Quote (page 71): "Conflict of interest: None declared" \\
\hline Notes & Location: Nanded, India \\
\hline
\end{tabular}

\section{Risk of bias}

\begin{tabular}{|c|c|c|}
\hline Bias & Authors' judgement & Support for judgement \\
\hline $\begin{array}{l}\text { Random sequence genera- } \\
\text { tion (selection bias) }\end{array}$ & Unclear risk & $\begin{array}{l}\text { Quote (page 68): "randomised" } \\
\text { Insufficient information }\end{array}$ \\
\hline $\begin{array}{l}\text { Allocation concealment } \\
\text { (selection bias) }\end{array}$ & Unclear risk & $\begin{array}{l}\text { Quote (page 69): "randomly allocated" } \\
\text { Insufficient information }\end{array}$ \\
\hline $\begin{array}{l}\text { Blinding of participants } \\
\text { and personnel (perfor- } \\
\text { mance bias) } \\
\text { Efficacy }\end{array}$ & High risk & Quote (page 68): "open-label" \\
\hline $\begin{array}{l}\text { Blinding of participants } \\
\text { and personnel (perfor- } \\
\text { mance bias) } \\
\text { Safety }\end{array}$ & High risk & Quote (page 68): "open-label" \\
\hline $\begin{array}{l}\text { Blinding of outcome as- } \\
\text { sessment (detection bias) } \\
\text { Efficacy }\end{array}$ & High risk & Quote (page 68): "open-label" \\
\hline $\begin{array}{l}\text { Blinding of outcome as- } \\
\text { sessment (detection bias) } \\
\text { Safety }\end{array}$ & High risk & Quote (page 68): "open-label" \\
\hline $\begin{array}{l}\text { Incomplete outcome data } \\
\text { (attrition bias) } \\
\text { Efficacy }\end{array}$ & Low risk & No missing outcome data \\
\hline $\begin{array}{l}\text { Incomplete outcome data } \\
\text { (attrition bias) } \\
\text { Safety }\end{array}$ & Low risk & No missing outcome data \\
\hline $\begin{array}{l}\text { Selective reporting (re- } \\
\text { porting bias) }\end{array}$ & Unclear risk & Insufficient information \\
\hline Other bias & Unclear risk & - \\
\hline
\end{tabular}

Abbreviations: GBH: gamma benzene hexachloride; SD: standard deviation.

Characteristics of excluded studies [ordered by study ID] 


\begin{tabular}{ll}
\hline Study & Reason for exclusion \\
\hline Chhaiya 2013 & No original data, same study population as in Chhaiya 2012 \\
\hline Goldust 2012 & $\begin{array}{l}\text { Suspicion of flawed data } \\
\text { Issue was presented and discussed at the annual meeting of the Cochrane Skin Group on 9-10 Jan- } \\
\text { uary } 2017 \text { in Berlin: unanimous decision to exclude the study. }\end{array}$ \\
\hline Goldust 2013 & $\begin{array}{l}\text { Suspicion of flawed data } \\
\text { Issue was presented and discussed at the annual meeting of the Cochrane Skin Group on 9-10 Jan- } \\
\text { uary } 2017 \text { in Berlin: unanimous decision to exclude the study. }\end{array}$ \\
\hline NCT02841215 & $\begin{array}{l}\text { Study of people with crusted scabies; not yet open for participant recruitment } \\
\text { Ranjkesh } 2013\end{array} \begin{array}{l}\text { Suspicion of flawed data } \\
\text { Issue was presented and discussed at the annual meeting of the Cochrane Skin Group on 9-10 Jan- } \\
\text { uary } 2017 \text { in Berlin: unanimous decision to exclude the study. }\end{array}$
\end{tabular}

Characteristics of ongoing studies [ordered by study ID]

\section{NCT02407782}

Trial name or title

Oral Ivermectin Versus Topical Permethrin to Treat Scabies in Children (SCRATCH)

\begin{tabular}{ll}
\hline Methods & Multicentre, randomized trial \\
& Duration: 1 year and 9 months, from January 2016 to September 2017 (estimated) \\
\hline Participants & Inclusion criteria \\
- Children up to 16 years of age \\
- Weight $>15 \mathrm{~kg}$ \\
Exclusion criteria \\
- Previous scabies therapy during the past 4 weeks \\
- Known allergy to ivermectin or permethrin \\
- Widespread eczematization or impetiginization \\
- Liver and renal failure
\end{tabular}

A: Permethrin $5 \%$ cream on day 1 and 10

B: Oral ivermectin $200 \mu \mathrm{g} / \mathrm{kg}$ body weight on day 1 and 10

- Estimated enrolment: 502 participants

\begin{tabular}{ll}
\hline Starting date & January 2016 \\
\hline Contact information & $\begin{array}{l}\text { Franck BORALEVI, Professor } 0556795941 \text { franck.boralevi@chu-bordeaux.fr } \\
\text { Fabienne NACKA, PhD } 0557820108 \text { fabienne.nacka@chu-bordeaux.fr }\end{array}$ \\
\hline Study ID & $\begin{array}{l}\text { Clinical trial registry: NCT02407782 } \\
\text { Other study ID number: CHUBX 2011/16 }\end{array}$ \\
\hline Notes & Location: Bordeaux, France \\
\hline
\end{tabular}


DATA AND ANALYSES

Comparison 1. Ivermectin $200 \mu \mathrm{g} / \mathrm{kg}$ ( 1 to 3 doses) versus permethrin $5 \%$ cream ( 1 to 3 applications)

\begin{tabular}{|c|c|c|c|c|}
\hline Outcome or subgroup title & No. of studies & $\begin{array}{l}\text { No. of partici- } \\
\text { pants }\end{array}$ & Statistical method & Effect size \\
\hline 1 Complete clearance - week 1 & 6 & 613 & $\begin{array}{l}\text { Risk Ratio (M-H, Random, } \\
95 \% \mathrm{Cl})\end{array}$ & $0.65[0.54,0.78]$ \\
\hline 2 Complete clearance - week 2 & 5 & 459 & $\begin{array}{l}\text { Risk Ratio (M-H, Random, } \\
95 \% \mathrm{Cl})\end{array}$ & $0.91[0.76,1.08]$ \\
\hline 3 Complete clearance - week 4 & 6 & & $\begin{array}{l}\text { Risk Ratio (M-H, Random, } \\
95 \% \mathrm{Cl})\end{array}$ & Subtotals only \\
\hline 3.1 IVER 1 dose versus PER 1 application & 1 & 80 & $\begin{array}{l}\text { Risk Ratio (M-H, Random, } \\
95 \% \mathrm{Cl})\end{array}$ & $1.0[0.86,1.16]$ \\
\hline $\begin{array}{l}3.2 \text { IVER } 1 \text { to } 3 \text { doses versus PER } 1 \text { to } 3 \\
\text { applications }\end{array}$ & 5 & 581 & $\begin{array}{l}\text { Risk Ratio (M-H, Random, } \\
95 \% \mathrm{Cl})\end{array}$ & $0.92[0.82,1.03]$ \\
\hline $\begin{array}{l}\text { 3.3 IVER } 2 \text { doses versus PER } 1 \text { applica- } \\
\text { tion }\end{array}$ & 1 & 80 & $\begin{array}{l}\text { Risk Ratio (M-H, Random, } \\
95 \% \mathrm{Cl})\end{array}$ & $0.97[0.83,1.14]$ \\
\hline $\begin{array}{l}4 \text { Subgroup analysis for } 1.3 .2 \text { - complete } \\
\text { clearance - week } 4\end{array}$ & 5 & & $\begin{array}{l}\text { Risk Ratio (M-H, Random, } \\
95 \% \mathrm{Cl})\end{array}$ & Subtotals only \\
\hline $\begin{array}{l}\text { 4.1 IVER } 1 \text { to } 3 \text { doses versus PER } 1 \text { to } 3 \\
\text { applications - } 5 \text { studies }\end{array}$ & 5 & 581 & $\begin{array}{l}\text { Risk Ratio (M-H, Random, } \\
95 \% \mathrm{Cl})\end{array}$ & $0.92[0.82,1.03]$ \\
\hline $\begin{array}{l}\text { 4.2 IVER } 1 \text { to } 3 \text { doses versus PER } 1 \text { to } 3 \\
\text { applications - } 3 \text { studies }\end{array}$ & 3 & 410 & $\begin{array}{l}\text { Risk Ratio (M-H, Random, } \\
95 \% \mathrm{Cl})\end{array}$ & $0.98[0.91,1.06]$ \\
\hline $\begin{array}{l}5 \text { Number of participants with } \geq 1 \text { ad- } \\
\text { verse event - week } 2\end{array}$ & 1 & 55 & $\begin{array}{l}\text { Risk Ratio (M-H, Random, } \\
95 \% \mathrm{Cl})\end{array}$ & $0.0[0.0,0.0]$ \\
\hline $\begin{array}{l}6 \text { Number of participants with } \geq 1 \text { ad- } \\
\text { verse event - week } 4\end{array}$ & 4 & 502 & $\begin{array}{l}\text { Risk Ratio (M-H, Random, } \\
95 \% \mathrm{Cl})\end{array}$ & $1.30[0.35,4.83]$ \\
\hline $\begin{array}{l}7 \text { Withdrawal due to adverse event - } \\
\text { week } 4\end{array}$ & 3 & 305 & $\begin{array}{l}\text { Risk Ratio (M-H, Random, } \\
95 \% \mathrm{Cl})\end{array}$ & $0.0[0.0,0.0]$ \\
\hline
\end{tabular}


Analysis 1.1. Comparison 1 Ivermectin $200 \mu \mathrm{g} / \mathrm{kg}$ ( 1 to 3 doses) versus permethrin $5 \%$ cream (1 to 3 applications), Outcome 1 Complete clearance - week 1.

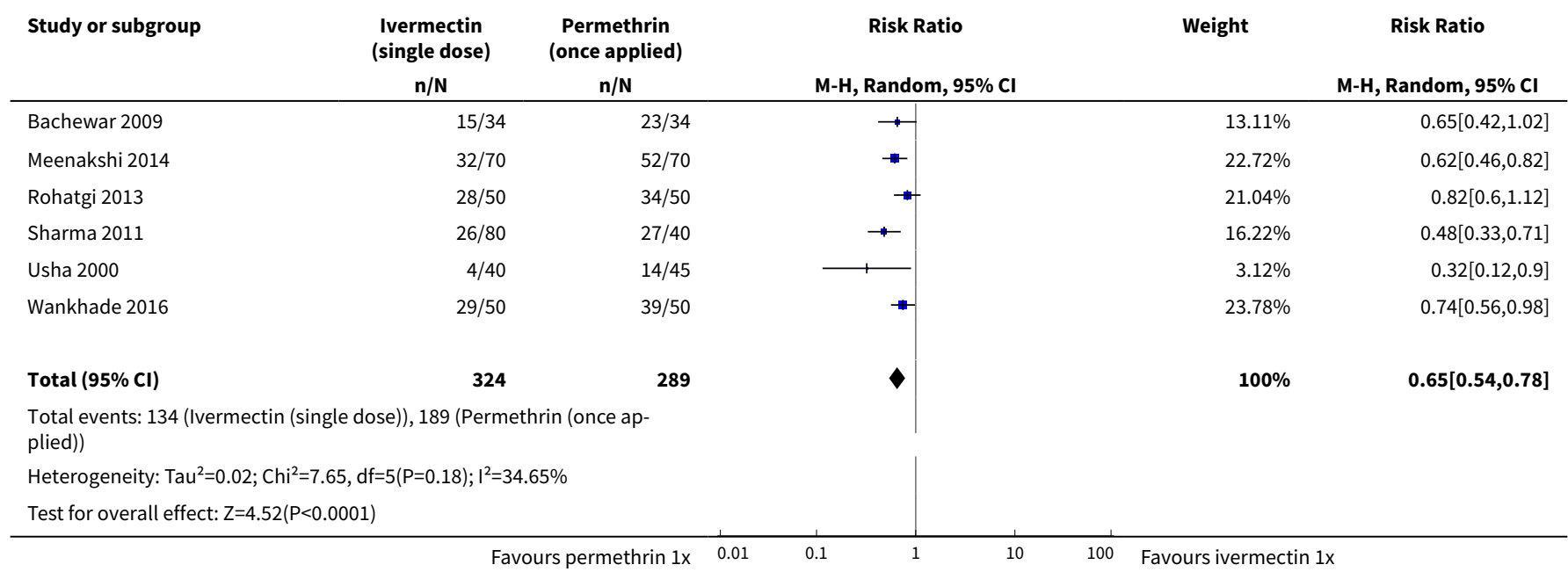

Analysis 1.2. Comparison 1 Ivermectin $200 \mu \mathrm{g} / \mathrm{kg}$ (1 to 3 doses) versus permethrin $5 \%$ cream (1 to 3 applications), Outcome 2 Complete clearance - week 2.

\begin{tabular}{|c|c|c|c|c|c|}
\hline Study or subgroup & $\begin{array}{c}\text { Ivermectin } \\
\mathrm{n} / \mathrm{N} \\
\end{array}$ & $\begin{array}{c}\text { Permethrin } \\
\mathrm{n} / \mathrm{N} \\
\end{array}$ & $\begin{array}{c}\text { Risk Ratio } \\
\text { M-H, Random, 95\% Cl }\end{array}$ & Weight & $\begin{array}{c}\text { Risk Ratio } \\
\text { M-H, Random, } 95 \% \text { CI }\end{array}$ \\
\hline Bachewar 2009 & $27 / 34$ & $27 / 34$ & + & $21.66 \%$ & $1[0.79,1.27]$ \\
\hline Mushtaq 2010 & $24 / 44$ & $20 / 42$ & $\rightarrow$ & $12.03 \%$ & $1.15[0.76,1.74]$ \\
\hline Rohatgi 2013 & $45 / 50$ & $46 / 50$ & 申 & $31.07 \%$ & $0.98[0.86,1.11]$ \\
\hline Sharma 2011 & $57 / 80$ & $33 / 40$ & + & $24.95 \%$ & $0.86[0.71,1.05]$ \\
\hline Usha 2000 & $14 / 40$ & $31 / 45$ & $\rightarrow$ & $10.29 \%$ & $0.51[0.32,0.81]$ \\
\hline Total $(95 \% \mathrm{Cl})$ & 248 & 211 & 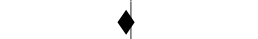 & $100 \%$ & $0.91[0.76,1.08]$ \\
\hline \multicolumn{6}{|c|}{ Total events: 167 (Ivermectin), 157 (Permethrin) } \\
\hline \multicolumn{6}{|c|}{ Heterogeneity: $\mathrm{Tau}^{2}=0.02 ; \mathrm{Chi}^{2}=10.23, \mathrm{df}=4(\mathrm{P}=0.04) ; \mathrm{I}^{2}=60.89 \%$} \\
\hline \multicolumn{6}{|c|}{ Test for overall effect: $\mathrm{Z}=1.08(\mathrm{P}=0.28)$} \\
\hline
\end{tabular}

Analysis 1.3. Comparison 1 Ivermectin $200 \mu \mathrm{g} / \mathrm{kg}$ ( 1 to 3 doses) versus permethrin $5 \%$ cream (1 to 3 applications), Outcome 3 Complete clearance - week 4.

\begin{tabular}{|c|c|c|c|c|c|}
\hline Study or subgroup & $\begin{array}{c}\text { Ivermectin } \\
\mathbf{n} / \mathbf{N}\end{array}$ & $\begin{array}{c}\text { Permethrin } \\
\mathrm{n} / \mathrm{N} \\
\end{array}$ & $\begin{array}{c}\text { Risk Ratio } \\
\text { M-H, Random, } 95 \% \mathrm{Cl}\end{array}$ & Weight & $\begin{array}{c}\text { Risk Ratio } \\
\text { M-H, Random, } 95 \% \mathrm{Cl}\end{array}$ \\
\hline \multicolumn{6}{|c|}{ 1.3.1 IVER 1 dose versus PER 1 application } \\
\hline Sharma 2011 & $36 / 40$ & $36 / 40$ & & $100 \%$ & $1[0.86,1.16]$ \\
\hline Subtotal $(95 \% \mathrm{Cl})$ & 40 & 40 & \rangle & $100 \%$ & $1[0.86,1.16]$ \\
\hline \multicolumn{6}{|c|}{ Total events: 36 (Ivermectin), 36 (Permethrin) } \\
\hline \multicolumn{6}{|c|}{ Heterogeneity: Not applicable } \\
\hline 1.3.2 IVER 1 to 3 do: & o 3 applications & & & & \\
\hline
\end{tabular}




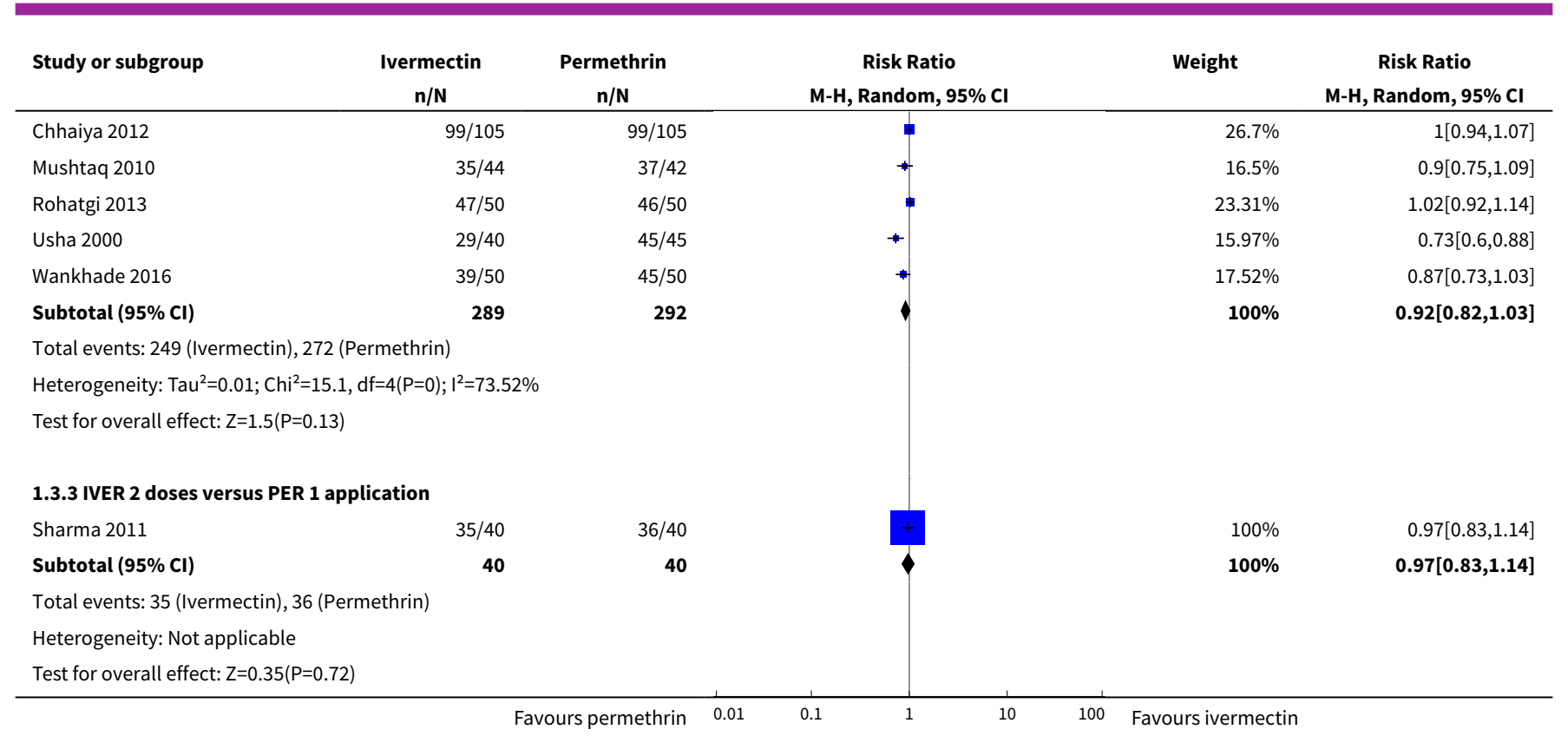

\section{Analysis 1.4. Comparison 1 Ivermectin $200 \mu \mathrm{g} / \mathrm{kg}$ ( 1 to 3 doses) versus permethrin $5 \%$ cream \\ (1 to 3 applications), Outcome 4 Subgroup analysis for 1.3.2 - complete clearance - week 4.}

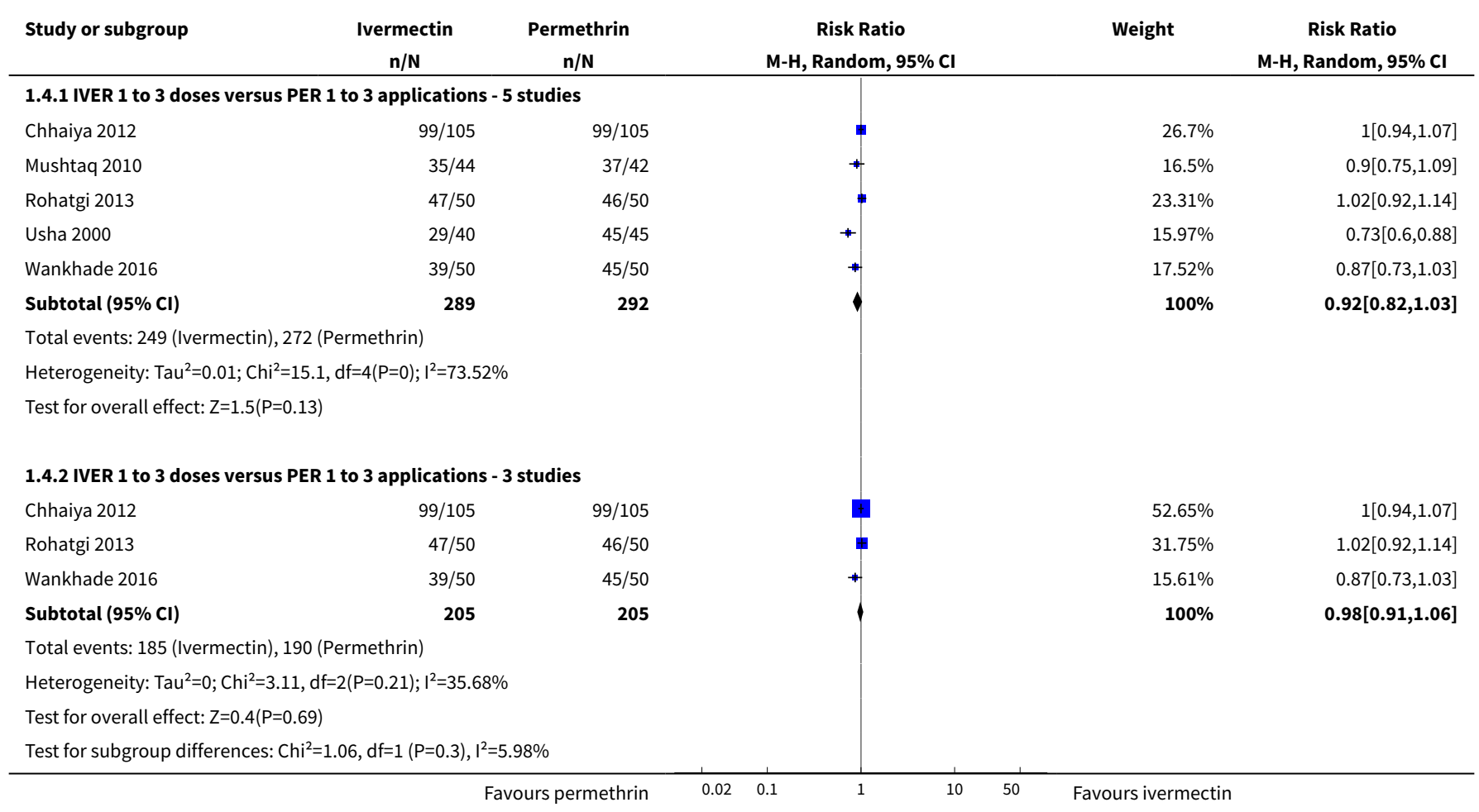


Analysis 1.5. Comparison 1 Ivermectin $200 \mu \mathrm{g} / \mathrm{kg}$ ( 1 to 3 doses) versus permethrin $5 \% \mathrm{cream}$

(1 to 3 applications), Outcome 5 Number of participants with $\geq 1$ adverse event - week 2.

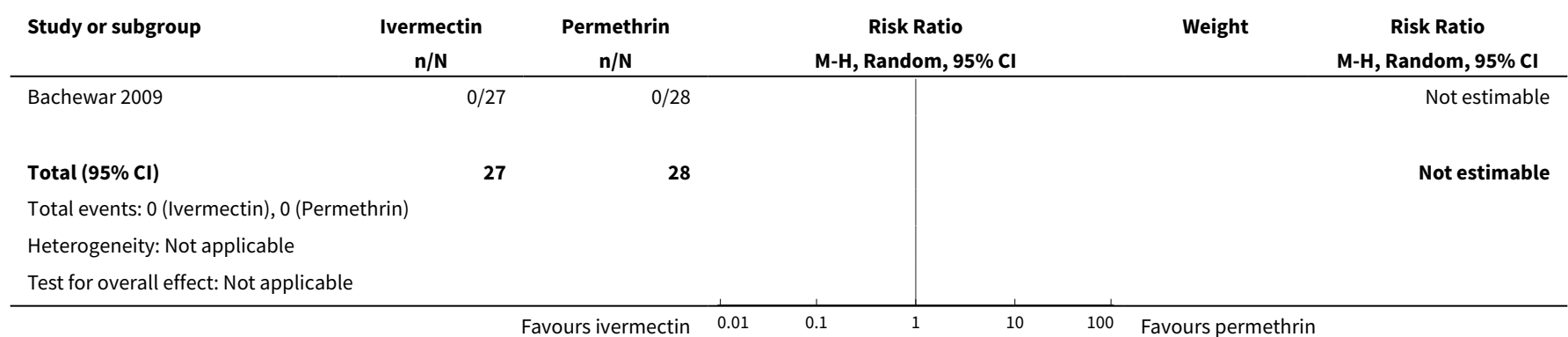

Analysis 1.6. Comparison 1 Ivermectin $200 \mu \mathrm{g} / \mathrm{kg}$ ( 1 to 3 doses) versus permethrin $5 \% \mathrm{cream}$ (1 to 3 applications), Outcome 6 Number of participants with $\geq 1$ adverse event - week 4 .

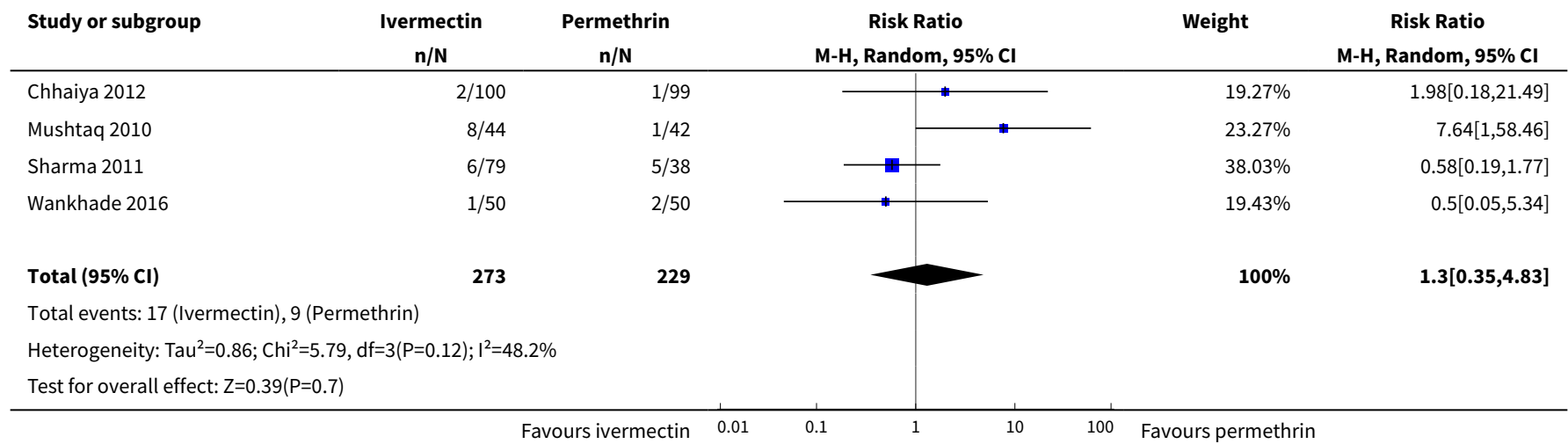

Analysis 1.7. Comparison 1 Ivermectin $200 \mu \mathrm{g} / \mathrm{kg}$ (1 to 3 doses) versus permethrin $5 \%$ cream (1 to 3 applications), Outcome 7 Withdrawal due to adverse event - week 4.

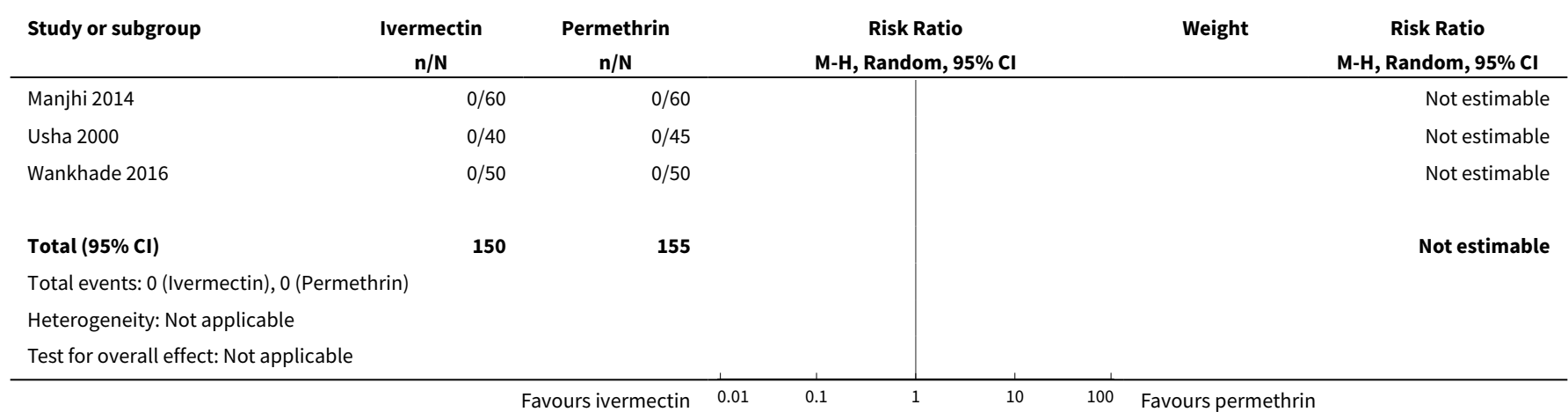


Comparison 2. Ivermectin $200 \mu \mathrm{g} / \mathrm{kg}$ ( 1 to 2 doses) versus permethrin $5 \%$ lotion ( 1 to 5 applications)

\begin{tabular}{|c|c|c|c|c|}
\hline Outcome or subgroup title & No. of studies & $\begin{array}{l}\text { No. of partici- } \\
\text { pants }\end{array}$ & Statistical method & Effect size \\
\hline 1 Complete clearance - week 1 & 2 & & $\begin{array}{l}\text { Risk Ratio (M-H, Random, } \\
95 \% \mathrm{Cl})\end{array}$ & Subtotals only \\
\hline $\begin{array}{l}1.1 \text { IVER } 1 \text { dose versus PER } 1 \text { applica- } \\
\text { tion }\end{array}$ & 1 & 120 & $\begin{array}{l}\text { Risk Ratio (M-H, Random, } \\
95 \% \mathrm{Cl})\end{array}$ & $0.93[0.74,1.17]$ \\
\hline $\begin{array}{l}1.2 \text { IVER } 1 \text { dose versus PER on } 5 \text { con- } \\
\text { secutive nights }\end{array}$ & 1 & 107 & $\begin{array}{l}\text { Risk Ratio (M-H, Random, } \\
95 \% \mathrm{Cl} \text { ) }\end{array}$ & $0.70[0.47,1.03]$ \\
\hline 2 Complete clearance - week 2 & 2 & & $\begin{array}{l}\text { Risk Ratio (M-H, Random, } \\
95 \% \mathrm{Cl} \text { ) }\end{array}$ & Subtotals only \\
\hline $\begin{array}{l}2.1 \text { IVER } 1 \text { dose versus PER } 1 \text { applica- } \\
\text { tion }\end{array}$ & 1 & 120 & $\begin{array}{l}\text { Risk Ratio (M-H, Random, } \\
95 \% \mathrm{Cl} \text { ) }\end{array}$ & $1.0[0.78,1.29]$ \\
\hline $\begin{array}{l}\text { 2.2 IVER } 2 \text { doses versus PER on } 5 \text { con- } \\
\text { secutive nights }\end{array}$ & 1 & 107 & $\begin{array}{l}\text { Risk Ratio (M-H, Random, } \\
95 \% \mathrm{Cl} \text { ) }\end{array}$ & $0.97[0.81,1.17]$ \\
\hline $\begin{array}{l}3 \text { Number of participants with } \geq 1 \text { ad- } \\
\text { verse event - week } 2\end{array}$ & 1 & 100 & $\begin{array}{l}\text { Risk Ratio (M-H, Random, } \\
95 \% \mathrm{Cl})\end{array}$ & $5.00[0.25,101.58]$ \\
\hline $\begin{array}{l}4 \text { Withdrawal due to adverse event - } \\
\text { week } 2\end{array}$ & 1 & 120 & $\begin{array}{l}\text { Risk Ratio (M-H, Random, } \\
95 \% \mathrm{Cl} \text { ) }\end{array}$ & $0.0[0.0,0.0]$ \\
\hline
\end{tabular}

\section{Analysis 2.1. Comparison 2 Ivermectin $200 \mu \mathrm{g} / \mathrm{kg}$ (1 to 2 doses) versus permethrin} $5 \%$ lotion (1 to 5 applications), Outcome 1 Complete clearance - week 1.

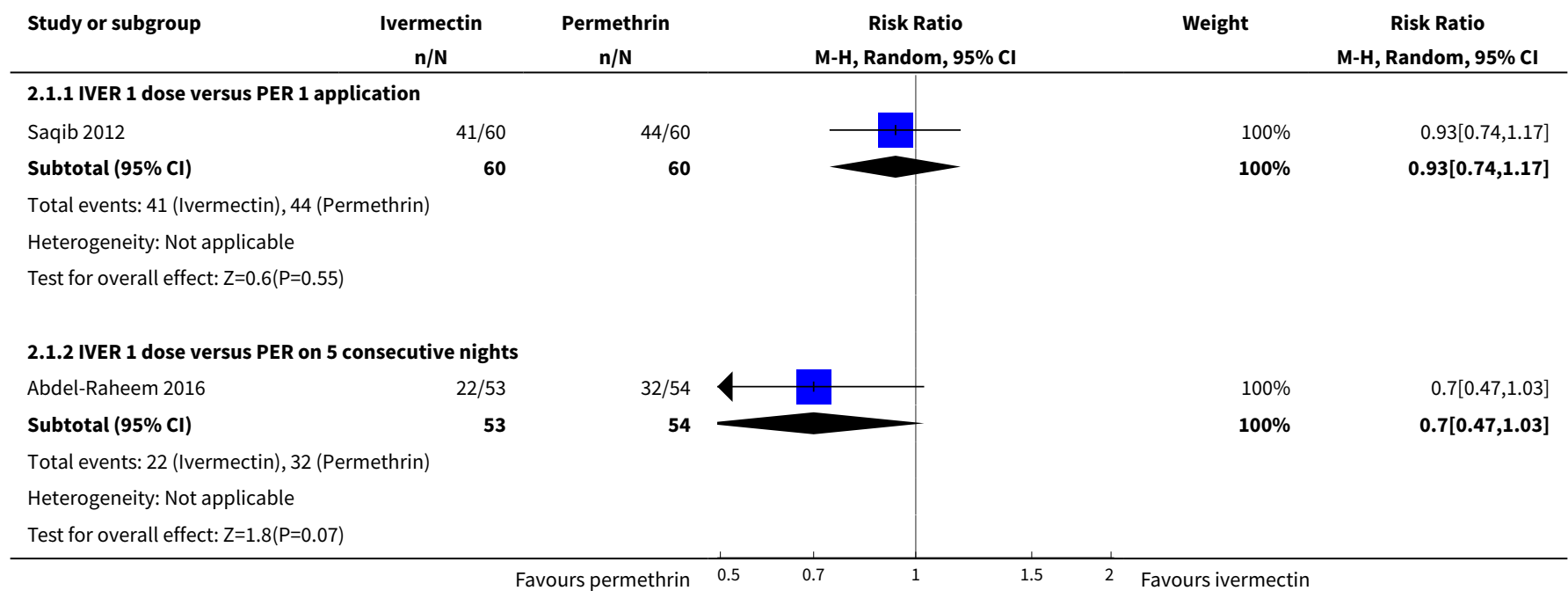


Analysis 2.2. Comparison 2 Ivermectin $200 \mu \mathrm{g} / \mathrm{kg}$ (1 to 2 doses) versus permethrin $5 \%$ lotion (1 to 5 applications), Outcome 2 Complete clearance - week 2.

\begin{tabular}{|c|c|c|c|c|c|}
\hline Study or subgroup & $\begin{array}{l}\text { Ivermectin } \\
\mathrm{n} / \mathrm{N}\end{array}$ & $\begin{array}{c}\text { Permethrin } \\
\text { n/N }\end{array}$ & $\begin{array}{c}\text { Risk Ratio } \\
\text { M-H, Random, } 95 \% \mathrm{CI}\end{array}$ & Weight & $\begin{array}{c}\text { Risk Ratio } \\
\text { M-H, Random, } 95 \% \mathrm{Cl}\end{array}$ \\
\hline \multicolumn{6}{|c|}{ 2.2.1 IVER 1 dose versus PER 1 application } \\
\hline Saqib 2012 & $40 / 60$ & $40 / 60$ & & $100 \%$ & $1[0.78,1.29]$ \\
\hline Subtotal $(95 \% \mathrm{CI})$ & 60 & 60 & & $100 \%$ & $1[0.78,1.29]$ \\
\hline \multicolumn{6}{|c|}{ Total events: 40 (Ivermectin), 40 (Permethrin) } \\
\hline \multicolumn{6}{|c|}{ Heterogeneity: Not applicable } \\
\hline \multicolumn{6}{|c|}{ 2.2.2 IVER 2 doses versus PER on 5 consecutive nights } \\
\hline Abdel-Raheem 2016 & $42 / 53$ & $44 / 54$ & & $100 \%$ & $0.97[0.81,1.17]$ \\
\hline Subtotal $(95 \% \mathrm{Cl})$ & 53 & 54 & 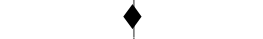 & $100 \%$ & $0.97[0.81,1.17]$ \\
\hline \multicolumn{6}{|c|}{ Total events: 42 (Ivermectin), 44 (Permethrin) } \\
\hline \multicolumn{6}{|c|}{ Heterogeneity: Not applicable } \\
\hline
\end{tabular}

Analysis 2.3. Comparison 2 Ivermectin $200 \mu \mathrm{g} / \mathrm{kg}$ ( 1 to 2 doses) versus permethrin $5 \%$ lotion (1 to 5 applications), Outcome 3 Number of participants with $\geq 1$ adverse event - week 2.

\begin{tabular}{|c|c|c|c|c|c|}
\hline Study or subgroup & $\begin{array}{c}\text { Ivermectin } \\
\mathrm{n} / \mathrm{N} \\
\end{array}$ & $\begin{array}{c}\text { Permethrin } \\
\mathrm{n} / \mathrm{N} \\
\end{array}$ & $\begin{array}{c}\text { Risk Ratio } \\
\text { M-H, Random, 95\% Cl }\end{array}$ & Weight & $\begin{array}{c}\text { Risk Ratio } \\
\text { M-H, Random, } 95 \% \mathrm{Cl} \\
\end{array}$ \\
\hline Abdel-Raheem 2016 & $2 / 50$ & $0 / 50$ & & $100 \%$ & $5[0.25,101.58]$ \\
\hline Total $(95 \% \mathrm{Cl})$ & 50 & 50 & & $100 \%$ & $5[0.25,101.58]$ \\
\hline \multicolumn{6}{|c|}{ Total events: 2 (Ivermectin), 0 (Permethrin) } \\
\hline \multicolumn{6}{|c|}{ Heterogeneity: Not applicable } \\
\hline
\end{tabular}

Analysis 2.4. Comparison 2 Ivermectin $200 \mu \mathrm{g} / \mathrm{kg}$ (1 to 2 doses) versus permethrin $5 \%$ lotion (1 to 5 applications), Outcome 4 Withdrawal due to adverse event - week 2.

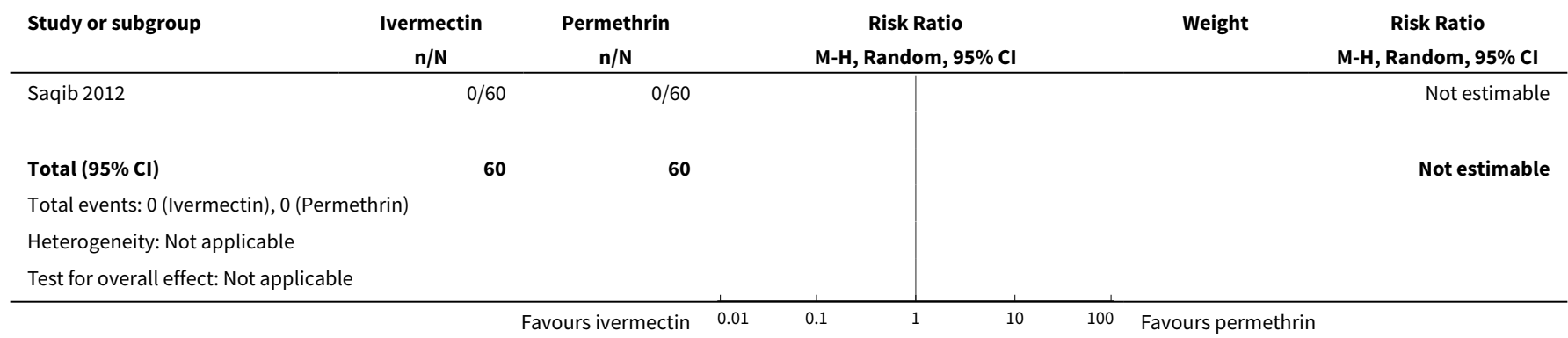


Comparison 3. Ivermectin $200 \mu \mathrm{g} / \mathrm{kg}$ (1 to 3 doses) versus ivermectin $1 \%$ lotion/solution (1 to 3 applications)

\begin{tabular}{|c|c|c|c|c|}
\hline Outcome or subgroup title & No. of studies & $\begin{array}{l}\text { No. of partici- } \\
\text { pants }\end{array}$ & Statistical method & Effect size \\
\hline 1 Complete clearance - week 1 & 1 & 62 & $\begin{array}{l}\text { Risk Ratio (M-H, Random, 95\% } \\
\text { Cl) }\end{array}$ & $0.84[0.65,1.08]$ \\
\hline 2 Complete clearance - week 2 & 1 & 62 & $\begin{array}{l}\text { Risk Ratio (M-H, Random, 95\% } \\
\text { Cl) }\end{array}$ & $1.0[0.94,1.06]$ \\
\hline 3 Complete clearance - week 4 & 2 & 272 & $\begin{array}{l}\text { Risk Ratio (M-H, Random, 95\% } \\
\text { Cl) }\end{array}$ & $0.99[0.95,1.03]$ \\
\hline $\begin{array}{l}4 \text { Number of participants with } \geq 1 \\
\text { adverse event - week } 4\end{array}$ & 1 & 201 & $\begin{array}{l}\text { Risk Ratio (M-H, Random, 95\% } \\
\mathrm{Cl} \text { ) }\end{array}$ & $5.05[0.25,103.87]$ \\
\hline $\begin{array}{l}5 \text { Withdrawal due to adverse event - } \\
\text { week } 4\end{array}$ & 1 & 62 & $\begin{array}{l}\text { Risk Ratio (M-H, Random, 95\% } \\
\text { Cl) }\end{array}$ & $0.0[0.0,0.0]$ \\
\hline
\end{tabular}

Analysis 3.1. Comparison 3 Ivermectin $200 \mu \mathrm{g} / \mathrm{kg}$ ( 1 to 3 doses) versus ivermectin $1 \%$ lotion/solution (1 to 3 applications), Outcome 1 Complete clearance - week 1.

\begin{tabular}{|c|c|c|c|c|c|}
\hline Study or subgroup & $\begin{array}{c}\text { Ivermectin sys. } \\
\mathrm{n} / \mathbf{N}\end{array}$ & $\begin{array}{c}\text { Ivermectin top. } \\
\mathrm{n} / \mathrm{N}\end{array}$ & $\begin{array}{c}\text { Risk Ratio } \\
\text { M-H, Random, 95\% Cl }\end{array}$ & Weight & $\begin{array}{c}\text { Risk Ratio } \\
\text { M-H, Random, } 95 \% \mathrm{CI}\end{array}$ \\
\hline Ahmad 2016 & $22 / 30$ & $28 / 32$ & & $100 \%$ & $0.84[0.65,1.08]$ \\
\hline Total $(95 \% \mathrm{CI})$ & 30 & 32 & & $100 \%$ & $0.84[0.65,1.08]$ \\
\hline \multicolumn{6}{|c|}{ Total events: 22 (Ivermectin sys.), 28 (Ivermectin top.) } \\
\hline \multicolumn{6}{|c|}{ Heterogeneity: Not applicable } \\
\hline
\end{tabular}

Analysis 3.2. Comparison 3 Ivermectin $200 \mu \mathrm{g} / \mathrm{kg}$ ( 1 to 3 doses) versus ivermectin $1 \%$ lotion/solution (1 to 3 applications), Outcome 2 Complete clearance - week 2.

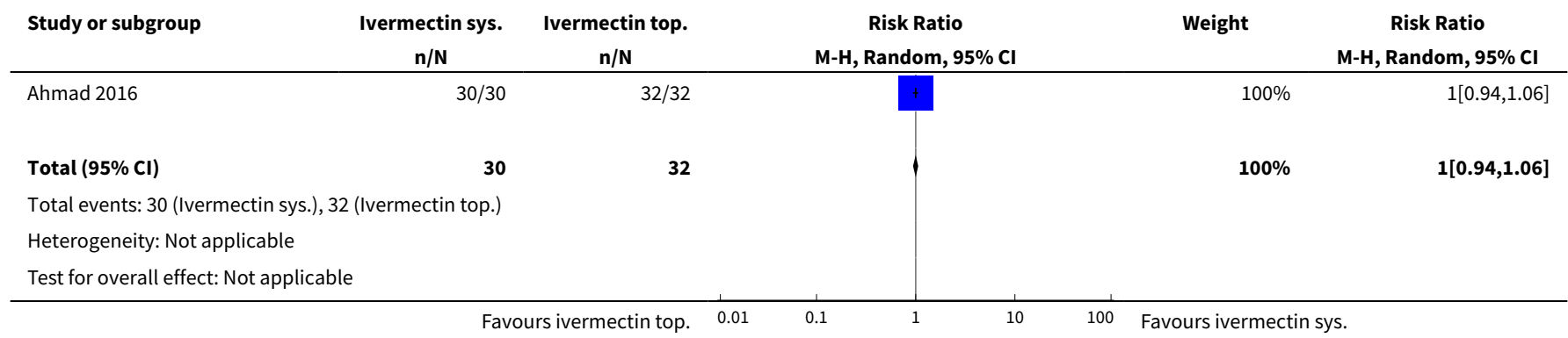


Analysis 3.3. Comparison 3 Ivermectin $200 \mu \mathrm{g} / \mathrm{kg}$ ( 1 to 3 doses) versus ivermectin 1\% lotion/solution (1 to 3 applications), Outcome 3 Complete clearance - week 4.

\begin{tabular}{|c|c|c|c|c|c|}
\hline Study or subgroup & $\begin{array}{l}\text { Ivermectin sys. } \\
\mathrm{n} / \mathbf{N}\end{array}$ & $\begin{array}{c}\text { Ivermectin top. } \\
\mathrm{n} / \mathrm{N}\end{array}$ & $\begin{array}{c}\text { Risk Ratio } \\
\text { M-H, Random, } 95 \% \mathrm{Cl}\end{array}$ & Weight & $\begin{array}{c}\text { Risk Ratio } \\
\text { M-H, Random, 95\% Cl }\end{array}$ \\
\hline Ahmad 2016 & $30 / 30$ & $32 / 32$ & $\boldsymbol{\phi}$ & $48.96 \%$ & $1[0.94,1.06]$ \\
\hline Chhaiya 2012 & $99 / 105$ & $101 / 105$ & & $51.04 \%$ & $0.98[0.92,1.04]$ \\
\hline Total $(95 \% \mathrm{Cl})$ & 135 & 137 & 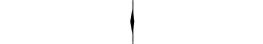 & $100 \%$ & $0.99[0.95,1.03]$ \\
\hline \multicolumn{6}{|c|}{ Total events: 129 (Ivermectin sys.), 133 (Ivermectin top.) } \\
\hline Test for overall effect & & & & & \\
\hline
\end{tabular}

Analysis 3.4. Comparison 3 Ivermectin $200 \mu \mathrm{g} / \mathrm{kg}$ (1 to 3 doses) versus ivermectin 1\% lotion/ solution (1 to 3 applications), Outcome 4 Number of participants with $\geq 1$ adverse event - week 4 .

\begin{tabular}{|c|c|c|c|c|c|}
\hline Study or subgroup & $\begin{array}{c}\text { Ivermectin sys. } \\
\text { n/N }\end{array}$ & $\begin{array}{l}\text { Ivermectin top. } \\
\mathrm{n} / \mathrm{N}\end{array}$ & $\begin{array}{c}\text { Risk Ratio } \\
\text { M-H, Random, 95\% Cl }\end{array}$ & Weight & $\begin{array}{c}\text { Risk Ratio } \\
\text { M-H, Random, 95\% Cl }\end{array}$ \\
\hline Chhaiya 2012 & $2 / 100$ & $0 / 101$ & & $100 \%$ & $5.05[0.25,103.87]$ \\
\hline Total $(95 \% \mathrm{Cl})$ & 100 & 101 & & $100 \%$ & $5.05[0.25,103.87]$ \\
\hline \multicolumn{6}{|c|}{ Total events: 2 (Ivermectin sys.), 0 (Ivermectin top.) } \\
\hline \multicolumn{6}{|c|}{ Heterogeneity: Not applicable } \\
\hline
\end{tabular}

Analysis 3.5. Comparison 3 Ivermectin $200 \mu \mathrm{g} / \mathrm{kg}$ ( 1 to 3 doses) versus ivermectin $1 \%$ lotion/solution (1 to 3 applications), Outcome 5 Withdrawal due to adverse event - week 4.

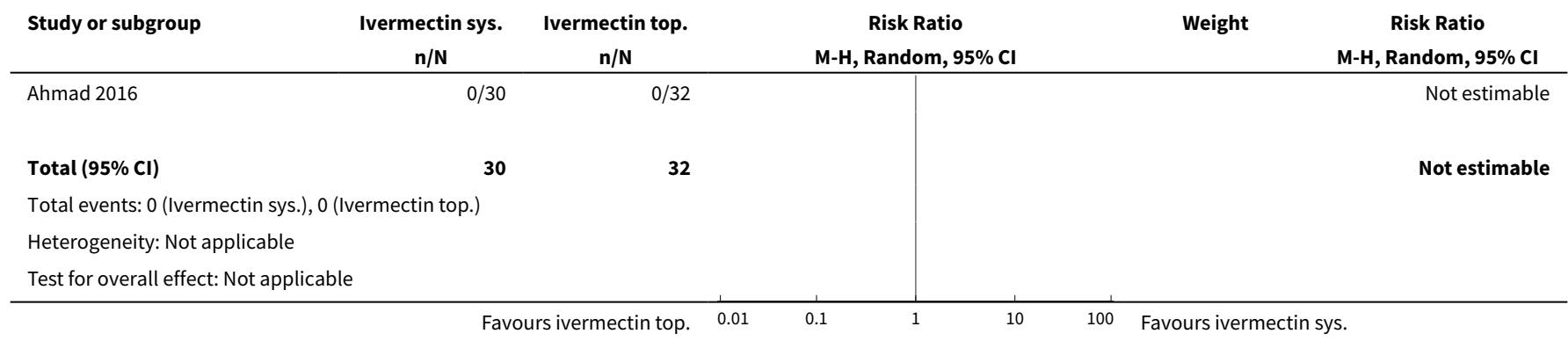

Comparison 4. Ivermectin 1\% lotion (1 to 3 applications) versus permethrin $5 \%$ cream (1 to 3 applications)

\begin{tabular}{lllll}
\hline Outcome or subgroup title & No. of studies & $\begin{array}{l}\text { No. of partici- } \\
\text { pants }\end{array}$ & Statistical method & Effect size \\
\hline 1 Complete clearance - week 4 & 1 & 210 & $\begin{array}{l}\text { Risk Ratio (M-H, Random, } \\
95 \% \mathrm{Cl})\end{array}$ & $1.02[0.96,1.08]$ \\
\hline
\end{tabular}




\begin{tabular}{lllll}
\hline Outcome or subgroup title & No. of studies & $\begin{array}{l}\text { No. of partici- } \\
\text { pants }\end{array}$ & Statistical method & Effect size \\
\hline $\begin{array}{l}\text { 2 Number of participants with } \geq 1 \text { ad- } \\
\text { verse event - week 4 }\end{array}$ & 1 & 200 & $\begin{array}{l}\text { Risk Ratio (M-H, Random, } \\
95 \% \mathrm{Cl})\end{array}$ & 0.33 [0.01, 7.93] \\
\hline
\end{tabular}

Analysis 4.1. Comparison 4 Ivermectin $1 \%$ lotion (1 to 3 applications) versus permethrin 5\% cream (1 to 3 applications), Outcome 1 Complete clearance - week 4.

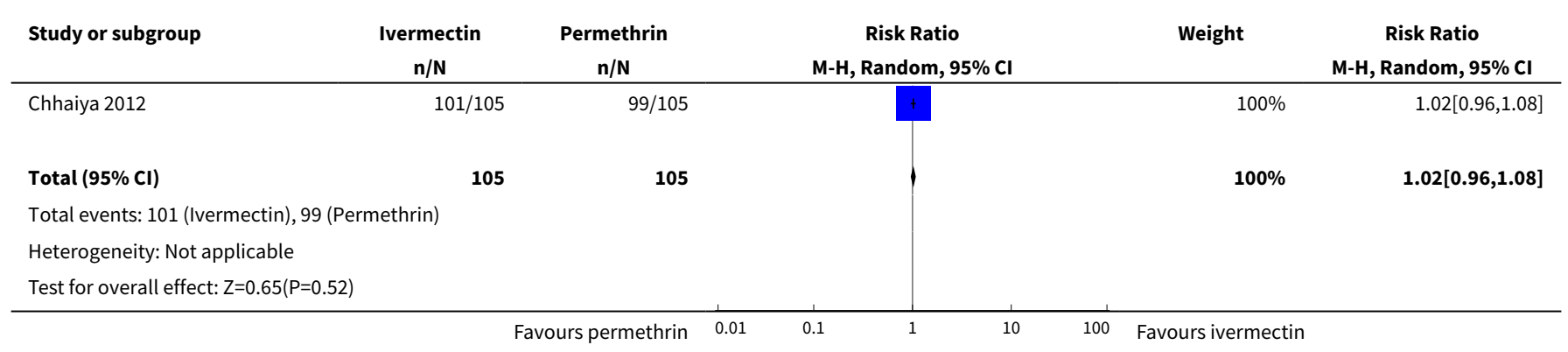

Analysis 4.2. Comparison 4 Ivermectin $1 \%$ lotion (1 to 3 applications) versus permethrin $5 \%$ cream (1 to 3 applications), Outcome 2 Number of participants with $\geq 1$ adverse event - week 4 .

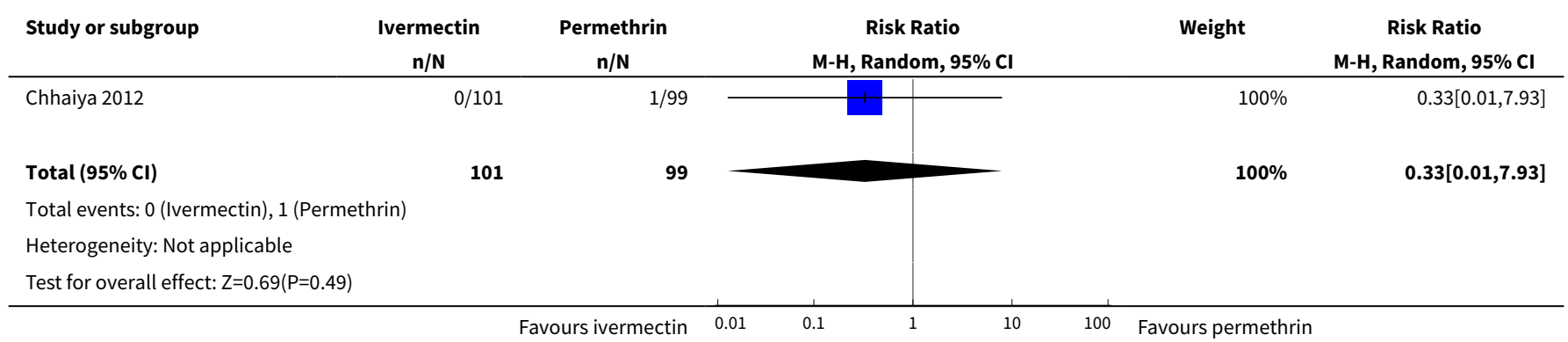

Comparison 5. Ivermectin $200 \mu \mathrm{g} / \mathrm{kg}$ (1 dose) versus ivermectin $200 \mu \mathrm{g} / \mathrm{kg}$ ( 2 doses)

\begin{tabular}{lllll}
\hline Outcome or subgroup title & No. of studies & $\begin{array}{l}\text { No. of partici- } \\
\text { pants }\end{array}$ & Statistical method & Effect size \\
\hline 1 Complete clearance - week 4 & 1 & 80 & $\begin{array}{l}\text { Risk Ratio (M-H, Random, 95\% } \\
\text { Cl) }\end{array}$ & $0.97[0.83,1.14]$ \\
\hline
\end{tabular}


Analysis 5.1. Comparison 5 Ivermectin $200 \mu \mathrm{g} / \mathrm{kg}$ (1 dose) versus ivermectin $200 \mu \mathrm{g} / \mathrm{kg}$ ( 2 doses), Outcome 1 Complete clearance - week 4.

\begin{tabular}{|c|c|c|c|c|c|}
\hline Study or subgroup & $\begin{array}{l}\text { Ivermectin } 1 \mathrm{x} \\
\mathrm{n} / \mathrm{N}\end{array}$ & $\begin{array}{l}\text { Ivermectin } 2 x \\
n / N\end{array}$ & $\begin{array}{c}\text { Risk Ratio } \\
\text { M-H, Random, } 95 \% \mathrm{CI}\end{array}$ & Weight & $\begin{array}{c}\text { Risk Ratio } \\
\text { M-H, Random, } 95 \% \mathrm{CI}\end{array}$ \\
\hline Sharma 2011 & $35 / 40$ & $36 / 40$ & & $100 \%$ & $0.97[0.83,1.14]$ \\
\hline Total $(95 \% \mathrm{Cl})$ & 40 & 40 & 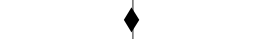 & $100 \%$ & $0.97[0.83,1.14]$ \\
\hline \multicolumn{6}{|c|}{ Total events: 35 (Ivermectin 1x), 36 (Ivermectin 2x) } \\
\hline \multicolumn{6}{|c|}{ Heterogeneity: Not applicable } \\
\hline
\end{tabular}

\section{APPENDICES}

\section{Appendix 1. Search strategy}

\begin{tabular}{|c|c|c|c|c|c|}
\hline Search set & $\begin{array}{l}\text { CIDG SRa/ } \\
\text { EconLit/ ERIC }\end{array}$ & CENTRAL & MEDLINE/Embase ${ }^{b}$ & LILACS $\mathbf{b}$ & IndMED \\
\hline 1 & scabies & scabies ti, ab & scabies ti, ab & scabies & scabies \\
\hline 2 & - & "scabies" [MeSH] & "scabies" [MeSH/Emtree] & permethrin & $\begin{array}{l}\text { sarcoptes sca- } \\
\text { biei }\end{array}$ \\
\hline 3 & - & $\begin{array}{l}\text { "sarcoptes sca- } \\
\text { biei" [MeSH] }\end{array}$ & $\begin{array}{l}\text { "sarcoptes scabiei" [MeSH/ } \\
\text { Emtree] }\end{array}$ & ivermectin & 1 or 2 \\
\hline 4 & - & 1 or 2 or 3 & 1 or 2 or 3 & 2 or 3 & - \\
\hline 5 & - & permethrin $\mathrm{ti}, \mathrm{ab}$ & permethrin ti, ab & 1 and 4 & - \\
\hline 6 & - & "permethrin" [MeSH] & "permethrin" [MeSH/Emtree] & - & - \\
\hline 7 & - & "pyrethrins" [MeSH] & "pyrethrins" [MeSH] & - & - \\
\hline 8 & - & ivermectin ti, ab & "pyrethroid" [Emtree] & - & - \\
\hline 9 & - & "ivermectin" [MeSH] & ivermectin ti, ab & - & - \\
\hline 10 & - & 5 or 6 or 7 or 8 or 9 & "ivermectin" [MeSH/Emtree] & - & - \\
\hline 11 & - & 4 and 10 & 5 or 6 or 7 or 8 or 9 or 10 & - & - \\
\hline 12 & - & - & 4 and 11 & - & - \\
\hline
\end{tabular}

aCochrane Infectious Diseases Group Specialized Register.

bSearch terms used in combination with the search strategy for retrieving trials developed by the Cochrane Collaboration (Lefebvre 2011). 
Appendix 2. Sensitivity analyses: summary table

\begin{tabular}{|c|c|c|c|c|}
\hline Comparison & Subgroup & Outcome & Sensitivity analysis & Meta-analysis \\
\hline \multirow{6}{*}{$\begin{array}{l}\text { Ivermectin } 200 \\
\mu \mathrm{g} / \mathrm{kg} \text { versus } \\
\text { permethrin } 5 \% \\
\text { cream }\end{array}$} & - & $\begin{array}{l}\text { Complete clear- } \\
\text { ance - week } 2\end{array}$ & $\begin{array}{l}\text { Without Usha } 2000 \text { (significant effect estimate): } \\
\text { RR } 0.96,95 \% \mathrm{Cl} 0.88 \text { to } 1.06\left(I^{2} \text { statistic }=0 \%\right)\end{array}$ & $\begin{array}{l}\mathrm{RR} 0.91,95 \% \mathrm{Cl} \\
0.76 \text { to } 1.08\left(\mathrm{I}^{2}\right. \\
\text { statistic }=61 \%)\end{array}$ \\
\hline & & & $\begin{array}{l}\text { Without Bachewar 2009; Rohatgi } 2013 \text { (some par- } \\
\text { ticipants were re-treated after } 1 \text { week): }\end{array}$ & \\
\hline & & & RR $0.81,95 \% \mathrm{Cl} 0.56$ to $1.19\left(\mathrm{I}^{2}\right.$ statistic $\left.=71 \%\right)$ & \\
\hline & $\begin{array}{l}\text { IVER } 1 \text { to } 3 \text { doses } \\
\text { versus PER } 1 \text { to } 3 \\
\text { doses }\end{array}$ & $\begin{array}{l}\text { Complete clear- } \\
\text { ance - week } 4\end{array}$ & $\begin{array}{l}\text { Without Usha } 2000 \text { (significant effect estimate): } \\
\text { RR } 0.97,95 \% \text { CI } 0.91 \text { to } 1.05\left(I^{2} \text { statistic }=31 \%\right)\end{array}$ & $\begin{array}{l}\text { RR } 0.92,95 \% \mathrm{Cl} \\
0.82 \text { to } 1.03\left(\mathrm{I}^{2}\right. \\
\text { statistic }=74 \%)\end{array}$ \\
\hline & & & $\begin{array}{l}\text { Without Usha 2000; Mushtaq } 2010 \text { (non-responders } \\
\text { re-treated after } 2 \text { weeks): }\end{array}$ & \\
\hline & & & RR $0.98,95 \% \mathrm{Cl} 0.91$ to $1.06\left(\mathrm{I}^{2}\right.$ statistic $\left.=36 \%\right)$ & \\
\hline
\end{tabular}

Abbreviations: $\mathrm{Cl}$ : confidence interval; IVER: ivermectin; PER: permethrin; RR: risk ratio.

\section{Appendix 3. Number of participants re-treated}

\begin{tabular}{|c|c|c|c|c|c|}
\hline Study & Initial treatment & Follow-up week 1 & $\begin{array}{l}\text { Follow-up } \\
\text { week } 2\end{array}$ & $\begin{array}{l}\text { Follow-up } \\
\text { week } 3\end{array}$ & $\begin{array}{l}\text { Follow-up } \\
\text { week } 4\end{array}$ \\
\hline
\end{tabular}

\section{Studies that treated participants once}

\begin{tabular}{|c|c|c|c|c|c|}
\hline \multirow[t]{2}{*}{ Manjhi 2014} & 1 x IVER $200 \mu \mathrm{g} / \mathrm{kg}$ & - & - & - & - \\
\hline & $1 \times$ PER 5\% & - & - & - & - \\
\hline \multirow[t]{2}{*}{ Saqib 2012} & 1 x IVER $200 \mu \mathrm{g} / \mathrm{kg}$ & - & - & - & - \\
\hline & $1 \times$ PER 5\% & - & - & - & - \\
\hline \multicolumn{6}{|c|}{ Studies that treated participants once and re-treated only non-responders } \\
\hline \multirow[t]{2}{*}{ Ahmad 2016} & $1 \times$ IVER $1 \%$ & Yes, 4/32 participants & - & - & - \\
\hline & 1 x IVER $200 \mu \mathrm{g} / \mathrm{kg}$ & Yes, $8 / 30$ participants & - & - & - \\
\hline \multirow[t]{2}{*}{$\begin{array}{l}\text { Bachewar } \\
2009\end{array}$} & 1 x IVER $200 \mu \mathrm{g} / \mathrm{kg}$ & $\begin{array}{l}\text { Yes, } 44.44 \% \text { of partic- } \\
\text { ipants }\end{array}$ & - & - & - \\
\hline & $1 \times$ PER $5 \%$ & $\begin{array}{l}\text { Yes, } 17.86 \% \text { of partic- } \\
\text { ipants }\end{array}$ & - & - & - \\
\hline Chhaiya 2012 & 1 x IVER $200 \mu \mathrm{g} / \mathrm{kg}$ & Yes, n unclear & Yes, n unclear & $\begin{array}{l}\text { Switch over to } \\
\text { PER 5\% }\end{array}$ & - \\
\hline
\end{tabular}


(Continued)

\begin{tabular}{|c|c|c|c|c|c|}
\hline & $1 \times$ IVER $1 \%$ & Yes, n unclear & Yes, n unclear & $\begin{array}{l}\text { Switch over to } \\
\text { PER 5\% }\end{array}$ & - \\
\hline & $1 \times$ PER 5\% & Yes, n unclear & Yes, n unclear & Yes, n unclear & - \\
\hline \multirow[t]{2}{*}{ Mushtaq 2010} & 1 x IVER $200 \mu \mathrm{g} / \mathrm{kg}$ & - & Yes, n unclear & - & - \\
\hline & $1 \times$ PER 5\% & - & Yes, n unclear & - & - \\
\hline \multirow[t]{2}{*}{ Rohatgi 2013} & 1 x IVER $200 \mu \mathrm{g} / \mathrm{kg}$ & Yes, n unclear & - & - & - \\
\hline & $1 \times$ PER $5 \%$ & Yes, n unclear & - & - & - \\
\hline \multirow[t]{2}{*}{ Usha 2000} & 1 x IVER $200 \mu \mathrm{g} / \mathrm{kg}$ & - & $\begin{array}{l}\text { Yes, } 12 \text { partici- } \\
\text { pants }\end{array}$ & - & $\begin{array}{l}\text { Cross-over if } \\
\text { treatment fail- } \\
\text { ure }\end{array}$ \\
\hline & $1 \times$ PER 5\% & - & $\begin{array}{l}\text { Yes, } 1 \text { partici- } \\
\text { pant }\end{array}$ & - & $\begin{array}{l}\text { Cross-over if } \\
\text { treatment fail- } \\
\text { ure }\end{array}$ \\
\hline \multirow{2}{*}{$\begin{array}{l}\text { Wankhade } \\
2013\end{array}$} & 1 x IVER $200 \mu \mathrm{g} / \mathrm{kg}$ & Yes, n unclear & - & - & - \\
\hline & $1 \times$ PER 5\% & Yes, n unclear & - & - & - \\
\hline \multirow{2}{*}{$\begin{array}{l}\text { Wankhade } \\
2016\end{array}$} & 1 x IVER $200 \mu \mathrm{g} / \mathrm{kg}$ & Yes, n unclear & - & - & - \\
\hline & $1 \times$ PER 5\% & Yes, n unclear & - & - & - \\
\hline
\end{tabular}

\section{Studies that treated all participants with more than 1 dose}

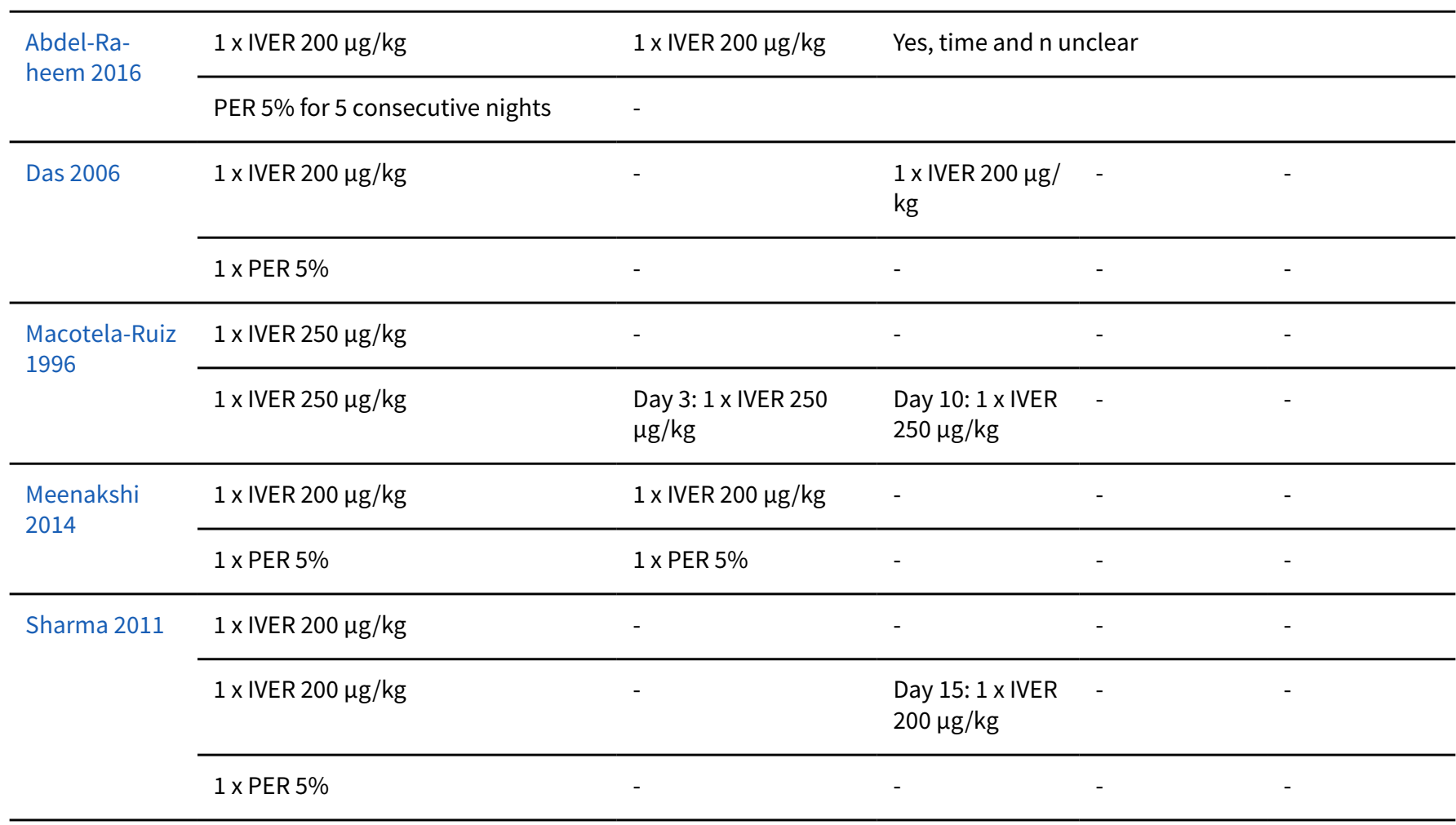


Abbreviations: IVER: ivermectin; PER: permethrin.

\section{Appendix 4. Definition and diagnosis of complete clearance}

\begin{tabular}{lll}
\hline Study & Name of outcome & Definition and evaluation \\
\hline Abdel-Raheem 2016 & Complete cure & - Negative parasitological examination with complete absence of new lesions \\
& & - residual and all new lesions were scraped for detection of mites \\
& - if only one mite was detected, this was considered as treatment failure
\end{tabular}

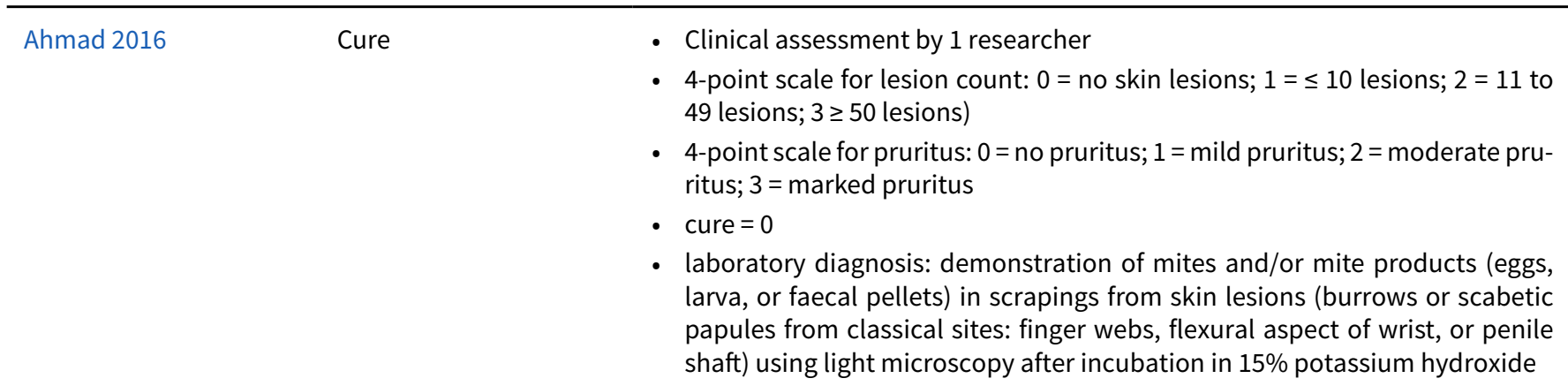

\begin{tabular}{ll}
\hline Bachewar $2009 \quad$ Cure & No new lesions papules, vesicles, and classical burrows \\
& $\begin{aligned} \text { examined by dermatologist and principal investigator to standardize clinical } \\
\text { evaluation }\end{aligned}$
\end{tabular}

\begin{tabular}{|c|c|c|}
\hline Chhaiya 2012 & $\begin{array}{l}\text { Clinical cure of scabietic } \\
\text { lesions }\end{array}$ & - No definition \\
\hline Das 2006 & Improvement clinically & - No definition \\
\hline Macotela-Ruiz 1996 & Cure & - Considerable improvement of dermatosis, no pruritus, no new lesions \\
\hline Manjhi 2014 & Complete improvement & $\begin{array}{l}\text { - Based on severity of pruritus or lesions } \\
\text { - lesion count: < 10: mild, } 11 \text { to } 49 \text { : moderate, > 50: severe } \\
\text { - pruritus on } 10 \text {-centimetre visual analogue scale: } 0 \text { - no pruritus, } 1 \text { to } 3 \text { - mild, } \\
4 \text { to } 6 \text { - moderate, } 7 \text { to } 10 \text { - severe } \\
\text { - complete improvement not defined }\end{array}$ \\
\hline
\end{tabular}

Meenakshi $2014 \quad$ Complete clinical cure

- Reduction in clinical grading score up to grade 0 or 1 and reduction in itching grading score up to grade 0,1 , or 2; "moderate or good improvement"

- clinical grading score: $0=$ free of lesions (no lesions), $1=10$ or fewer lesions (mild), 2 = 11 to 49 lesions (moderate), $3=50$ or more lesions (severe)

- itching grading score: participant was asked for reduction in pruritus, grading was done on given scale by the observer: $0=0 \%$ (no pruritus), $1=1 \%$ to $25 \%$ (mild pruritus), $2=26 \%$ to $50 \%$ (moderate pruritus), $3=51 \%$ to $75 \%$ (severe pruritus), $4=76 \%$ to $100 \%$ (very severe pruritus)

\begin{tabular}{lll}
\hline Mushtaq 2010 & Cure of disease & No lesions \\
\hline Rohatgi 2013 & Cure & $\begin{array}{l}\text { Absence of clinical lesions and no new lesions like papules, vesicles, and clas- } \\
\text { sical burrows suggestive of live parasite }\end{array}$ \\
\hline Saqib 2012 & Cure & No itching, cutaneous lesions/burrows, and negative microscopy \\
\hline
\end{tabular}


- Reduction in both the number of lesions and the grade of pruritus by more than or equal to $50 \%$ (that is, moderate and good improvement) and negative microscopy

\begin{tabular}{lll}
\hline Usha 2000 & Complete clearance & Good improvement \\
\hline Wankhade 2013 & Cure rate & No definition \\
\hline Wankhade 2016 & Cure & $\begin{array}{l}\text { No new clinical lesions and improvement in pruritus, no new lesions like } \\
\text { papules, vesicles, and classical burrows suggestive of live parasite seen }\end{array}$ \\
\hline
\end{tabular}

\section{CONTRIBUTIONS OF AUTHORS}

SR was the contact person with the editorial base, co-ordinating the contributions from the co-authors; sought additional information about papers; entered data into RevMan 5 (RevMan 2014); worked on the Methods section; updated the clinical sections of the Background based on the Cochrane Review 'Interventions for treating scabies' by Mark Strong and Paul Johnstone (Strong 2007). SR screened all hits using the inclusion/exclusion criteria; screened reference lists of included studies for additional randomized controlled trials; independently extracted data using the standardized form; performed the 'Risk of bias' evaluation for all included trials; analysed and interpreted data; wrote the final draft of the review.

CD screened all hits using the inclusion/exclusion criteria and independently extracted data using the standardized form; performed the 'Risk of bias' evaluation for all included trials. CD discussed data analysis strategies with SR and checked the data entered into Review Manager 5. CD also contributed substantially to writing the Cochrane Review.

SR and CD performed the GRADE assessment of all comparisons.

SR, CD, and AN jointly finalized the review. AN was solely responsible for the medical input and the 'Implications for practice' section.

\section{DECLARATIONS OF INTEREST}

SR and CD have no conflicts of interest. CD, SR, and AN previously published a systematic review on scabies treatments (Dressler 2016a).

CD is a member of the Cochrane Scientific Committee.

AN is a member of the expert panel of the German consensus-based guideline for the diagnosis and treatment of scabies published in January 2016 (AWMF (Arbeitsgemeinschaft der Wissenschaftlichen Medizinischen Fachgesellschaften e.V.), Association of the Scientific Medical Societies in Germany; register number: 013-052).

\section{SOURCES OF SUPPORT}

\section{Internal sources}

- Liverpool School of Tropical Medicine, UK.

\section{External sources}

- Department for International Development (DFID), UK.

Grant: 5242

\section{DIFFERENCES BETWEEN PROTOCOLANDREVIEW}

We have changed the secondary outcome 'number of patients requiring re-treatment' to 'number of participants re-treated'. We found this to be a more suitable outcome measure considering our research question.

In case of inconsistent or implausible outcome data within a publication, we asked the corresponding author for clarification, irrespective of the date of publication.

We clarified in the Types of participants section that we only included studies investigating people with classical scabies. 


\section{N D X T ERMS}

\section{Medical Subject Headings (MeSH)}

Administration, Oral; Administration, Topical; Antiparasitic Agents [administration \& dosage] [ ${ }^{\star}$ therapeutic use]; Ivermectin [administration \& dosage] [*therapeutic use]; Permethrin [administration \& dosage] [therapeutic use]; Randomized Controlled Trials as Topic; Scabies [ ${ }^{*}$ drug therapy]; Treatment Outcome

\section{MeSH check words}

Humans 